Learning from a Living Archive:

Rejuvenating Child and Youth Rights and Participation

Vicky Johnson, Tessa Lewin and Mariah Cannon REJUVENATE Working Paper 1

December 2020 
Cover photograph: A group of girls play a baseball game in Batey No.1, near Tamayo, Dominican Republic.

Photographer: ( ) Markel Redondo/UNHCR/Panos Pictures

Illustrations: All illustrations (c) Tessa Lewin/Institute of Development Studies

Suggested citation: Johnson, V.; Lewin, T. and Cannon, M. (2020) Learning from a Living Archive: Rejuvenating Child and Youth Rights and Participation, REJUVENATE Working Paper 1, Brighton: Institute of Development Studies, DOI: 10.19088/REJUVENATE.2020.001

Authors:

Vicky Johnson. ORCID: 0000-0002-2623-3377.

Tessa Lewin. ORCID: 0000-0001-6500-8589.

Mariah Cannon.

Published December 2020

Copyright @ Institute of Development Studies 2020.

ISBN: 978-1-78118-737-1

DOI: $\underline{10.19088 / R E J U V E N A T E .2020 .001 ~}$

This is an Open Access paper distributed under the terms of the $\underline{\text { Creative }}$ Commons Attribution Non Commercial 4.0 International licence (CC BY-NC), which permits use, distribution and reproduction in any medium, provided the original authors and source are credited, any modifications or adaptations are indicated, and the work is not used for commercial purposes.

No potential conflict of interest was reported by the authors.

Institute of Development Studies

Library Road, Brighton, BN1 9RE, UK

www.ids.ac.uk

IDS is a charitable company limited by guarantee and registered in England Charity Registration Number 306371

Charitable Company Number 877338 


\section{Ack nowledgements}

We would like to thank the following individuals for their kind support of our work and for challenging us to think more critically: Michael Gibbons, Anna Windsor, and Maureen Greenwood-Basken; and our Local Advisory Group: Sara Bragg, Rachel Thomson, and Andy West, who helped us to clarify our scope and direction. We are indebted to our interviewees who freely gave their time, out of very busy schedules, to share their experience and knowledge; and, to all of the researchers and practitioners, young and old, who have worked collectively over the past three decades to create the rich resources that we drew on in our living archive (see page 18 for an explanation of this, as well as the Annex for a full list of the interviewees, and References for the project literature on which we based this report). The practitioners we have interviewed are indicative of the field, but there are many key people currently missing from our work whom we hope to add to this archive in time.

We would also like to thank other colleagues within the Institute of Development Studies for their hard work and support: Erika López Franco, Amy Cowlard, Harriet Hamilton, Katy Miller, and Deborah Shenton.

For further information about the REJUVENATE project, housed in the Institute of Development Studies, please contact:

Tessa Lewin, Institute of Development Studies: T.Lewin@ids.ac.uk; or

Vicky Johnson, Centre for Remote and Sustainable Communities, Inverness College, University of the Highlands and Islands (partner in the REJUVENATE Project): Vicky.johnson.ic@uhi.ac.uk.

Mariah Cannon, Institute of Development Studies: M.Cannon1@ids.ac.uk. 


\section{Authors}

Vicky Johnson is Director of the Centre for Remote and Sustainable Communities at the University of the Highlands and Islands (UHI) and is an Honorary Associate at the Institute of Development Studies (IDS). She has over 20 years of experience leading international teams as a principal investigator, complemented by her entrepreneurship and multi-stakeholder engagement in the international non-governmental organisation sector. Research interests include understanding how marginalised people can be supported as agents of change in rapidly changing environmental, political, and cultural contexts. Recent research includes: Youth Uncertainty Rights (YOUR) World Research with marginalised youth in Ethiopia and Nepal (Economic and Social Research Council (ESRC)-FCDO's Poverty Alleviation Fund). Vicky's most recent book, with West, is: Children's Participation in Global Contexts: Going Beyond Voice (2018, Routledge).

Tessa Lewin is a Research Fellow in the Participation, Inclusion and Social Change cluster at IDS, where she co-convenes the MA in Gender and Development. Her work involves creative, visual and participatory research, teaching, and communication. Her recent research has focused on gender politics, sexuality, visual activism, and child rights. Her doctoral research investigated the nature of queer visual activism in South Africa. She is well known for her work as a creative facilitator, often with children and young people, and has worked on projects involving digital storytelling, PhotoVoice, radio drama, animation, and participatory video.

Mariah Cannon is a Research Officer at IDS and holds a Masters in International Development. Her current work focuses on children's and youth participation in promoting children's rights and community development. Recent projects include work on ethically involving children with disabilities in research, and tackling the drivers of child labour and modern slavery in South and Southeast Asia. 
Contents

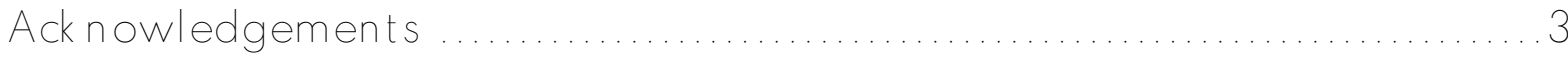

Authors ................................................................. 4

List of boxes, figures and tables......................................... 7

For eword ............................................................... 8

Introduction ...................................................... 10

The purpose of this paper ......................................... II

A brief history of children's participation ........................... 12

Framing and reconceptualising rights as living rights ................ 15

Outline of the paper .............................................. 17

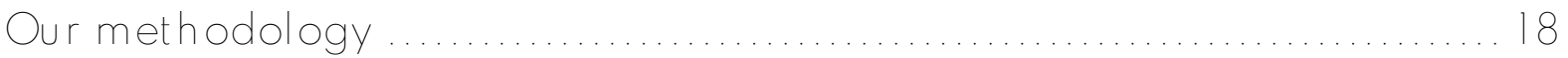

Creating a living archive ........................................ 18

In-depth and short interviews with experts in the field................ 19

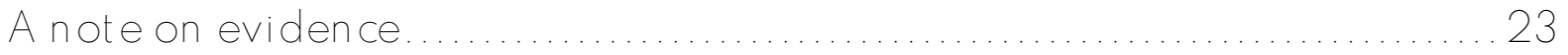

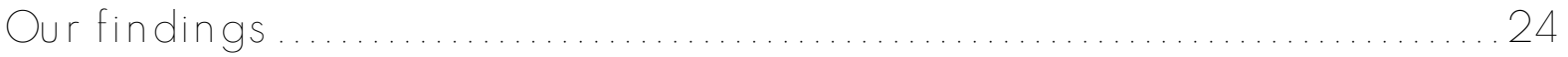

The language of child rights and children's/youth participation .......24

What has worked ...................................................... 26

Space: Creating spaces for including and involving children and youth ................................................ 28

Support: Capacities, empowerment, and intergenerational support ...................................................... 31

System change: Building child-friendly and accountable systems.................................................... 34

Approaches and methods for working with children/youth ............ 39

Child/youth-led work .............................................. 39

Community-driven work including children ........................40 40

What has not worked: Evidence on limitations ......................... 43

Outsider solutions............................................... 43

Tokenisticleadership...............................................44 44

Misguided funders ............................................... 44

Adultism/gerontocracy .........................................44

A way forward .......................................................... 45

Rejuvenating social justice with child rights: Why rejuvenate? ........45

The Ndoro Ndoro model ................................................. 45

REJUVENATE principles ............................................. 47

Relationships.................................................... 47

Evolving capacities ................................................. 49

Justice .......................................................... 51

Unusual suspects ............................................. 52 
Visual and creative praxis ........................................ 54

Empowerment ....................................................... 55

Norms ............................................................ 56

Accountability .................................................... 58

Transformation ......................................................... 58

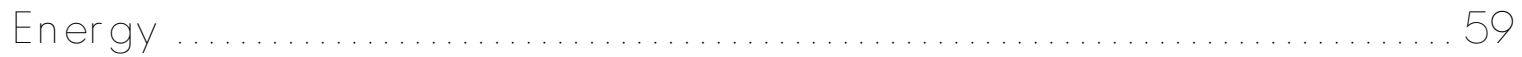

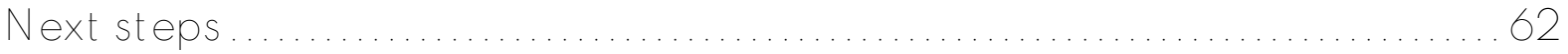

Youth organising .................................................. 62

Child/youth-centred community approaches: rejuvenating communities ................................................... 63

Creative praxis ................................................... 66

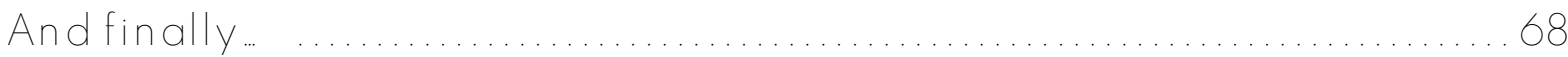

Annex: List of interview participants ....................................69 69

In-depth interviews ...............................................69 69

Short interviews/consultations .......................................70

References ............................................................. 71

Living archive of project examples (Phase One) ...................... 71

Organisational websites and blogs cited in interviews and exemplar boxes............................................... 80

Broader academic references in the text ................................ 81 


\section{List of boxes, figures and tables}

\section{List of Boxes}

Box 1: Case study - Community-based youth work .......................... 27

Box 2: Case study - Good to be me ......................................... 30

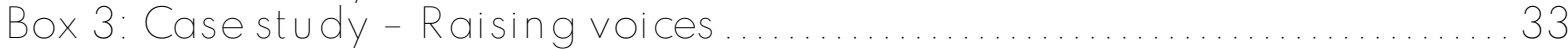

Box 4: Case study - Children's groups and networks in Afghanistan .... 34

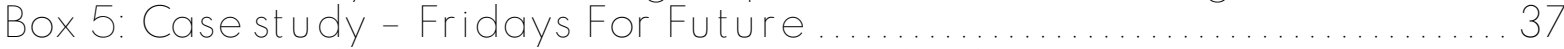

Box 6: Case study - 100l Nights: Building Children's Resilience to

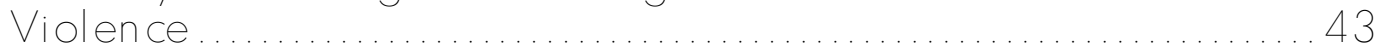

Box 7: Case study - Listening to Smaller Voices...............................48

Box 8: Case study - Children's emotional responses to the absence of transnational migrant parents ..............................49 4

Box 9: Case study - Tatu Tano .......................................... 50

Box 10: Case study - Le Mouvement Africain des Enfants et Jeunes Travailleurs (African Movement of Working Children and Youth)

Box 11: Casestudy - Ana Taban: Wearetired

Box 12: Case study - SCREAM: Supporting Child Rights through Education, the Arts, and the Media......................... 54

Box 13: The Warren Youth Project ...................................... 55

Box 14: Case study - Aware Girls ........................................ 56

Box 15: Case study - Young Women's Freedom Centre.................... 57

Box 16: Case study - Accountapreneurs ................................... 58

Box 17: Case study - Tostan ............................................ 59

Box 18: Case study - United We Dream ...................................60

Box 19: Case study - Community support for youth with mental illness.

\section{List of Figures}

Figure 1: The focus of our research

Figure 2: Authors representation of Hanson and Nieuwenhuys (2013) Children's (Living) Rights

Figure 3: Authors' representation of Hanson and Nieuwenhuys (2013) situated Children's (Living) Rights

Figure 4: Map of provenance of living archive project documents (blue/dark grey) and interview participants (green/light Figure 5: The 3Ps to the 3Ss.

Figure 6: Authors' representation of Cipriani's explanation of

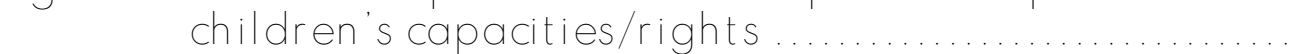

Figure 7: Ndoro Ndoro model

\section{List of Tables}

Table 1: Time span for the project documents an alysed ...................20

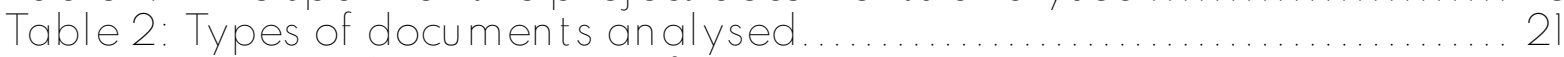

Table 3: Geographical spread of sample. 


\section{Foreword}

I'm only a child and I don't have all the solutions, but I want you to realise, neither do you.

Severn Cullis-Suzuki, 12 years old, Rio Earth Summit, 1992

You come to us young people for hope. How dare you. You have stolen my dreams and my childhood with your empty words... all you can talk about is money and eternal fairy tales of economic growth. How dare you.

Greta Thunberg, 16 years old, UN Climate Action Summit, 2019

These words, 27 years apart, come from children. They are an urgent call to arms, a call for change, a recognition that so much is not working. They are also a demand for adults to recognise young people as competent social agents. This research encountered, time and time again, positive examples of social transformation, led by children and young people with support from adult allies. However, we are still very far from a world where this is the recognised norm.

The United Nations Convention on the Rights of the Child (UNCRC), the cornerstone for child's rights around the world, was adopted in 1989. The UNCRC is the most widely ratified treaty in history, however it came from a child rights movement that was largely framed around the protection of minors (Kosher et al. 2016; OHCHR 1990). Some criticism of the UNCRC suggests that efforts to implement it have been technocratic and top-down and that these fail to recognise children and young people not only as active subjects but also as active members of their communities. Others suggest that progress has been made and that the UNCRC offers a structural-institutional approach to child and youth rights that both listens to children (and acts based on what is heard), and understands the importance of children and youth being embedded in their communities.

We write this in dark times, in what Reinsborough (as cited in Khasnabish and Haiven 2014: 1) has called a 'slow motion apocalypse' and in which 'the most morally repugnant forms of social inequality and social discrimination are becoming politically acceptable' (de Sousa Santos 2018: vii). The Covid-19 pandemic has brought many of these unequal power structures into sharp relief, as have the recent, highly visible, instances of racial injustice. The pandemic has exacerbated existing inequities, and children generally occupy the lowest status in intergenerational hierarchies. So, while it may appear that children are less affected than adults by the pandemic, it does in fact subject them to more acute physical, psychological, and educational vulnerabilities. Previous disasters indicate that girls are particularly vulnerable. While the pandemic has created many obvious challenges, it has also been articulated as an opportunity for taking stock and addressing these inequities.

Adults have created these environmental, social, and political circumstances, but today's children will be the ones to inherit the consequences. Children are a significant part of our communities, they have good ideas, and often they are not as constrained by, or invested in, institutions or practices in the same way that adults tend to be. They are also positioned differently in relation to the media and technologies of communication so are likely to have different perspectives to contribute. Contributions from children and youth have been invisible in community development and social justice processes for too long. Although children and youth are often 
regarded merely as the beneficiaries of projects for 'vulnerable children', or 'youth in difficult circumstances', there are numerous examples where children and youth have organised campaigns that have created real structural changes which benefit not only themselves, but also their communities. 


\section{Introduction}

This paper reflects the findings of the first phase of the REJUVENATE project, which set out to understand and map approaches to integrating children, youth, and community participation in child rights initiatives. We did this through a scoping of existing practitioner and academic literature (developing a project-based literature review matrix), a mapping of key actors, and the development of a typology of existing approaches. We brought all three of these elements together in what we are calling a 'living archive', which is an evolving database that currently comprises 100 matrices, and a 'collection' of key field practitioners (many of whom we have interviewed for this project). Each matrix has been completed with project and study information from a combination of grey and published literature. The matrices are collated responses to a series of standardised questions including some that contribute to our understanding of approaches in global contexts (see boxes throughout the paper for examples). We draw on literature from children's and youth geographies, the sociology and anthropology of childhood and youth, education, international development, and documents that elaborate on projects that include children and young people. We are looking for projects and practitioners that move towards child/youth-led work and its intersection with social change work (see Figure 1).

Figure 1: The focus of our research

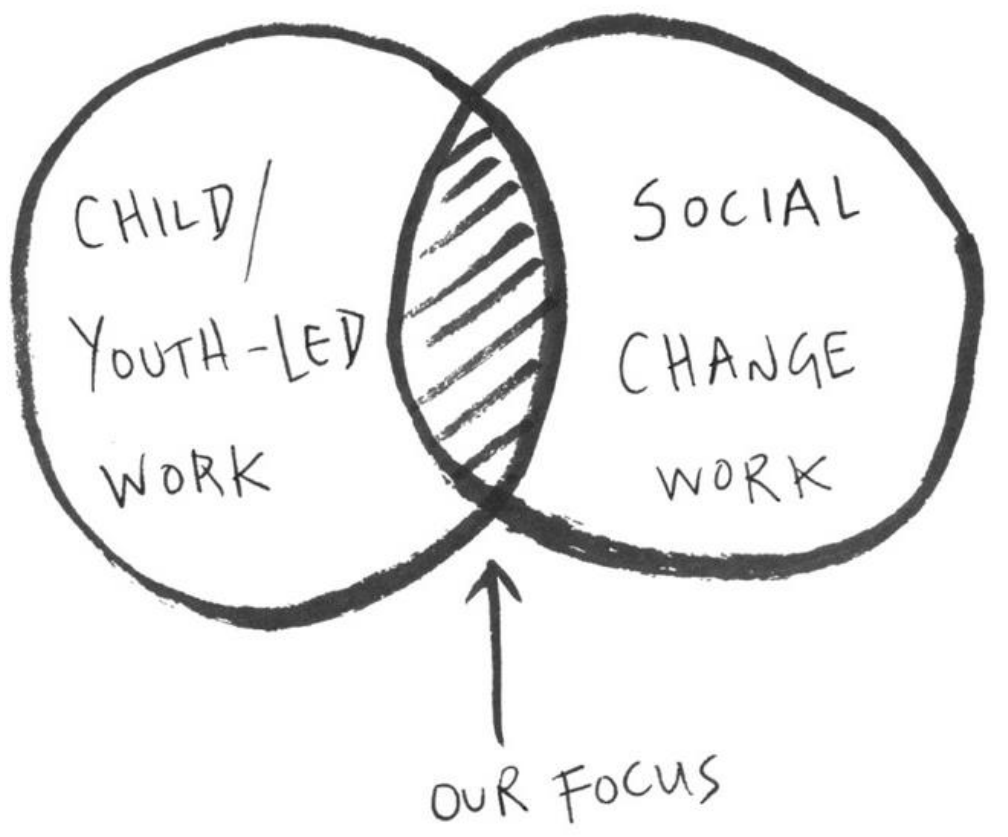

We compiled the living archive through an iterative snowballing process that drew on sources by key people, influential projects, and theoretical literature; some of the projects or methodologies we looked at were suggested by those we interviewed; some of the people whom we interviewed were chosen because they emerged as key thinkers or practitioners in the literature. We hope to build on this living archive to advocate for approaches that increase civic and cultural support for the principles of child rights, to gain more widespread civic engagement in their pursuit, and to support the empowerment of children, youth, and local citizens as champions of child rights. An important component of this work is the tying together of community-led and child/youth-led work. 
In this paper we:

- present a user-friendly summary of the existing tradition of substantive children's participation in social change work;

- share case studies across various sectors and regions of the world;

- highlight ongoing challenges and evidence gaps;

- showcase expert opinions on the inclusion of child rights and, in particular, child/youthled approaches in project-based work.

We recognise that this paper is far from exhaustive, and we intend it to be a springboard for further work that substantively recognises the importance of children's participation in work to further child rights, and to enrich and rejuvenate the societies of which children are a part.

Our primary audience includes academics, decision makers, advocates, and programme implementers involved in working with children and young people to further child rights in diverse contexts.

\section{The purpose of this paper}

This project emerged from a desire to rejuvenate the field of child rights, 30 years after the creation of the United Nations Convention on the Rights of the Child (UNCRC). While steady progress has moved the UNCRC into national child rights laws, policies, and action plans, there is still a huge gap between the ideal of participatory child rights and the reality of social norms within which these rights are enacted. Social hierarchies, structured through racism, patriarchy, and gerontocracy, are still the predominant global norm. This means that children generally, and particularly girls and transgender children, sit at the bottom of social hierarchies. It also means that understandings of 'children's needs' are often based on adults' perceptions of those needs. Despite strong evidence supporting the importance of including children's and young people's participation in development practice, work that genuinely consults with and incorporates children's views and understandings is still minimal (Gero and Asker 2012). Where children are listened to, it is often to more vocal and invited voices, to the exclusion of the more marginal (Tisdall and Davis 2004).

Not enough young people are given the opportunity to contribute to the work that directly affects them. This is a lost opportunity for them and for their societies, particularly if we consider that half the population of the world's low-income countries is under the age of 18 (UNICEF 2019). Investment in child/youth-focused and -led work is valuable because: it will help to change conditions for young people and their communities (J. Hart 2008; Johnson and West 2018; Wessells pers. comm. 2019); and it will help to build competent social justice leaders (McGill et al. 2015; O'Kane pers. comm. 2019).

Our research has consistently indicated that we need to work with children because they are important community stakeholders, with specific views and needs. If we fail to do this, our projects will fail:

there is a powerful body of evidence showing how prevailing attitudes towards children, based on the view that adults both know best and will act in their best interest, have 
failed many children. Many of these failures resulted from the refusal to listen to the voices of children themselves.

(Lansdown 2001: 3)

As Johnson and West argue

all adults were children, but they were young at a different time and in a different context. Children and young people are all experts in their own lives and their developing and shifting identities. They experience many unique processes of marginalisation and intersecting aspects of exclusion and inclusion.

Uohnson and West forthcoming, 2021)

In a global context of 'illiberal mobilisation' (Goetz 2019) and de-democratisation (Verloo and Paternotte 2018) in which rights and democracy are under unprecedented pressure, investing in child rights work, and developing children's critical agency, can provide a vital intergenerational counterforce. This is particularly so in relation to new media technologies that many young people are especially able to understand and use. This paper aims to amplify, and articulate, learning from the existing participatory work being done in the field.

Children and youth already perform productive roles in families and society that are often invisible (Johnson et al. 1995). They are accustomed to navigating and negotiating traditional and community power dynamics, and rapidly changing environmental and political environments; and they are able to embrace uncertainty with new and creative strategies.

The research gathered here indicates that the only way for real change to happen - not just for the lives of children and young people, but for the communities they live in - is for children to be involved in determining what programmes are introduced, how they are designed, and what decisions get made. Our findings suggest that we urgently need a cultural shift that recognises children's and young people's ability to make decisions and take action, while avoiding shifting the responsibility to them. As Dr Robert Ross, CEO of the California Endowment, argues, '[Youth organising is] a triple bottom line investment: you get an issue benefit, you get a community benefit, and you get a leadership development benefit for young people' (FCYO 2018: 4). Children are part of our communities and unless we address the power dynamics and systems that limit their social, political, and economic engagement, we prevent them from enriching these communities. By acknowledging that 'children are agents of constructive change' (Wessells pers. comm. 2019), we recognise the need for processes that support children's and youth involvement and go beyond participation to support deep agency and substantive leadership.

\section{A brief history of children's participation}

The protection and care of children in most societies prior to the Industrial Revolution was considered to be the responsibility of individual families and communities, with children being thought of as the personal property of their parents (Kosher et al. 2016: 9). The rapid social changes that accompanied industrialisation ushered in a growing concern for child welfare, partly driven by the child labour reform movement (R. Hart 1992). During this period, child protection rights (from harmful work) and provision rights (the right to education) developed (Kosher et al. 2016: 11). 
Between 1890 and 1920, numerous professional child welfare services were established (Ansell 2005; Kosher et al. 2016: 11; Wells 2015: 25). Many of these were private charities focused on 'saving' disadvantaged children and often involved separating children from their families (Wells 2015: 27). The twentieth century saw worldwide recognition of child rights, and the responsibility for children's welfare increasingly shifted towards the state (ibid:: 28). However, it was only in the second half of this century that the notion of children as citizens, capable of social and political participation, developed (Ansell 2005: 226; Kosher et al. 2016: 11).

On the global stage, the League of Nations in 1924 adopted the Geneva Declaration on the Rights of the Child, a document drafted by Eglantyne Jebb, the founder of the Save the Children Fund. In 1946, the United Nations Children's Fund (UNICEF) was established as part of the UN's reconstruction efforts after the Second World War. Leading up to the adoption of the UNCRC in 1990, better social policies were developed for children, both in industrialised countries and lower-income ones. Despite the UNCRC's wide ratification, it has been taken up differently in different geographical contexts, and learning across these contexts has sometimes been constrained by language (Latin American implementation, for example, tends to be written about in Spanish or Portuguese). Some have criticised the UNCRC for being based on a Western construction of childhood (see, for example, Pattanaik 2004). Others have adopted regional policy mechanisms to support its local efficacy, for example, the member states of the African Union have developed the African Charter on the Rights and Welfare of the Child.

Perhaps the UNCRC's central constraint lies in its basis on protection rather than justice approaches. In other words, children were still understood to be beneficiaries rather than competent actors (Cipriani 2009; Kosher et al. 2016), a fact which prompts Wells (2015) to point out that the narrative of a move from a child-saving agenda to child-rights agenda is too simplistic. She argues that 'in practice, the field of child welfare constantly shifts around these two poles rather than moving decisively from one to the other' (ibid:: 23). The idea of children as (full) rights holders is still contested (R. Hart 1992; Kellett 2009: 43). In other words, there is a resistance to the idea that children hold both protection and freedom rights; that children are both 'vulnerable beings in need of protection', and 'also active agents' (Bonvin and Stoecklin 2016: 19) capable of intentionality and reflexivity, and of providing expert testimony about their lives (Thomson 2009: 1). Ansell (2005: 226) has suggested that the shift from the child as a dependent, to child as a citizen remains incomplete. Within this context, children's participation becomes extremely important to the full realisation of their rights.

The UNCRC is often characterised by the typology of the '3Ps': protection, provision, and participation (Lansdown 1994; Toope 1996). Although the UNCRC has led to the development of national Child Acts globally, there is still a tendency to focus on protection and provision rather than on participation. The participation component is articulated in Article 12 of the UNCRC, which expresses 'the Right to be Heard'. That right includes raising children's voices and the responsibility of duty bearers (including parents and states) to listen to them and act on their perspectives (Lansdown pers. comm. 2019). Article 12 remains an important basis for many of the productive interventions towards participatory approaches with children that have occurred in the 30 years since the convention. 
The significant inclusion of participation rights in the UNCRC reflects its development at a time in which participation ${ }^{1}$ was central to development practice and discourse. 'Participation' means active involvement in something and has historically been linked to active adult citizenship (Arnstein 1969) and children's citizenship (Cockburn 2007; Invernizzi and Williams 2008; Kellett 2009: 43; Larkins 2014; Lister 2007).

Roger Hart's (1992) extremely influential ladder of children's participation adapts Arnstein's (1969) ladder of citizen participation. Hart's ladder of children's participation shows the range of 'children's participation' from non-participation (manipulation, decoration, tokenism) to full participation (adults and young people sharing decision-making). Many subsequent frameworks have critiqued and built on Hart's ladder, for example Treseder's (1997) spectrum and Shier's (2001) pathways to participation. The development, through the 1990s, of discourses on children's and youth citizenship, participation, agency and empowerment, runs alongside the emergence of the 'new sociology of childhood' (James et al. 1998), and the 'social studies of childhood' (Wells 2015). The 'social studies of childhood' recognises the interdisciplinary nature of childhood and youth and includes the incorporation of children's geographies, the anthropology of childhood, and childhood in history (Wells 2015).

Despite these numerous developments in our thinking on children, 'most adult constructions of child participation do not connect with child agency or active citizenship but are wedged in more passive agendas of listening and consulting' (Kellett 2009: 43). Children are generally thought to enjoy protection rights (protection and provision) but they may not be able to exercise liberty rights (participation) depending on their context, and their capacity in that context (Cipriani 2009). Perceived competency varies according to different social norms about children, so the amount of control that adults have in deciding children's interests depends on social understandings of childhood, not on children themselves (ibid.).

Jason Hart (2008), borrowing from critiques of adult participation work, suggests that children's participation, in practice, exhibits two fundamental flaws. The first is that in its focus on 'the local', children's participation often loses the connection to the broader political arenas that ultimately structure people's realities. In other words, that focus has a depoliticising effect. The second concern, drawing from Nancy Fraser's work $(1997,2003)$ and related to the first, is that 'children' or 'young people' become caught up in a politics of recognition rather than redistribution, and their participation becomes tokenistic. One of the recurring narratives in our interviews was the prevalence of 'decorative or token participation', where individual children or young people are brought to policy spaces as 'youth representatives'. Chernor Bah identifies these tokenistic representations as a persistent failure of participation attempts:

every children's advisory role that tries to remove the power and magic of children's voice combines their participation into the status quo of adult platforms. What happens is about making the organisations better, it is not about making children's lives better. It is about making the organisation look better, because then they can say that they have done children's participation. It doesn't support the individual transformation of children,

\footnotetext{
${ }^{1}$ A timeline of the development of participation within the context of international development can be found in PLA Notes 50: Critical reflections, future directions (Chambers et al. 2004).
} 
or children like them, within the societies that they come from... even when you get substance, it's just about rewarding super man and super woman.

(Bah pers. comm. 2019)

\section{Framing and reconceptualising rights as living rights}

One useful response to the constraints of the framing of child rights and children's participation is the concept of 'living rights', which comes from a group of influential thinkers across global contexts led by Karl Hanson and Olga Nieuwenhuys (2013). They articulate children's rights as 'living rights' or 'rights under construction' - where there is a gap between the imagined child and the actual social practices of children. 'Living rights' sit at the intersection between social practices and children's rights (see Figure 2).

Figure 2: Authors' representation of Hanson and Nieuwenhuys' (2013) Children's (Living) Rights

\section{GAP}

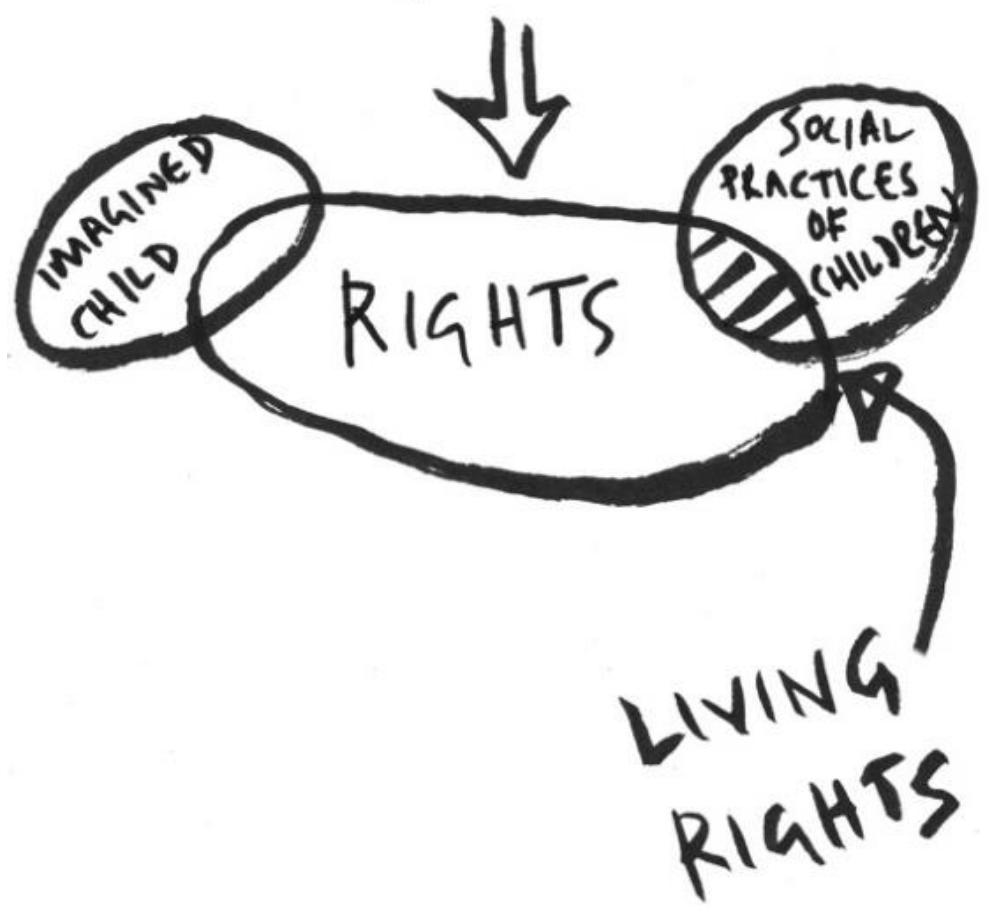

Living rights were first conceptualised when Hanson and Nieuwenhuys discussed the difference between rights on paper and how children who experience injustice navigate and negotiate rights in their everyday lives (Nieuwenhuys pers. comm. 2019). Their model recognises that children are involved in shaping what their rights become in the social world. Hanson's work has been shaped by his experience of having been a youth activist, an experience he was able to reflect on within the academic study of child rights (Hanson pers. comm. 2019). He noted how apparent it was, for example, in juvenile justice systems that if children's agency is not taken seriously, then programmes invariably fail ( $i b i d$.). The living rights model recognises that local understandings of rights predate the UNCRC and are rooted in a broad conceptualisation of 
social justice. The way that children's rights play out in particular contexts is shaped by interactions between a moral economy, the state and social movements, and their relationship with the social structures - community, local and global - that they are situated within (see Figure 3).

Figure 3: Authors' representation of Hanson and Nieuwenhuys' (2013) situated Children's (Living) Rights

\section{SOCAR JUSTICE}

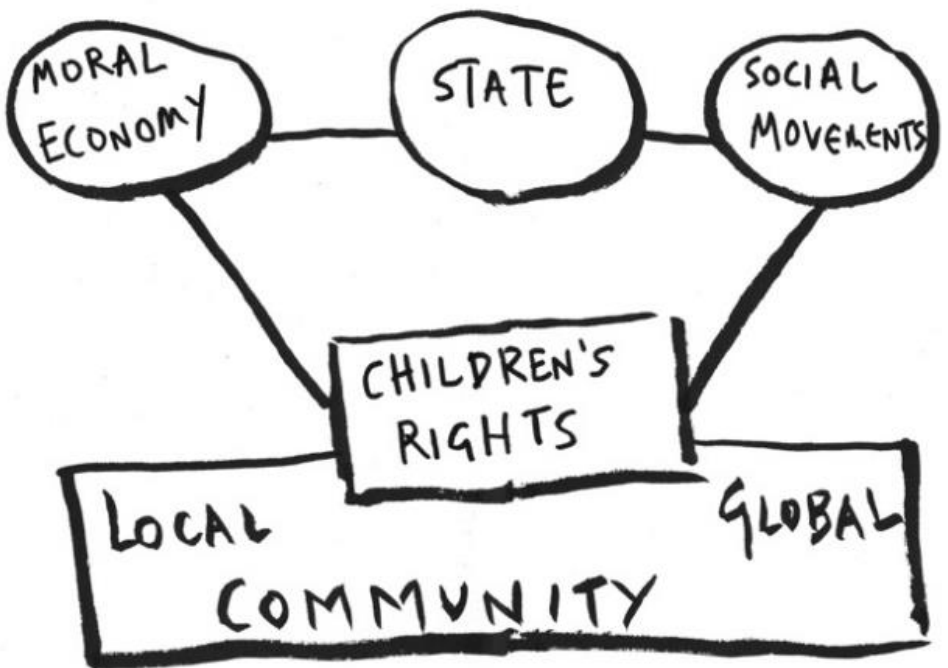

When children's rights encounter children's perspectives (and other social actors) they are adapted from concept to practice. Hanson and Nieuwenhuys (2013) call this process 'translation'. Children's meaningful participation on issues that concern them is central to the effective translation of their rights in their local context, and is underpinned by an understanding that children are not isolated individuals but are embedded within families and communities, and therefore interact with local and global social norms.

A living rights lens helps us to see children and youth as integral to everything; as people with valuable insights and contributions that are vital to all our futures, and community members that should be listened to. Because this lens situates children's rights within a structuralinstitutional framework, it links the everyday and the local to broader socio-political structures. This model is politicised both in its framing of children's rights as embedded within a social justice framework, and its emphasis on the collective nature of these rights. Many of our interviewees made this point in different ways:

What happens now is that participation is about the rewarding of the individual, and it gives an individual opportunities without thinking about her connectedness with other people of her community. And how do we make sure that the rewards, that the relationship that we are having translates not just to that one girl?

(Bah pers. comm. 2019) 
Saji Prelis (pers. comm. 2019) cautioned against viewing social change as driven by individuals: 'We don't see efforts for collective action, for collective impact, because we see our superiority and our exceptionalism as the way to make change. It is absolutely foolish for us to think this way'.

This project builds on Hanson and Nieuwenhuys's (2013) conceptualisation of living rights as part of social justice. The next section outlines the rest of the paper and provides further detail on our research methodology.

\section{Outline of the paper}

This paper starts with an overview of the methodology we used for 'Phase One' of a continuing project. In this first phase, we developed our 'living archive' (creating a growing database of people and project-based literature, with accompanying analysis matrices - see References); we carried out interviews with field experts; and we undertook an analysis, across these data, to suggest a framework with which to move forward, with a view to rejuvenating the field of child and youth rights and participation.

One of the central questions that we asked of the literature, and of our interviewees, was: 'What has worked in this field?'. We structure our analysis of the answer to this question into three parts - Space, Support, and System Change. These three concepts - space, support, and system change (3Ss) build on, and move beyond, the three Ps of the UNCRC: protection, provision and participation (3Ps). Each concept is briefly introduced, followed by a presentation of the evidence relating to it from our living archive (both the interviews and the literature).

This is followed by a section on methods, which illuminates some of the creative methods used to include and engage with children. This forms the basis of a methods repository, that we will build on in Phase Two of this project. We position the section on methods immediately after the 3Ss, to acknowledge that the use of creative and participatory methods that surface the voices of children and youth is not enough. We need also to adapt the spaces, support, and systems to ensure that children are not only listened to, but heard, and that action is taken. This includes child- and youth-centred and focused approaches.

Our methods section is followed by a short section on 'what hasn't worked' constructed from interviewees' accounts of what they would avoid or do differently in the future.

The last section of the paper outlines the 'REJUVENATE principles', which grew out of this Phase One research process and presents a 'best practice' field guide for child/youth-led rights work.

These principles are underpinned by a socioecological 'change-scape' model, Ndoro Ndoro, which is introduced to help to visualise research and practice that is child-and youthcentred/sensitive/focused, intergenerational and community-driven. 


\section{Our methodology}

The research process for this review of experience involved a rigorous review of available project-based academic and grey literature, including archival material from Johnson and interviewees' collections of grey literature, and the Participation Resource Centre at the Institute of Development Studies. In addition, 41 interviews, 32 of which were in-depth (see page 19 for details), were undertaken with stakeholders and experts (across global contexts, academic disciplines and communities of practice) to capture case studies, expert opinions, challenges, and gaps. The project involved iterating between the project literature and our interviews. During this process we identified further learning, resources, and networks that will contribute to the ongoing development of this work. This paper marks the start of an ongoing mapping process and, as such, aims to be indicative rather than comprehensive.

\section{Creating a living archive}

This consisted of 100 projects sourced from interviewees, and grey and published literature. Of these projects, roughly 40 per cent were documented between 1990 and 2010, and 60 per cent post-2010. This was to ensure that we were drawing on learning from the across the past 30 to 40 years. We selected literature with projects that both evidenced substantive participation with children or youth, and that were practice-based or applied research, and screened these according to their significance. They were triangulated by independent research on these initiatives. Projects were also screened based on the degree to which children/youth were involved in the research or implementation process, with an emphasis on projects that involved children/youth in multiple stages including design, analysis, and dissemination, as well as being participants. While recognising that there exists a broad range of research methodologies that involve children or have children as the subjects, we excluded projects that did not present evidence of direct work with children/youth. We also ensured that our review represented a geographic, temporal, and thematic spread.

Figure 4 shows a map of the practice-based literature reviewed and interviews. This suggests a large basis on which to grow networks and partnerships across global contexts.

We view this as the start of an inclusive process of contributing to and building up international dialogue about children's and youth participation and creating regional networks to share learning on concepts, rights, and goals. This initial phase of the process invited interviewees to identify further people, groups, and organisations to follow up with regionally. This snowballing approach will allow us to continue to broaden and deepen our mapping process in future phases of this project. 
Figure 4: Map of provenance of living archive project documents (blue/dark grey) and interview participants (green/light grey)

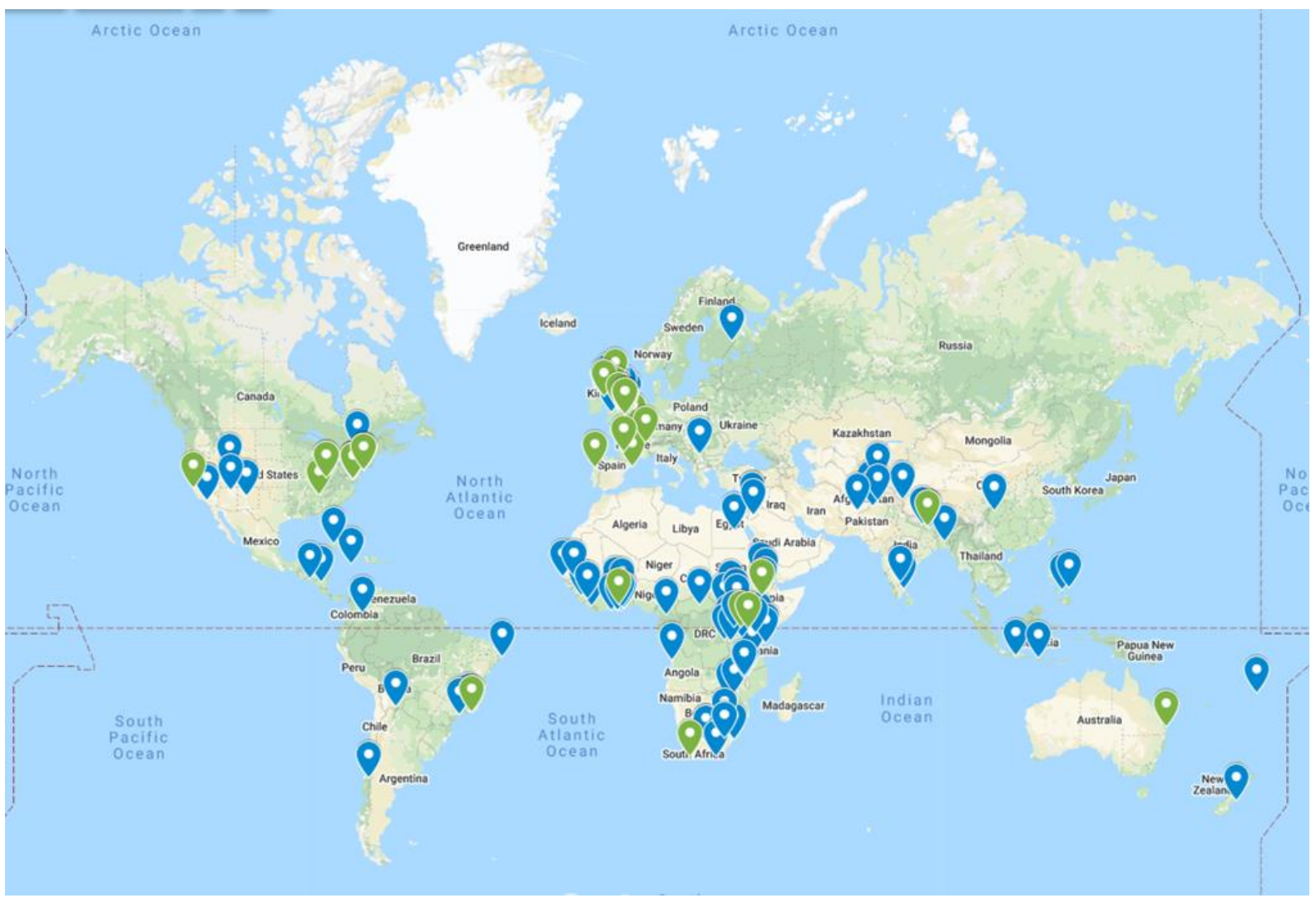

Source: $\odot$ 2020, Google Maps, My Maps

\section{In-depth and short interviews with experts in the field}

At this scoping stage, 41 'field experts' were interviewed, of whom 32 were interviewed in detail. These experts were chosen for their depth and breadth of experience, and because they are both thinkers and practitioners. Most of the global experts we interviewed for this project had been youth activists themselves, so embodied the notion of children as active agents of change in communities. Others had witnessed first-hand how valuable children's and youth perspectives were in understanding broader issues of environment, development, community development and social or child protection. Interviews sometimes aimed to follow up on or source certain projects or to have brief discussions about ideas. Some interviews were also due to opportunities during the timescale of Phase One, where experts were in the same location as the authors or team. In other circumstances, Skype and other remote forms of communication were arranged in order to have a range of participants across the global North and South (see Figure 4). Whether interviews were followed up as in-depth interviews was sometimes an indication of the time availability for the participant and the interviewer. The team will follow up with other academics and practitioners during Phase Two of REJUVENATE.

An interview schedule was constructed by discussing and piloting interviews with a Local Advisory Group, ${ }^{2}$ who suggested how questions could be developed in order to remap and rejuvenate the field of child rights and participation. This schedule provided prompts for in-

\footnotetext{
${ }^{2}$ Members of the Local Advisory Group were Sara Bragg, Rachel Thomson, and Andy West.
} 
depth interviews that were carried out between April and October 2019. Participants were chosen from different communities of practice, including experts identified by our philanthropic funders and by our research team. Other interviewees were chosen for their regional expertise and for their capacity to link theory to practice.

Ethical approval was gained through the Institute of Development Studies (IDS) and informed consent forms and information sheets designed for the purposes of the research were provided to each interviewee. Each interview took between 30 and 120 minutes depending on the availability of participants. The interviews were taped and transcribed. The draft paper was verified to ensure interviewees were happy with how their views were represented and the quotes used to illustrate key arguments and points in the paper.

Our methodology was designed to ensure that learning and literature from academia and practice, from diverse global contexts, could be made more broadly accessible. Our thematic analysis of the interviews was also compared with analysis of the literature data and then collated and reviewed during a joint synthesis process to triangulate our findings.

To capture the embodied nature of supporting children's and youth agency, some trials were done to film 'talking heads' (i.e. short video interviews that highlight the passion and priorities of the interviewee). This was also important to demonstrate the central importance of the behaviour and attitudes of adults who work with children. This is something we hope to pursue further in our future work.

The project-based literature we analysed comprised 100 documents in total: 46 were from grey literature (32 research reports and 14 project reports); 38 were from peer-reviewed journal articles; 6 were from edited book chapters; 5 were from webpages of projects referred to us from interviewees; 5 documents were other types of published literature, such as PhD theses and working papers.

The documents range from the 1980s to the current time, and around 62 are written post-2010. Table 1 summarises the time span captured. The historical examples serve to reflect the progression of including children in research and interventions, so lessons are learned, and we avoid 'reinventing the wheel'. The later examples show that there is a continuation of innovative and inclusive approaches to giving children and youth space in community-driven and child/youth-centred and led projects.

Table 1: Time span for the project documents analysed

\begin{tabular}{|l|l|}
\hline Year & Count \\
\hline 1980s-1990s & 19 \\
\hline $2000-09$ & 19 \\
\hline 2010 - present & 62 \\
\hline
\end{tabular}


Table 2: Types of documents analysed

\begin{tabular}{|c|c|c|}
\hline Type of document & Count & Description \\
\hline Grey literature - research report & 32 & $\begin{array}{l}\text { Evaluations, survey results, specific study } \\
\text { outcomes }\end{array}$ \\
\hline Grey literature - project report & 14 & $\begin{array}{l}\text { Documents more generally about projects, } \\
\text { activities, outcomes, etc. }\end{array}$ \\
\hline Journal article - peer-reviewed & 38 & $\begin{array}{l}\text { Journals from childhood and youth studies } \\
\text { including the sociology of childhood and } \\
\text { children's geographies, anthropology, } \\
\text { development studies and education }\end{array}$ \\
\hline Book chapter - edited book & 6 & Books on children's and youth participation \\
\hline Webpages & 5 & $\begin{array}{l}\text { Sources elaborate on projects identified in } \\
\text { interviews that are not published elsewhere }\end{array}$ \\
\hline $\begin{array}{l}\text { IDS Participatory Resource Centre } \\
\text { grey and published literature }\end{array}$ & 5 & $\begin{array}{l}\text { PLA Notes (see specifically } 25,42,50 \text { ); IDS } \\
\text { Bulletin; Working Papers; PhD Theses }\end{array}$ \\
\hline
\end{tabular}

Table 3: Geographical spread of sample

\begin{tabular}{|c|c|c|}
\hline North America & 5 & Central Africa \\
\hline Western Europe & 2 & South Asia \\
\hline United Kingdom & 9 & Southeast Asia \\
\hline Balkans/Eastern Europe & 2 & Pacific/Oceania \\
\hline Middle East and North Africa & 6 & East Asia \\
\hline East Africa & 14 & Latin America and Caribbean \\
\hline West Africa & 11 & Central Asia \\
\hline \multirow[t]{2}{*}{ Southern Africa } & 11 & Multiple \\
\hline & & TOTAL \\
\hline
\end{tabular}

The projects illustrate a range of methodological approaches and have been analysed considering how far they include children and youth throughout processes of research and implementation in a meaningful way. For a first selection criterion, projects were considered for whether they work on children and young people, with them, or were led by children or youth.

Projects that carried out research on children or delivered services that were intended for them were not included in the living archive. 
Projects that were carried out with or by children and youth were included. The team recognises that the process has not ended up with a comprehensive set of literature or interview participants but that the living archive is the start of a process in which the networks of people and literature included grow; and it is acknowledged that both the process and the networks are far greater than we can represent here. This is the purpose of Phase Two in which we wish to reach out to more people and projects.

Relatively few projects were written up and described as being child- or youth-led in terms of ideas being initiated by young people (11 examples in the living archive could be categorised in this way). R. Hart (1992) discussed the importance of participation where ideas are initiated by children as distinct to those where ideas for research and projects are initiated by adults and then involve children and young people as participants.

Many of the examples of projects and research selected at this stage for the living archive illustrate processes that are carried out with children and youth, often offering and illuminating exciting approaches to share more widely. It is not necessarily the case that these projects were seen as less participatory than those led by children (so not as a continuum) but that each project followed different modes and methods of inclusion of children and youth depending on the purpose of the project and the context in which they were designed and carried out. Many of the selected projects took into account local concepts and social norms regarding childhood and youth across global contexts.

In the living archive, Cannon, with the help of López Franco from the team, followed the project literature review matrix (as mentioned in the Introduction) developed with Johnson and Lewin and checked with the Local Advisory Group. This allowed further categorisation for the living archive. Therefore, analysis of projects carried out with children and youth for the living archive was as follows:

- 48 projects involved children/youth in the production of data as interview and focus group discussion participants or in the development and implementation of creative and participatory methods;

- 15 projects involved children and youth in the implementation of interviews in research processes;

- 26 involved children/youth in the initial design of the project;

- 11 were unspecified.

In terms of approach, all the methodologies that were inclusive of children and youth were qualitative. Some specified a particular disciplinary approach, such as ethnography (seven examples), others had more standard qualitative research approaches, including interviews, focus groups, and the use of some visual and narrative approaches ( 46 examples, including two child-to-child projects). Other documents specified participatory approaches more explicitly using terms such as participatory action research (PAR), participatory programming, impact assessment or addressing participatory governance ( 56 articulated that they were participatory/PAR). Note the total is more than 100 as some lay between qualitative and participatory in their description. 


\section{A note on evidence}

The term 'evidence' is much contested, particularly within qualitative research (Eyben et al. 2015) and 'there is a growing body of work that has raised fundamental questions about both the feasibility [and desirability] of the idea of evidence-based or evidence-informed practice' (Biesta 2010: 491). Ours is a qualitative analysis that provides evidence in the form of experience, lessons learned and project examples, and includes a thematic analysis that underpins the emerging principles. We have gathered and analysed experience from some of the key thinkers and practitioners in the field of child rights globally. As such, this reflects a tradition, and an 'expert assessment' of what has and has not worked within this tradition. We write to inform practitioner decisions and encourage further research and learning in this area.

The following section of this paper looks at the findings of Phase One of the project and includes discussions on terminology, what works in children's participation, and what does not work. 


\section{Ourfindings \\ The language of child rights and children's/youth \\ participation}

Why participation? A rights programme cannot function without it... if you are doing it for or on behalf of children, they need to be the ones deciding.

Mark Canavera (pers. comm. 2019)

The diverse interpretations of participation, together with some of the pitfalls evidenced in its practice, have prompted two primary responses from practitioners who are committed to a more substantive interpretation of this concept. The first is an expansion and qualifying of participation; it is exemplified in Lundy's (2007) work which argues for a more detailed framing of children's participation as requiring four key elements: space, voice, audience, and influence. The second response is a rejection of the term 'participation' altogether and the preference for the use of other terminology such as empowerment or agency.

Andy West (pers. comm. 2019) notes that in the 1980s and 1990s, concepts of empowerment and emancipation, rather than participation were used in work on issues of youth homelessness and juvenile justice. Johnson $(2015,2017)$ argues that although child rights discourses have gained ground since the introduction of the UNCRC and children's voices have been raised in many different areas of their lives, we now need to focus on who is listening to, and acting on, children's perspectives. Michael Wessells (pers. comm. 2019) argues that what is needed is for children to have agency: 'The term participation is too light, we are beyond participation and into the language of empowerment and agency.' Don Cipriani (pers. comm. 2019) agrees and suggests that 'anything else [other than children/youth's agency] is paternalism'.

Many of our interviewees talked about the current terms we use being inadequate, that we may need more ambitious language than that of 'participation'. Canavera (pers. comm. 2019) suggested replacing the word participation with 'agency and decision-making'. Cipriani suggested that participation might work as a framing with very young children, but that it was inappropriate when talking about older children:

Participation is granted or not - for younger children participation could be a fitting word but pre-adolescents on, I think this is a space where some pushing could be helpful to redefine the language for something much more ambitious where one is not granting participation or not, but it is again, the full spirit of youth owning the agenda.

(Cipriani pers. comm. 2019)

Others indicated that we might need a range of different framings for different audiences. Swatee Deepak (pers. comm. 2019) talked about the need to use language strategically and noted that depending on the audience whom we are addressing, 'we code-switch all the time'. Yaw Ofosu-Kusi suggested that many parents would be dismissive of the language of child rights: 'If you give a father at home a leaflet about child rights from school he will generally throw it in the bin' (Ofosu-Kusi pers. comm. 2019). 
Nieuwenhuys (pers. comm. 2019) suggested that because participation, in a sense, means everything that we do, it is meaningless. West (pers. comm. 2019) asks, 'Participation in what? Participation to maintain existing power relationships, or to address power used negatively, and social norms that harm children?'

Irene Rizzini (pers. comm. 2019) pointed out that in the Latin American context neither 'participation' nor 'agency' translate well and protagonismo, or protagonism, works better. Colleagues at Porto University, in Portugal, are exploring these various terminologies and their usages, working with child rights experts in Brazil to create a dictionary on the sociology of childhood in English and Portuguese (Trevisan pers. comm. 2019). West (pers. comm. 2019) described spending significant amounts of time in the early stages of the YOUR World Research project (Johnson et al. 2019) with youth and national team members, agreeing on a shared understanding of different concepts such as marginalisation, insecurity, and uncertainty. He suggests referring to children's 'views, decisions, and actions', rather than children's 'agency'. ${ }^{3}$ Project literature reviewed from the living archive on children's participation also shows the numerous and diverse terms or framings that scholars and practitioners use. Often authors use a variety of these framings within one article. For Phase Two we are building up a more comprehensive categorisation of terminology used that ties in with articulated rationale or motivation for participatory work.

Our analysis for Phase One demonstrates a range of terminology used across the project literature, including the following:

- to amplify/listen to children's voices (for example, Johnson et al. 1995; Mizen and OfosuKusi 2010b; Plush 2009; Swart 1990; van Blerk et al. 2019);

- $\quad$ to support the empowerment of children (Achaleke 2017; Ambiente (CESESMA) 2012; Bereményi et al. 2017; Cahill 2010; Dyson and Amara 2016; Haynes and Tanner 2015; Mclvor 2001; McGill et al. 2015; Monzani, Sarota and Venturi 2018; O'Kane 2007; Promundo et al. 2013; Törrönen and Vornanen 2014; van Blerk et al. 2019);

- to promote rights with reference to the UNCRC (for example, Baker and Hinton 2001; Blackburn et al. 2005; Chawla and Driskell 2006; Crowley and Skeels 2010; Johnson et al. 1995; Lundy et al. 2011; Nombo and Cassiem 2007);

- to move towards child/youth-centred/sensitive/focused, intergenerational approaches (Ansell et al. 2012, 2019; Punch 2000; Wessells 2010).

Examples of how children and youth can be meaningfully involved in social justice work can be found throughout this text in the form of case study boxes. These case studies were put forward by our interviewees as examples of organisations or processes that effectively incorporate the views, ideas, and decisions of children and young people in order to further social justice and rejuvenate their communities.

\footnotetext{
${ }^{3}$ A terminology that we have borrowed for our Ndoro Ndoro spiral on page 46 .
} 
26

What has worked

In this section, drawing on our analysis of both the practice-based literature and our interviews, we cluster the insights of what works into three categories - space, support, and system change - and on this basis propose moving on beyond the BPs (protection, provision, participation) of the UNCRC, to these SSs (space, support, systems). In this section we take each of these in turn and connect them to the evidence from both the literature and our interviews with field experts.

Space. We need to create and build on existing safe spaces for children and young people. These spaces - both existing and those re-imagined - allow them to build confidence through dialogue with peers and to engage constructively with adults in positions of power. We also expand the concept of space to mean creating space in project and decision-making processes to meaningfully include children and youth.

Support. Our research consistently surfaced examples of children and youth asking adults to listen to and support them. It revealed that young people think not only of themselves but also their communities and future generations. In addition to providing children and young people with space, adults have a responsibility to support children and youth to apply their agency.

System change. Social change requires confronting social norms and structural inequities based on hierarchies such as race, class, gender, sexuality and disability, but also 'adultism'. Social attitudes towards young people in many global contexts assume they should be seen and not heard. Children and young people are thought to be part of social problems rather than potential allies in finding the solutions to these problems. Adults need to be engaged to change their own perspectives and the harmful institutions and social norms that make young people's positive contributions to decision-making invisible.

Figure 5: The BPs to the 3Ss

$3 P_{s} \longrightarrow 3 S_{s}$

Protection..$\rightarrow$ Space

Provision $\rightarrow \rightarrow$ SUPPORT

Participation $\rightarrow$ System Change 
The literature that we analysed comprehensively indicates that participatory development work with children has significant instrumental, conceptual, capacity-building, and connectivity benefits. ${ }^{4}$ Instrumental impact relates to a project influencing the development of policy, practice or service provision, shaping legislation, or altering behaviour; conceptual impact happens when a project contributes to the understanding of policy issues, or reframing debates; capacitybuilding impact relates to technical and personal skill development; and connectivity to increased relationships, partnerships and networks that can support impact.

Our analysis took each of these categories of instrumental, conceptual, capacity-building, and connectivity as a starting point. We then mapped each onto our three categories - space, support and system change - and broadened the frame to include empowerment and accountability. The logic of this is that in order to create the instrumental benefit evidenced in the literature, we need to create space for children and youth; to do so, requires a conceptual shift among adults - to recognise and then support children's capacities (a benefit also evidenced in the literature); and with both of these come the increased capacity, connectivity, empowerment, and accountability necessary for systemic change.

\section{Box 1: Case study - Community-based youth work}

Research conducted by Michael Wessells and Carlinda Monteiro in Angola suggests that a combined focus on youth and community is not only successful, but also necessary, in disrupting cycles of violence. Community-based programmes that provide youth-specific support and involve youth in community projects, while simultaneously creating opportunities for adults to learn about youth experiences, led to increased perceptions of youth as positive influences in communities and improved adult-youth relationships. Some specific aspects of the project included: training seminars run separately for adults and youth; a community-chosen project implemented with significant youth involvement, which built on the idea of positive youth contributions; and youthfocused activities, such as peer dialogues

'The results suggest that a dual focus on youth and community development contributes to peacebuilding and the disruption of cycles of violence.'

(Wessells and Monteiro 2006: 121). and community drama.

Along with a community-based approach, Wessells and Monteiro argue against the sole use of Western trauma approaches to address past experiences of youth, stating that these fail to account for ongoing experiences of poverty and deprivation. Instead, they call for more holistic approaches that meet physical and mental needs and build youth capacities to participate fully in their societies. Additionally, cultural contexts must be considered and integrated into processes of conflict resolution and prevention (Wessells and Monteiro 2006).

\footnotetext{
${ }^{4}$ These indicators are used by the Economic and Social Research Council/Foreign Commonwealth and Development Office (ESRC-FCDO)-funded Impact Initiative to measure impact.
} 


\section{Space: Creating spaces for including and involving children and youth}

Children need their own spaces in which they can develop their autonomy among peers, and not in an adult-led context. Ben Cislaghi suggests that this is a necessary first step in a process of confidence-building for children/young people:

I think, as humans, we need spaces in which we can maybe gain the confidence that these things actually do not matter only to us, but to others... and this takes time, and this is the kind of spaces that we need to create in communities which then requires potentially to segregate people first.

(Cislaghi pers. comm. 2019)

West (pers. comm. 2019) argues that safe and participatory spaces for children and youth outside cultural norms can allow the creativity and space that children need to build confidence and 'an opportunity to be a different you'.

Our research suggests that it is incumbent on adult organisers and facilitators to create spaces that prioritise the involvement of children and youth perspectives in how the space(s) are used and allow children and young people to feel comfortable in them. Central to this is ensuring that children and young people are involved in decision-making about the space. Research suggests that young people often want very different interventions to those that adults think they might want. Young people in the UK city of Hull, for example, who had experienced homelessness wanted counselling to enable them to talk about their experiences, not the sports or training the adults imagined they might need (West pers. comm. 2019).

There has been much theorisation about how safe and participatory spaces for children and young people are critical to build self-confidence and to support each other as peers, both to think together and to enter into dialogue with adults and decision makers (Johnson 2011; Johnson and West 2018; Mannion 2009). An example from Shier (2010) discusses the nongovernmental organisation (NGO) CESESMA (Centre for Education in Health and Environment) that works with coffee growers in Nicaragua. With a strong rights focus, spaces are seen as important for children to work together to understand, promote and defend their rights. In this example the older children and youth also recognise the importance of peers working together to influence adult-dominated spaces (Shier 2010). When interviewed late in the programme, adults discussed how they had gradually recognised children's contributions, gained respect for them as valuable participants and suggested they had changed their attitudes towards including children and youth in broader community development.

As well as creating physical spaces for children and young people, we need to create space for their involvement in public life. A cluster of literature advocates for participatory work with children, on the grounds that it supports children's and youth capacity building, increased confidence and empowerment. Zubair et al. (2002) argue that a Save the Children 'reflect-action' process in a refugee camp in Pakistan gave participants more confidence, and increased their voice, influence, and mobility. It also made participants more aware of camp service provision options ( $i b i d$.). 
Many projects that actively created space for children's involvement reported that such involvement was essential to ensure a better basis for action (Lundy et al. 2011; Pankhurst et al. 2018). This acknowledges the fact that children often have expert knowledge (Clark 2007; Gibbs et al. 2013; Guijt et al. 1994; Pankhurst et al. 2016; Tanner 2010; Veitch et al. 2014; Wellard et al. 1997) and are able to surface unexpected findings (Mizen and Ofosu-Kusi 2010b), or identify gaps in needs and priorities (Krueger et al. 2015). Chawla and Driskell (2006: 194), for example, in the Growing up in Cities Project, observed that there was a 'near complete lack of connection between what local officials viewed as the needs of local young people (more opportunities for sports and recreation) and what young people expressed as their needs (adequate clean water and sanitation)'. Similarly, Wessells' (2010) work shows that without including girls' knowledge, some things will remain invisible, for example, the lack of reintegration services for girls who are forcibly recruited to armed forces in Angola. Children's involvement is also often essential for improving policy, for example, to improve inclusion of disabled children in schools in Laos (Grimes 2009).

Some authors note that working with children for research yields better results when they interview each other, as they are more likely to open up to peers (Robson et al. 2009). Examples from across the living archive demonstrate the importance of creating spaces for children to work together to analyse their situations, make decisions and initiate change: for example, Stephenson (1998) working with MYRADA children's clubs in Bangalore; or Nombo (2007) working with the Institute for Democracy in South Africa (IDASA) in South Africa to create spaces for children and young people aged 12 to 20 to work together to monitor government budgets.

The project 'Rights through Evaluation' in South Africa and Nepal involved children and youth who had been previously invisible or ignored in broader community and environmental projects. In Nepal, evaluation of a seemingly successful project which provided women with goats, found that children had come out of school to look after the goats. Another child-led evaluation showed that water taps were built too high for children to reach to collect water. In South Africa, children had not been consulted in forestry, water, tourism and early years projects, and working with them showed that projects in these areas could be improved with their ideas Johnson and Nurick 2001; Nurick and Johnson 2001). 


\section{Box 2: Case study - Good to be me}

Brighton and Hove City Council in the United Kingdom has implemented a Personal, Social, Health and Economic (PSHE) Education Programme of Study to complement the UK Department for Education's national curriculum. PSHE was designed in collaboration with partners in education, health, youth, community and voluntary sectors and is implemented throughout Brighton and Hove schools. PSHE topics include bullying, sexual health, citizenship, drug and alcohol use, and diversity. At St Luke's primary school in Brighton, teachers are using the Good to be me (GTBM) theme for students students aged 3 to 11 years to teach about race and discrimination:

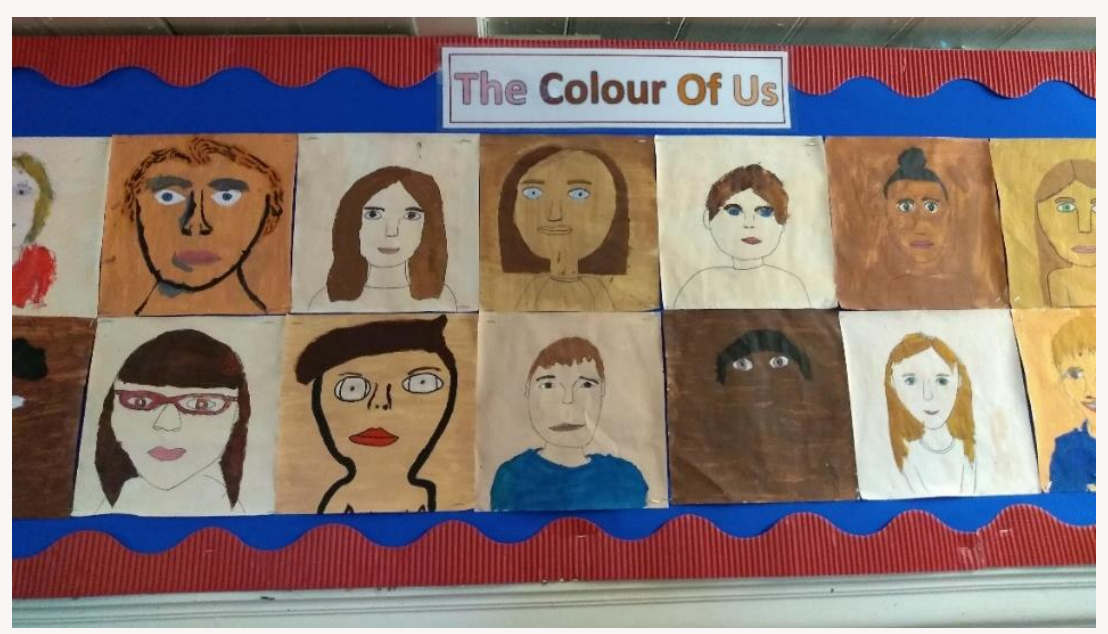

The aim of these lessons is to support children's exploration of their identity and grow a sense of belonging, thereby supporting their emotional health and wellbeing. The lessons have a particular focus on race and ethnicity and give children the opportunity to develop their confidence in using positive language to recognise and describe their skin tone as a part of their identity.

(Brighton and Hove City Council 2019)

In an interview, Sarah Jackson and Anoushka Visvalingham, the two teachers, explained that the use of the GTBM theme emerged due to 'responses of children in the school to do with race and ethnicity and perhaps showing that they didn't feel comfortable... or [were] trying to hide aspects of their race or ethnicity, especially if Black or Asian' (Jackson pers. comm. 2019). Another contributing factor for the use of GTBM included information from first-generation immigrant parents who attended coffee mornings, to share more about their experiences and those of their children (Visvalingham pers. comm. 2019). Activities conducted as part of the GTBM programme included painting skin colours, discussing similarities and differences, organised play, among others.

GTBM lessons received positive pupil responses, with children noting in their evaluations that the most important thing that they learnt as a result of GTBM was that, 'some people don't like their skin colour and some people judge skin colour. It's the first time we have learned about skin colour. Skin colour is a topic we need to talk about and we need educating about' (St Luke's School 2019). 


\section{Support: Capacities, empowerment, and intergenerational support}

\section{Capacities}

We can think of capacities in two ways. Evolving capacities as children grow up, and building capacities and capabilities through children's and youth participation, in processes of research and project development and implementation. All children inherently have some capacities and some power. However, as articulated in 'Framing and reconceptualising rights as living rights' (page 15), how far these capacities are recognised can have significant implications for the extent to which children are able to enjoy liberty rights. Children are generally thought to enjoy protection rights but they may not be able to exercise liberty rights depending on the context and their capacity in that context (Cipriani 2009). For children with less competency, protection rights become more important. For those with greater competency, liberty rights take on greater prominence (see Figure 6). Crucially, whether children are able to claim liberty rights is not just about children's actual capacities, but also their perceived capacities (here the link to context is important).

Figure 6: Authors' representation of Cipriani's explanation of children's capacities/rights

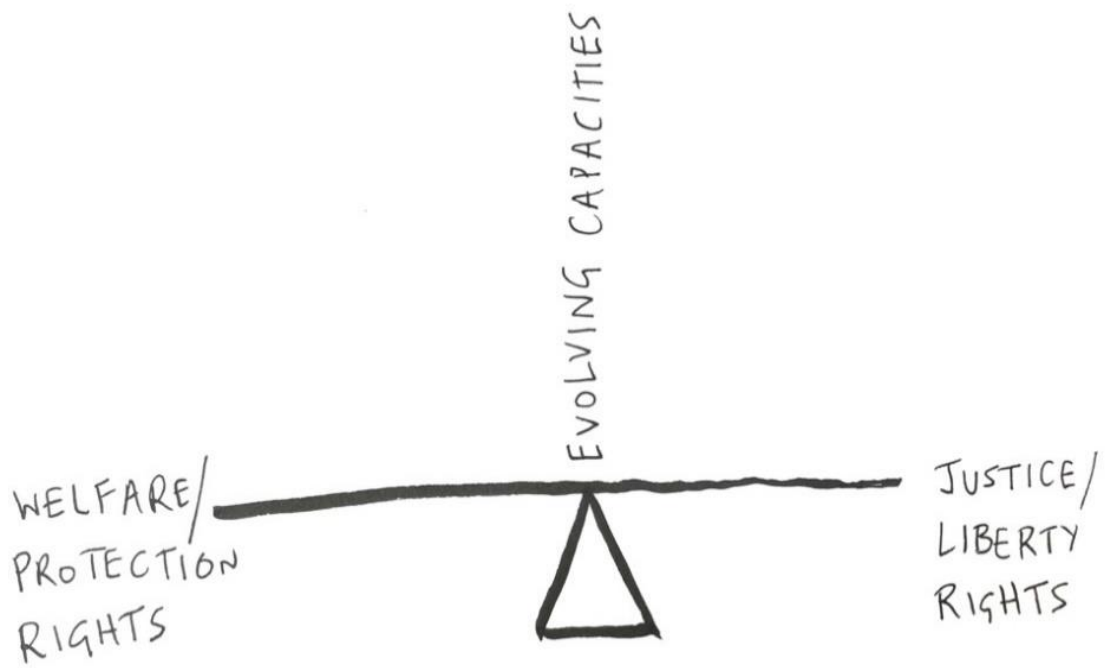

Clark-Kazak's (2009) notion of 'social age' is a useful conceptual tool for understanding how children's capacities vary according to their context. A six-year-old in one context, for example, may have far fewer responsibilities than her counterpart in another context, and her social age (and capacities), therefore, may be significantly less than those of her counterpart. In articulating 'social age' as distinct from 'chronological age', we are able to draw attention to the fact that the biological 'realities' 5 of physical development have different socio-political implications in different contexts (James et al. 1998, cited in Clark-Kazak 2009: 1309). In other words, 'social age can be analytically and practically distinguished from biological development' (Clark-Kazak 2009: 1310). Delinking biological and social constructions of age encourages a more situated analysis of children that works against ghetto-ising children or projects that "target" them in isolation' as outside their social contexts (ibid:: 1308).

\footnotetext{
${ }^{5}$ There is evidence that this too is a social construction; see, for example, Roberts (2013).
} 
Canavera notes that children of all ages can identify what they want:

Children are very confident about what they want pretty young. By the age of five they can tell you what they want...by the time they are teenagers, they are fully capable of making whatever decision they want to. Unless they have been subject to some circumstances that force them to take decisions that are harmful to themselves or others, or circumstances that push them to take decisions that adults perceive to be bad. They are probably going to work through their decisions and come to a pretty good one.

(Canavera pers. comm. 2019)

Underpinning the importance of engaging children and youth is an understanding of their evolving capacities. Article 5 of the UNCRC recognises this and outlines our obligation to provide support consistent with these evolving capacities to enable children to exercise their rights.

\section{Empowering adults to provide intergenerational support}

Part of the complexity of children's participation is that it requires adults to help children to realise their agency when it is limited or denied (Ofosu-Kusi and Mizen pers. comm. 2019). Much of the literature on children's participation speaks to the need to alter adult thinking, through evidencing children's and young people's capacity, with adult permission and support, to participate effectively. Gerison Lansdown reflects on progress through multiple initiatives globally that surface children's perspectives and voices, and that have shown that children have both the desire and the capacities to contribute to decision-making (Lansdown 2010). In order to realise participation rights as expressed in the UNCRC, she also suggests that governments need to be held to account on the obligations in the convention that include developing legislative and institutional frameworks to support children systematically in their right to participate (Lansdown 2010: 22). Finally, children need respect in communities as rights bearers whose agency should be supported (ibid.).

Many of the projects that we analysed evidenced adults becoming more aware of the impact of their behaviour on children (Rhodes et al. 1995), or government officials learning from their engagement with children (Blackburn et al. 2005). Research has shown that children can design and implement programmes (Mclvor 2001; Wellard et al. 1997), keep a project running (PercySmith and Thomas 2009), develop employment contracts (Klocker 2011) and budgets (Nombo and Cassiem 2007), and perform technical tasks, such as water testing (Goodman 2005). Many projects to engage children as citizens (Baker and Hinton 2001; Cox and Robinson-Pant 2003; Guerra 2002; Kimiagar 2016; Trajber et al. 2019) are designed both to engage children actively in their communities and, in doing so, to evidence children's capacity.

In the Tatu Tano child-led organisation in Tanzania, children selected adult members for child protection committees. This improved the functioning of the committee and 'being selected by the children made them [adults] feel honoured and gave them an added sense of responsibility' (Clacherty 2018: 18). 


\section{Box 3: Case study - Raising voices}

Based in Kampala, Uganda, Raising Voices aims to prevent violence against children and women. Through partnerships with more than 60 organisations spread throughout the Horn, East and Southern Africa, Raising Voices works to change the relationship dynamics between men and women and boys and girls to create lasting social change. Raising Voices' work is deeply committed to addressing the social norms and power differentials that perpetuate violence and does so through a combination of activism, innovation, and influence.

Their Good School toolkit was created in collaboration with schools in Uganda to address the findings of a Raising Voices study which showed that 60 per cent of children regularly experienced violence at school. The six phases and three packages of the toolkit lead students, educators, and the community through a sustainable process of behaviour change. By involving community members in the process, the programme can generate support from a wide variety of stakeholders. An evaluation of the toolkit found that violence against children had decreased in intervention schools by 42 per cent and that students felt safer and that they belonged more at schools that were implementing the Good School toolkit.

To address the different types of violence experienced by secondary school students, particularly higher levels of sexual violence perpetuated against girls from their male classmates and teachers, additional content was developed and is being piloted in two secondary schools. There are two supplementary modules: Power, Peer Violence, Gender; and Leadership, as well as more student-led activities. The effectiveness of these adaptations to the toolkit was to be tested in a randomised control trial in 2020 (Marriam pers. comm. 2019; Raising Voices 2013).

\section{Empowering children and supporting their action}

Several projects show that participatory engagement with children increased children's social confidence (Allen 1998; Haynes and Tanner 2015; Robson et al. 2009; White 2002) - a factor that can lead to social changes beyond individual children. Clacherty (2018), for example, shows that children attending Tatu Tano groups were more able to provide for themselves; girls were more outspoken about, and better at reporting, sexual harassment and gender-based violence; and peace training in these clubs helped boys to break the cycle of violence. In some cases, an increase in children's confidence was linked to their awareness of their capacity to influence social change (Gioacchino 2019; van Blerk et al. 2019). In other cases, these processes fostered solidarity among the children and young people (Trajber et al. 2019). Most of these examples are concerned with the development of relational agency (Oswell 2013).

Several examples of projects that evidenced broad social change were linked to instances where parents and other adults were also engaged in projects involving children or young people. Projects fostered intergenerational dialogue (Ansell et al. 2019; Dyson and Amara 2016; Monzani et al. 2018; Vaitla et al. 2017), or intergenerational or community action, for example, around 
encouraging girls' school attendance (Kesho Kenya) or abandoning female genital cutting (Vaitla et al. 2017).

Beyond raising adults' awareness of the power that children and youth have, and supporting their intrinsic capacities - i.e. helping young people to become good at things - Prelis (pers. comm. 2020) emphasises the responsibility that adults have to then support young people in doing the things that they are good at; in putting their agency into action. When youth action is embedded in community-led processes, it can reposition them as people who are valuable and influential in their communities (Wessells pers. comm. 2020). It is this relational shift in the social identity of children that facilitates them to transform not just themselves but also their communities, that effective support can achieve (ibid.).

\section{Box 4: Case study - Children's groups and networks in Afghanistan}

In the early 2000s in Afghanistan, Save the Children UK (SCUK) combined work on community-based protection mechanisms and development of children's groups and networks. The community-based work focused on training agencies, such as NGOs, youth groups, UNICEF and government and police representatives, in the child protection monitoring and response approach, which involves awareness raising for children and adults as well as advocacy on child rights issues. Children first came together in regional consultations hosted by SCUK to learn about their rights and express their opinions to local and regional authorities. Attendants were then supported by SCUK to create their own groups - typically based at a school but also expanded to include working and disabled children who were out of school. Additionally, working children were assisted in forming their own groups in specific localities. While children met on their own to discuss issues concerning them, SCUK also provided capacity building in child rights, facilitation, developing inclusive children's groups, life skills, theatre for development, radio production skills and film-making skills. Groups have been able to make positive changes for children in their communities. Issues that arise in the groups are brought to child protection centre facilitators who work to resolve the issue with other authorities. For example, a girls' group raised the issue of clean drinking water in their school and were able to commission the district education representative and governor to speak to the International Rescue Committee to provide supplies to construct a tap (O'Kane 2007).

'Also we gained clean water for our girls' school... we solved the problem as IRC agreed to send the materials needed to access clean water in our school.'

(O’Kane 2007: 227)

\section{System change: Building child-friendly and accountable systems}

Numerous studies indicate that projects involving children's participation have positively contributed to broader social change and improvements in communities (Adams and Ingham 1998; Haynes and Tanner 2015; Monzani et al. 2018; Percy-Smith and Burns 2013; Promundo et al. 2013). Some of the literature links children's participation to their own behavioural change, such as increased school attendance (Narayanasamy et al. 1996; Zubair et al. 2002). Promundo's 
work, for example, engaging boys in Brazil has shown impact with regards to their behaviour around gender and sexuality (e.g. improved condom usage, fewer sexually transmitted infection symptoms, as well as fewer incidences of intimate partner violence). Some of the boys have also shown a greater likelihood of contributing to household chores after involvement in Promundo's programmes (Promundo et al. 2013). The African Movement of Working Children (MAEJT) has shown that children became more literate, work less often, are in better health, have more leisure time, and feel better protected against violence and abuse after engagement with their local groups (African Movement of Working Children and Youth 2016a).

Beyond the changes seen in children themselves through their participation, are broader social and political changes. Guerra's (2002) paper on children's budget councils in Brazil demonstrates that children can be encouraged to take a more proactive role in school and at home and in community spaces, such as neighbourhood associations. This has served to change adults'/teachers'/politicians' attitudes towards children's involvement in these adult-dominated spaces (Guerra 2002). Youth can also become more involved in project opportunities to explore emotions and experiences around stereotypes and immigration, providing new insights (Cahill 2010). In an evaluation of child and youth participation in peace-building in Colombia, McGill et al. (2015) provide evidence on children and young people's positive contribution to peacebuilding initiatives in communities, families, and schools, specifically on their roles as powerful catalysts to transform their societies.

Supporting children's participation fosters greater connectivity between adults and children, and between communities and children (Haynes and Tanner 2015; Rhodes et al. 1995; Trajber et al. 2019). If we see empowerment as a process of changing power relations, rather than an outcome (Ghosh and Chopra 2019; Kabeer 2008), this connectivity is not only vital to empower children and young people, it is vital to any sustainable social change within the families and communities in which children and young people are embedded. Part of this process involves creating trust and ownership among children and youth and the communities and institutions that govern local power dynamics and social norms.

I don't see most programmes in the world, for child protection at least, to be designed around what children want. Their programmes are designed around what agencies have developed the capacity to do. That is a serious failure. I am restricting my thinking right now to my experience about the child protection community, but I think that this could equally apply to nutrition, water and sanitation, or any other development area which don't take children's voices seriously.

(Canavera pers. comm. 2019)

Adults and organisations in communities can take children's views seriously, even where children's perspectives challenge both them and the social norms around childhood. Listening to children can help surface such differences. The politics of evidence means that accountability has to be measured not just in a reductive numerical fashion, but by understanding the improvements in wellbeing and children's and young people's complex lives (Fattore et al. 2017). This may also mean pragmatically changing power relationships to find spaces and ways of taking children's views, decisions and actions seriously (West pers. comm. 2019). 
This excerpt from an interview with Blair Glencorse, Executive Director of the Accountability Lab, articulates the connections between young people, accountability and institutional change:

I came to the conclusion that, really, accountability is what it's all about. Unless we can get this relationship between people in power and citizens right, it's going to be very hard to deal with everything else. And... it has to be about young people. It has to be a generational change because it's going to take a long time. It's not linear and it needs... a movement really of young people who are going to push for a different way of doing things, and more inclusive and fair and accountable societies... If that's the case... we have to engage young people where they are rather than where we want them to be and that means really what we're trying to do is shift norms... The emphasis within the governance community on institutions and rules and compliance and enforcement doesn't really work very well. That's not to say it's not important, but we decided with young people in particular, that it just wasn't filling them with much energy (and didn't give them a sense of a different future that they could help to build). Actually, in many cases there was mistrust in government. So we, as an organisation, do things a bit differently, I think, to most other organisations in the field. We've tried to flip that narrative and make it positive; to make it solutions-oriented, to hold up people doing the right things. Role models with positive energy around. These issues of accountability in local governments and corruption, which can often be very negative, so we're youthfocused, creative and positive.

(Glencorse pers. comm. 2019)

Edda Ivan-Smith echoes this view:

... by involving children, young people throughout any action research and programme cycle (from planning to evaluation), there is some accountability to them for any rejuvenated community development process. Just as gender has been 'tagged' as having to be monitored in terms of process and outcome indicators for community-driven processes, supported for example by the World Bank, so could issues of age - how children have been involved; using outcomes that are defined by them and measured as indicators of success.

(Ivan-Smith pers. comm. 2019)

In the same way that adults can be taught to recognise children's capacities, through individuals, we can build the capacity of systems to operate differently. Prelis (pers. comm. 2019) suggests that this might involve prioritising engagement with trustworthy people within institutions: 'I think we need to put more effort on trusting people and enable them to reclaim the power that enables institutions.'

An illustrative example is the Participatory Rights Assessment Methodologies project in Malawi and Peru, which supported governments, civil society, and other actors in the delivery of rights and created institutional change that was more inclusive and informed by children (Blackburn et al. 2005). This project was carried out in partnership and funded by the former Department for International Development (DFID). It worked with all stakeholders, from children to government representatives from ministries, such as the ministries of education. Children who were included in the research were at school and involved in school improvement plans. A key finding of the 
research was realising the importance of commitment to the process of change rather than having a tool-driven assessment. A key concern in the project was recognising whose voices are heard in traditional communities and making clearer the extent to which children's voices are not listened to by authorities. Ultimately if we are interested in social justice, social change initiatives need to be accompanied by efforts to foster political change (Wessells pers. comm. 2020).

Box 5: Case study - Fridays For Future

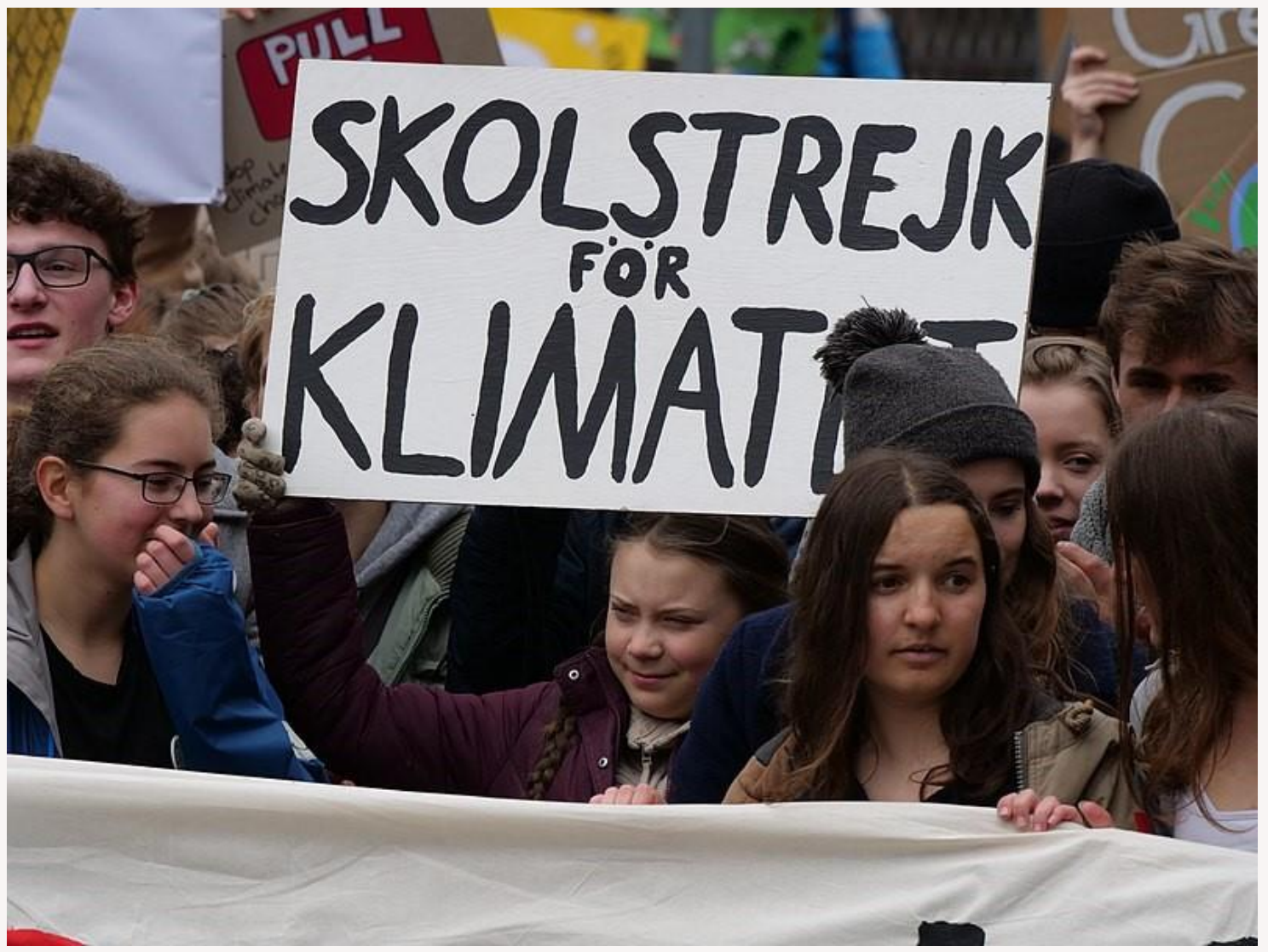

Greta Thunberg at the front banner of the FridaysForFuture demonstration Berlin, 29 March 2019. Photographer: (c) Leonhard Lenz. CC0 1.0 Universal Public Domain.

Arguably the most well-known current example of youth organising is the Fridays For Future movement, which began in August 2018 with a single student, Greta Thunberg, protesting outside the Swedish parliament demanding immediate action on climate change. Thunberg personalised the youth climate movement by providing an individual reference point around which parallel movements could coalesce. Her school strikes have brought together multiple and geographically diverse youth movements. The movement has expanded to more than 200 countries and has galvanised more than 14 million people to go on strike (Fridays For Future 2020). In their biggest single day event on 20 September 2019, 4 million youth in 4,000 cities in 167 countries participated in a school strike for climate. This incredible mass mobilisation began as a single act shared via social media platforms, Twitter and Instagram. 


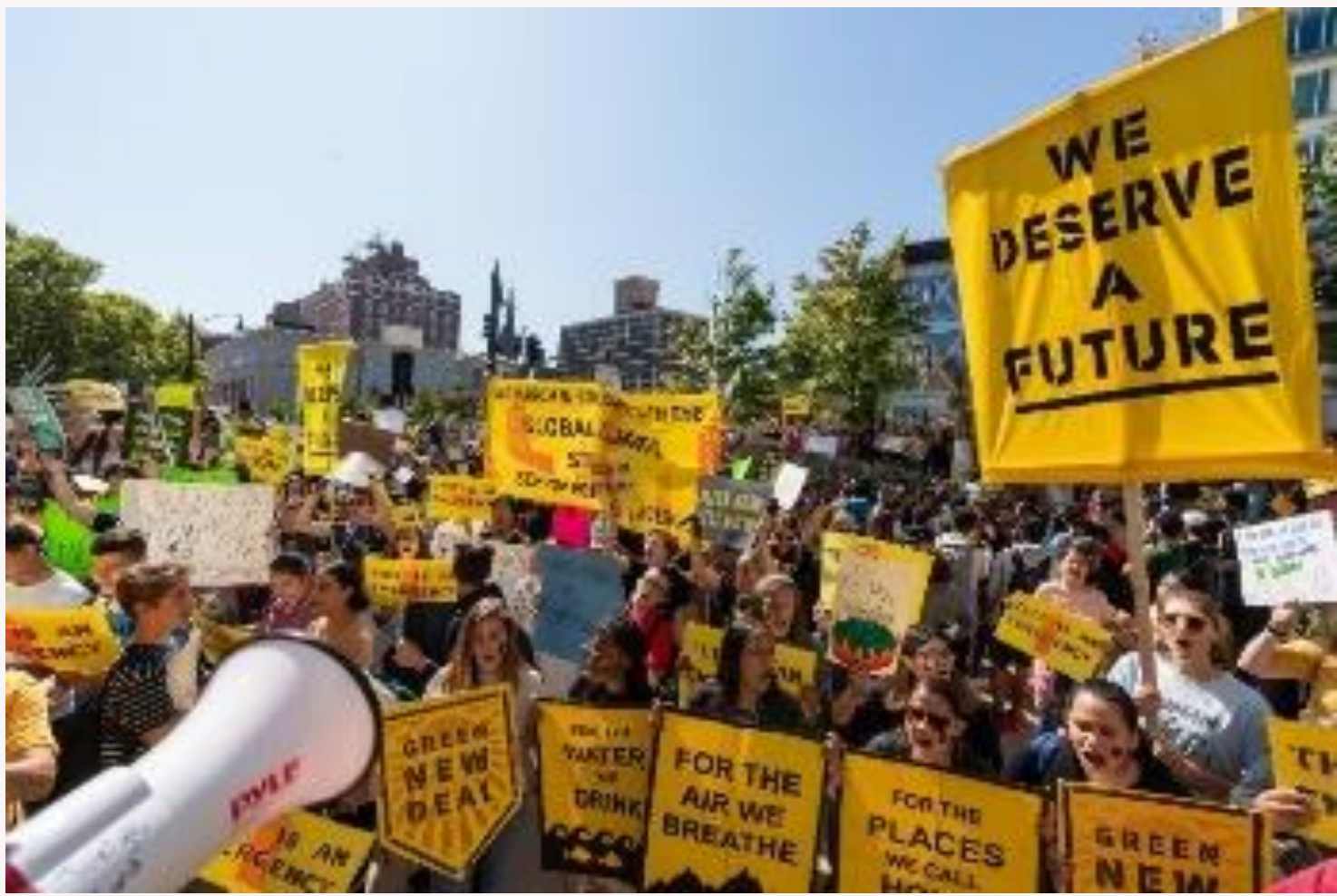

'By the time they reached National Grid, 100 species had gone extinct'. Photographer: @ Gabriel Civita Ramirez. CC BY-SA 2.0.

Greta Thunberg, while the most recognisable face of the youth climate movement, is not the only young activist demanding change and accountability. There has been an explosion of youth movements that are participating in school strikes, taking part in conferences, and advocating for change - the original Fridays For Future website links to some of these but there are more that are not directly affiliated. For example, web searches for 'school strikes USA' produce results for multiple movements with similar objectives, such as the Zero Hour, Youth Climate Strike, and One Up Action. Notably, many of these other movements emphasise the importance of inequality, race, and discrimination in environmental degradation and the negative effects of climate change. According to Zero Hour, an organisation founded by Jamie Margolin, Nadia Nazar, Madelaine Tew, and Zanagee Artis, the organisation 'fights for intersectional solutions to the climate crisis, and focuses on addressing the root systems of oppression, like colonialism, that caused the climate crisis in the first place' (Zero Hour and the National Children's Campaign, n.d.). Cofounder Artis says Zero Hour 'has built a movement around addressing the issue of climate change as a systematic injustice to marginalized peoples around the world' (Janfaza 2020). Inside and outside the US, youth leaders from marginalised populations are leading the youth climate movement albeit with reduced media attention (Evelyn 2020). To name a few: Autumn Peltier, chief water commissioner for the Anishinabek Nation in Canada; Militza Flaco, of the Emberá Querá community of Emberá Nation in Panama, who is part of the Guardians of the Forest climate activist group; Isra Hirsi, co-executive director of the US Youth Climate Strike; Vanessa Nakate, Ugandan youth climate activist and founder of the Rise Up Movement; Ili Nadiah Dzulfakar, co-founder of Klima Action Malaysia; and Ridhima Pandey of India who jointly filed a complaint to the UN accusing the 
world's largest economies of violating children's rights due to their inaction on climate change (Brown 2019; Burton 2019; Evelyn 2020; Janfaza 2020; Ocharoenchai 2019; Varagur 2019).

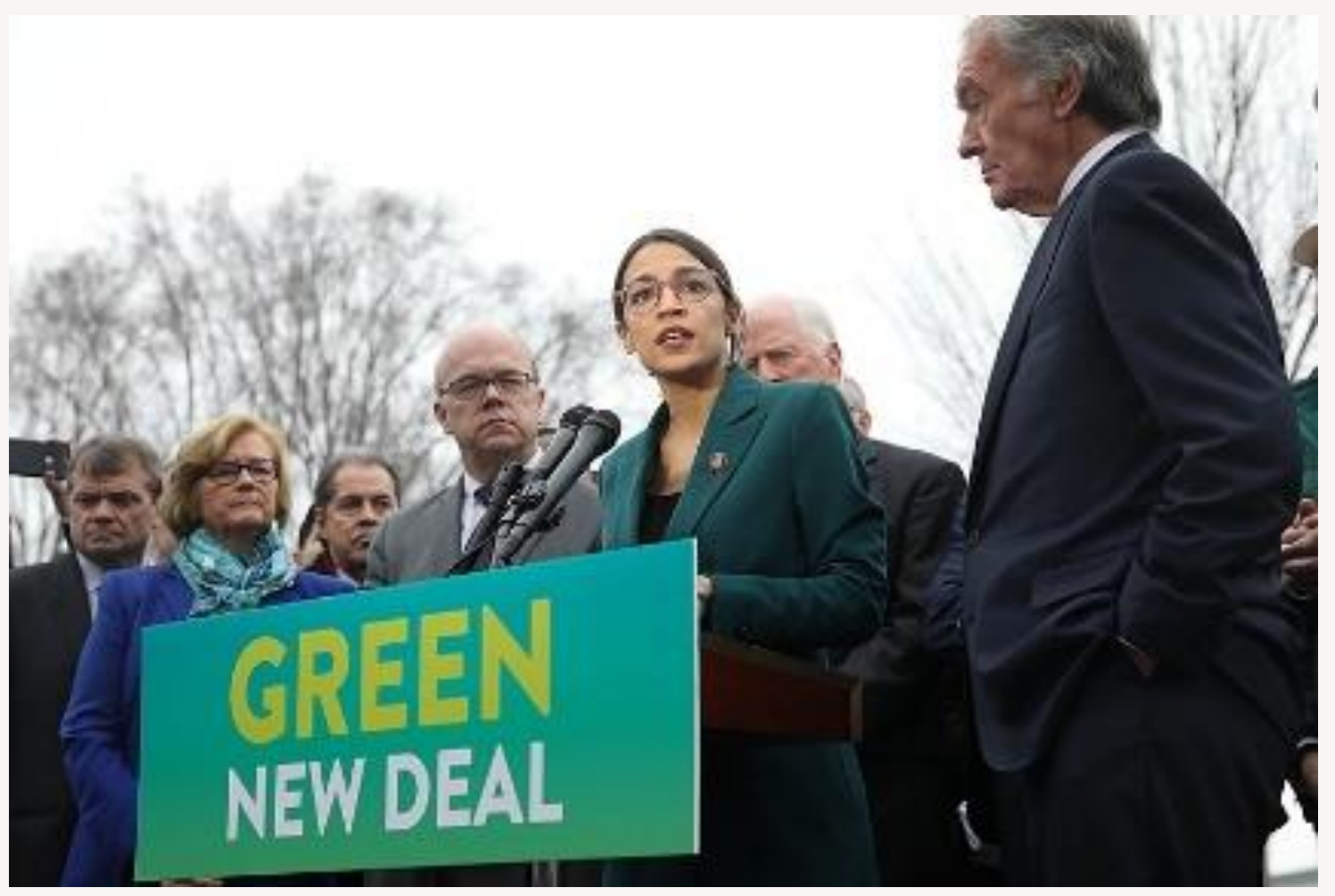

Green New Deal. Photographer: @ Senate Democrats. CC BY 2.0.

Youth strikes have been paired with political actions led by young politicians, such as Representative Alexandria Ocasio-Cortez, who introduced the Green New Deal to address climate change and inequality. In media images of her speech, both her age and ethnicity stand in contrast to those of her co-sponsors - mainly older, Caucasian men.

\section{Approaches and methods for working with children/youth}

This section outlines some of the common approaches used to engage children and to create space for their involvement.

\section{Child/youth-led work}

Some of the most powerful youth-led work results from young people experiencing hardship and discrimination and deciding themselves to get evidence to support their activism. This is evident in youth-led organisations and in youth-led research on issues that are decided on or supported by youth.

One example of the youth-led work within research is the Dreaming of No Judgement report in Utah, in the US, which focuses on the effects of immigration politics on young everyday lives and addresses civil and human rights (Mestizo Arts and Activism Collective 2014). It provides space 
for young migrants to express their feelings about how they are stereotyped in communities (Cahill 2010). Young people decided to conduct focus groups with other young immigrants; they also made a docudrama to communicate their experiences of racism, and jointly wrote a poem that they performed to policymakers. However, policymakers do not always welcome such direct communication and young people have met challenges from individuals when expressing their opinions about politically sensitive issues.

During the earthquake in Nepal, youth became very active in regeneration work. Because of the unusual circumstances of the earthquake, and despite the hegemonic norm in Nepal tending towards young people being seen and not heard, their contribution was allowed, and even appreciated. As a result, many adults in Nepal have changed their attitudes towards young people (Shrestha pers. comm. 2019).

International Planned Parenthood Foundation (IPPF) successfully supported the use of photo narratives in a youth-led research project on sexual rights and youth-friendly sexual and reproductive health services. The findings were helpful in formulating youth-friendly policies and services (Johnson et al. 2013).

\section{Community-driven work including children}

Contextual analysis uses a socioecological approach to understand the broader social norms within which children are situated, with a view to shifting these norms. Children and youth are engaged and are central to the process of analysis and intervention (as suggested by West pers. comm. 2019; Johnson 2011; Lundy 2007; Wessells pers. comm. 2019).

The socioecological change-scape (Johnson 2011; Johnson 2017) places children and youth, their identities, ideas and inclusion at the centre, and adds their relationships with families and communities as another layer, with the broader social, cultural, political, and environmental context wrapping around all these. In a reciprocal, dynamic process children are not only affected by social norms and the expectations and rapidly changing conditions they grow up in but can be creative agents of change and can influence the world that they experience.

There is often a 'listening gap' when child protection programmes are based on Western notions of harm and damage, with a reluctance to start from local people's own perspectives. Wessells (pers. comm. 2019) suggests that instead of basing interventions on assumptions, practitioners can use games and creative methods to engage adults and children; traditional practices can be understood through a process of ethnographic research that engages children and youth alongside key people in the community, including chiefs, community healers, spiritual and religious leaders, mothers, fathers, and other family.

Processes can start with deep learning informed by different perspectives to understand how children are situated and what harms and protective factors are normalised. Perspectives vary with developmental stages, gender, social roles, and other inequalities, including disability, social class, and caste. Different people and different children will have different perspectives.

Assumptions surrounding childhood can be put aside to understand local contexts, and spaces can be created to facilitate reflection and prioritisation with communities including children (Wessells pers. comm. 2019). 
In Ethiopia, following the United Nations Development Programme's (UNDP) community conversations, CHADET, an organisation that works with migrating girls, starts their interventions with conversations with elders and adults in rural communities. Their aim is to gain trust and to understand social norms and decision-making processes and pressures on families and communities. CHADET works with existing structures such as iddirs, ${ }^{6}$ or funeral societies, to ensure ongoing interventions are more sustainable (Teshome et al. 2014). Their work was previously not child-centred because staff, as well as adults, were influenced by social norms of childhood that assumed that adults would be able to come to the best solution for children. More recently, through a process of training and child- and youth-led research, staff at CHADET have seen the value of listening to children throughout their processes. They found that excluding youth and children's perspectives led to finding adult-centric problems that did not support innovative youth strategies which offered different ways of doing things to what had been done previously (Admassu pers. comm. 2019).

To some extent, methodology can also be informed by Child Rights Situational Analysis (CRSA), exemplified by Claire O'Kane's (pers. comm. 2019) past and current projects with NGOs in India, Nepal, and Cambodia. Learning from these processes has also suggested that time needs to be taken to ensure that staff in organisations possess the necessary skills to work with children and young people based on ethical principles and that adults who have power in communities are supportive of children's participation. A key component of success is lead-in time to gain better understanding of what will work in particular contexts, rather than just jumping in and getting it wrong (O'Kane pers. comm. 2019).

Canavera's work in communities in South Sudan to address child protection demonstrates how children can be involved in local solutions that include intergenerational perspectives (Canavera et al. 2016). Children aged 12 to 17 years participated in focus groups alongside adult focus groups; young perspectives were therefore integrated into analysis alongside adult perspectives. Previously, as participants of all ages indicated, attempts to strengthen child protection systems had not been culturally sensitive and were external impositions.

In community research that is inclusive of youth in southern Africa, Ansell and colleagues specifically examine intergenerational analysis in looking at the impact of AIDS in that region (Ansell et al. 2012) and of social cash transfer schemes, such as pensions (Ansell et al. 2019). In both projects, researchers engage with adults and youth in communities through qualitative focus group discussions and interviews. Young people were encouraged to develop dramas and songs about their experiences and some started policy workshops with adults and broader stakeholders. Mapping was also used to understand financial flows within and between households (Ansell et al. 2019).

Ansell et al.'s (2012) research on AIDS raises ethical issues and suggests that young people should share experiences in more private settings before sharing in group or public settings. In this way, outputs can then be anonymised and brought forward for collective analysis. The research on the impact of social cash transfers highlights that having households as targets for social protection is not necessarily an effective strategy: firstly, they are fluid rather than static and bounded, and their composition and relationships change; secondly, intergenerational

\footnotetext{
${ }^{6}$ Iddirs are 'informal financial and social institutions' (Teshome et al. 2014) that are widespread throughout Ethiopia.
} 
relationships and youth perspectives are not always fully understood. Young people interviewed about cash transfers did not want to receive 'free money' and wanted to contribute to development (ibid.).

Some of our interviewees have conducted 'rapid ethnographies' and mapping processes in order to establish and make visible children's roles in specific societies (Wessells pers. comm. 2019). This research might identify how young people feel about their developing and shifting identities, as well as behaviours that are embedded in traditional and social norms, such as their evolving capacities and capabilities as they grow up, the expectations of peers and adults, and the social expectations around transitions to adulthood.

Different methods may be appropriate to use with different ages of children and youth. Interviewees suggested that arts, creative, visual, and moving methods were insightful across ages and generations so assumptions should not be made that these methods are only appropriate with certain age groups: co-construction and piloting with different ages of young people is important throughout any process.

It may often be the case that younger children are left out of empowering processes with children and youth, but there is a wealth of evidence that engaging younger children is important for understanding their lives and feelings. It can also be productive to do group work with a range of ages, for example younger children, 8- to 12-year-olds and then 13- to 17-yearolds (O'Kane pers. comm. 2019). The child-to-child approach also has a long history of engaging younger children through peer-to-peer messages on health. Particularly relevant to this document are processes where research to transform services, institutions and societies has included children. Missing younger children out of peer-to-peer processes and child-led research would be omitting important perspectives from children in communities (Young pers. comm. 2019).

A few projects from the living archive engage with young children by using forms of the Mosaic Approach (Clark and Moss 2011). A recent global resource to engage with young children, which includes the Mosaic Approach, draws on multidisciplinary academics and practitioners to draw out steps for engagement and tools that can be modified to different contexts (Johnson et al. 2014). The methods that are included in the guide and toolkit funded by the Bernard van Leer Foundation are categorised into: in-situ; visual; free and structured; narrative and performance; and play and games. The funder identified a gap in participation of younger children (aged five to eight years) and tools were modified from use with older children to this younger age group.

There are also many projects that have engaged with older ages of children and youth. For example, 1,500 girls took part in a survey with the Aware Girls organisation (Aware Girls et al. 2014). This was youth-led as the young Feminist Movement in Pakistan originally set up the project and young women designed and implemented the survey. The survey uncovered important information about the prevalence and experiences of domestic violence and how they fit within social norms. Similarly, in 'Which Way Now?' young people (aged 16 to 19 years) leaving care worked with staff to develop research questions to explore issues identified by other children and young people who had already left care (West 1998). One youth researcher said that, 'the interviewees were able to respond to us more as we have been in [a] similar situation and were able to relate to them more'. Although staff from the Warren Youth Centre in Hull in 
the United Kingdom, identified the issues, they engaged youth fully in the design, implementation, and analysis of the research ( $i b i d$.).

\section{Box 6: Case study - 100l Nights: Building Children's Resilience to Violence}

1001 Nights: Building Children's Resilience to Violence was a 12-month project in Tunisia run by Search for Common Ground (SFCG). The aim of the project was to build children's resilience to violence through engaging educational materials and activities conducted in school. The project was run in 20 different schools in 10 of Tunisia's 24 governates, reaching nearly 900 children and 40 teachers.

Working with the animation company, Big Dad Boo Productions, SFCG developed a multimedia curriculum to encourage students to have discussions around concepts of democracy, human rights, non-violence and empathy.

The project also goes beyond the classroom to engage children outside school. In six different communities, Peace Clubs facilitate skills development around nonviolent communication and provide mentorship opportunities for youth. Since the Peace Clubs are situated within the community, they help to build connections between youth and local political processes.

The success of the project is evident in the extent of parent, school, and community engagement. Schools that were not part of the initial project have independently fundraised to bring the programme to their students.

This project highlights the importance of embedding youth work within existing community structures while simultaneously engaging the wider community and system in which children live and develop (Search for Common Ground 2019).

\section{What has not worked: Evidence on limitations}

\section{Outsider solutions}

Many of our interviewees argued that we need to avoid 'imposition of outsider approaches', or projects that come from an international orientation and do not fit with the local context and culture. It is particularly important to avoid those approaches that focus on deficits and victimhood and that undermine empowerment and a more reflexive approach (Wessells pers. comm. 2019).

Several stressed that a 'white saviour approach' needs to be avoided where an outsider goes into a situation and teaches children about their rights. Rights are lived and experienced by children and youth and we can do more by understanding their struggle to access and negotiate rights in their everyday lives (Hanson pers. comm. 2019; Nieuwenhuys pers. comm. 2019). 
It may also be in the interest of NGOs to perpetuate accepted ways of working and to ensure that they continue to work in an area. Often NGOs do not have time to stop to reflect on their attitudes and work on the ground with children (Shrestha pers. comm. 2019). Often in a community-based process, the NGO, not the community, actually decides what should be done (Wessells pers. comm. 2019).

\section{Tok enisticleadership}

Tokenistic leadership can refer to several situations. It is the idea that one eloquent youth leader makes a movement. It can mean putting people in leadership roles without giving them the support they need to fulfil those roles. It can also involve putting young people in leadership roles and then limiting the scope of the role to the extent that that young people do not have any real, actionable power.

Every children's advisory role that tries to remove the power and magic of children's voice and combines their participation into the status quo of adult platforms. And then what happens is about making the organisations better, it is not about making children's lives better. It is about making the organisation look better, because then they can say that they have done children's participation. It doesn't support the individual transformation of children, or children like them, within the societies that they come from... even when you get substance, it's just about rewarding super man and super woman.

(Bah pers. comm. 2019)

\section{Misguided funders}

Many of the practitioners we interviewed spoke of the difficulties of funding environments where they are asked to produce products rather than being supported to do substantive work. They spoke of 'project-itis' and 'NGO-isation'. Others talked about the burden of 'needy donors' who practise 'elimination by complexity' - whereby donor requirements are so complex that they discourage people from applying for funds.

\section{Adultism/gerontocracy}

Another problem that many interviewees identified was 'adultism' - adult-led projects that do not recognise power and are both hierarchical and paternalistic. A related problem is adults who assume they know what children and youth think, need, and want and who fail to actually listen to children. Several interviewees suggested that so much of what works is about approach and attitude, not necessarily financial resources: 'in most cases, actually, money is the least valuable resource' (Glencorse pers. comm. 2019).

However, Prelis pointed out that we need to be attentive to language; he suggested, for example, that we talk not about ageism, but gerontocracy which 'refers to the distribution of power', rather than perceptions of age-based attributes (Prelis pers. comm. 2020). This insight is also valuable when applied to adultism - the problem is not just that adults are assumed to be competent (and children and young people are not) but also that because of this, they are invested with power over children and young people; and children and young people are divested of power. 


\section{A way forward}

The following section introduces our REJUVENATE principles, and the Ndoro Ndoro model, which underpins these. We suggest these principles as the guidelines to facilitate the 3Ss; they provide the essence of the best practice from across the living archive of project literature and expert interviews, and they indicate some of the ingredients for good practice in this field.

\section{Rejuvenating social justice with child rights: Why rejuvenate?}

We currently live in a world of divided and conflicted communities. Without a new and energised approach to engaging with children and youth alongside adults, this will not change.

We therefore need to build intergenerational solutions for lasting social change. Doing this effectively requires addressing the social norms that fail to see children and youth as an integral part of this process.

Children and young people have innovative ideas and are already positive contributors to social change. Despite this, they are often not asked for their opinions. We urgently need to demonstrate the evidence on how their contributions help to advance social justice and make the case for supporting and expanding existing initiatives that substantively include children and youth.

The goal of REJUVENATE is to showcase this evidence base, while integrating children's and youth perspectives with those of adults who are working towards social justice and children's and youth living rights.

This is particularly urgent given the current rapid political and environmental changes and shifts in cultural norms.

\section{The Ndoro Ndoro model}

Ndoro in Shona is the spiral shell emblem that symbolises wealth. Our 'Ndoro Ndoro' model is grounded in a sociocultural ecological theory (Bronfenbrenner 1979, 2005) that situates children and youth in relation to their context (see Figure 7). It is based on the change-scape model (Johnson 2011, 2017) in which children and youth are positioned at the centre of transformational processes of change, from where they work to shift attitudes of adults and other stakeholders. Children's and youth views, decisions, and actions are negotiated and discussed with peers and adults in spaces that allow for dialogue and the development of strategies that can change contexts. These dialogues encourage a process of engagement between children, youth, and adults, and leads to positive impacts on children's lives while rejuvenating communities. 


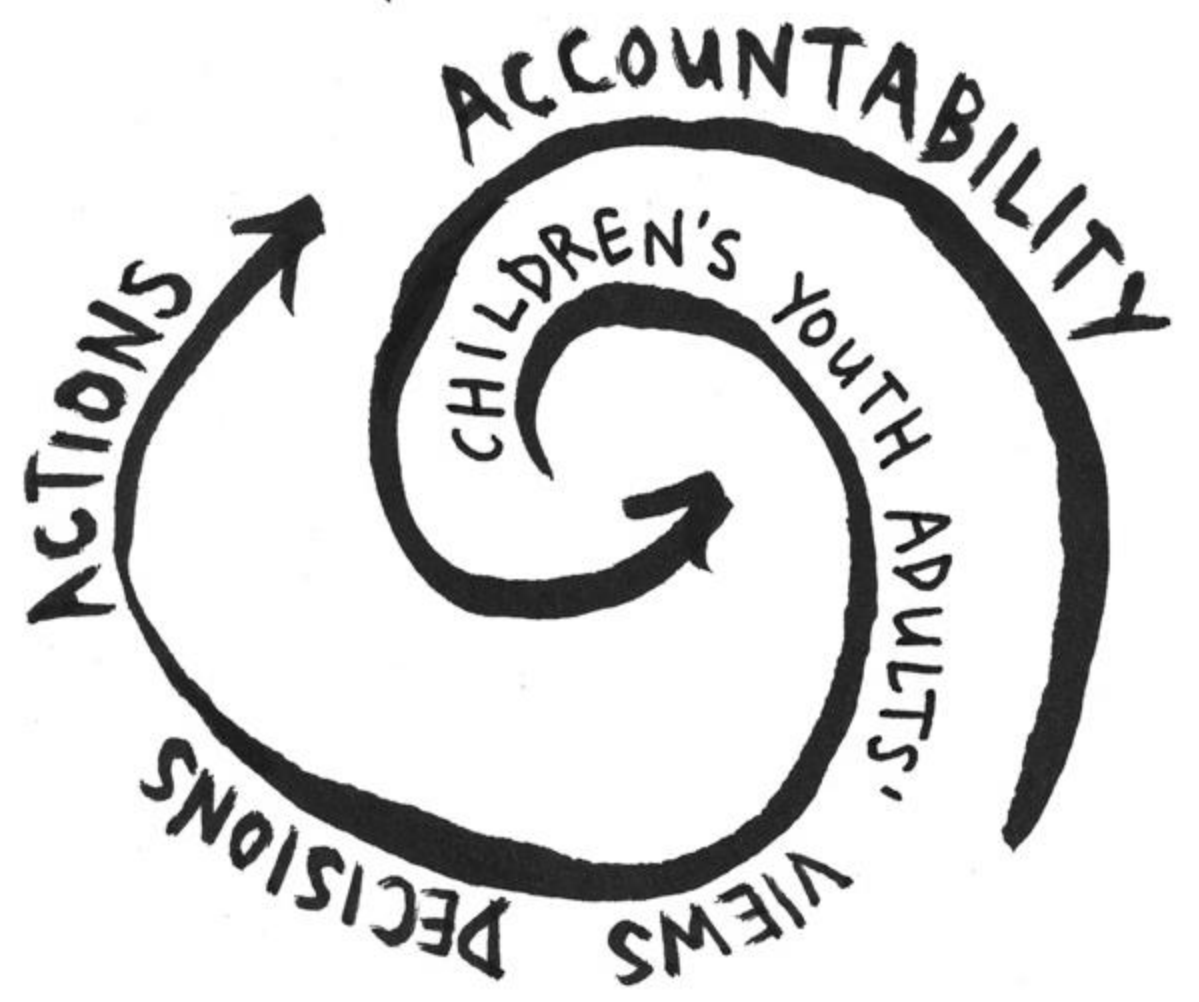

\section{NDORO - NDORO}

Mechanisms need to be developed to ensure that all development processes are accountable to children, youth, and adults, leaving no one behind. Accountability entails understanding how duty bearers, including parents, adults in communities, NGOs and civil society organisations (CSOs), states, public and private bodies, and services, international bodies and funders, respond to children's views and ideas. The Ndoro Ndoro model therefore has one spiral labelled accountability that spirals towards children at the centre and a second spiral that spirals outwards and represents the energy and rejuvenation generated by children and youth when they influence their different contexts by having their views, decisions, and actions taken seriously in their diverse communities. 


\section{REJUVENATE principles}

These fieldwork principles draw, through our living archive of documents and interviews, on the substantial learning in the field of child rights over the 30 years since the ratification of the UNCRC. We hope that adults working with children will draw on them to facilitate more horizontal collaborative work with children and young people. They are underpinned by our Ndoro Ndoro model, and we suggest three areas of activity within which these principles can be used - these are the three strands of child/youth organising, child/youth-centred community approaches, and creative praxis. (We articulate these from page 62.)

We intend that these principles be further developed, tested, and critiqued. They are as follows:

Relationships

Evolving capacities

Justice - personal and social

Unusual suspects

Visual and creative praxis

Empowerment

Norms - social and institutional

Accountability

Transformation

Energy

\section{Relationships}

'Relationships' relates both to our socioeconomic model, and to what has worked in the field. A relational way of being human acknowledges the support that all humans require for survival and the fulfilment of sustainable futures. Many younger people feel pressured by adult expectations, and despair at environmental destruction and inequitable political and social systems; yet they still want to belong and to contribute to their families and communities.

Understanding what children do, and what they want in their everyday lives includes understanding intergenerational and interdependent relationships. Finding out how children feel about themselves and others, and the type of support they want, provides insight into children's realities and their ability to access their rights. Relationships between adults and children need to take into consideration local norms of childhood and how these evolve and can be developed. We must learn to value the strategies that young people use, including their peer relationships, to navigate the challenges of rapidly changing contexts. 
Relationships are also vital to successful projects. Most of the people whom we interviewed emphasised the importance of finding and developing partnerships built on mutual trust. They highlighted the importance of finding the right allies and taking the time to build relationships with these allies. Social change is a complex process and works best as a collective approach built through an ecosystem of allies.

\section{Box 7: Case study - Listening to Smaller Voices}

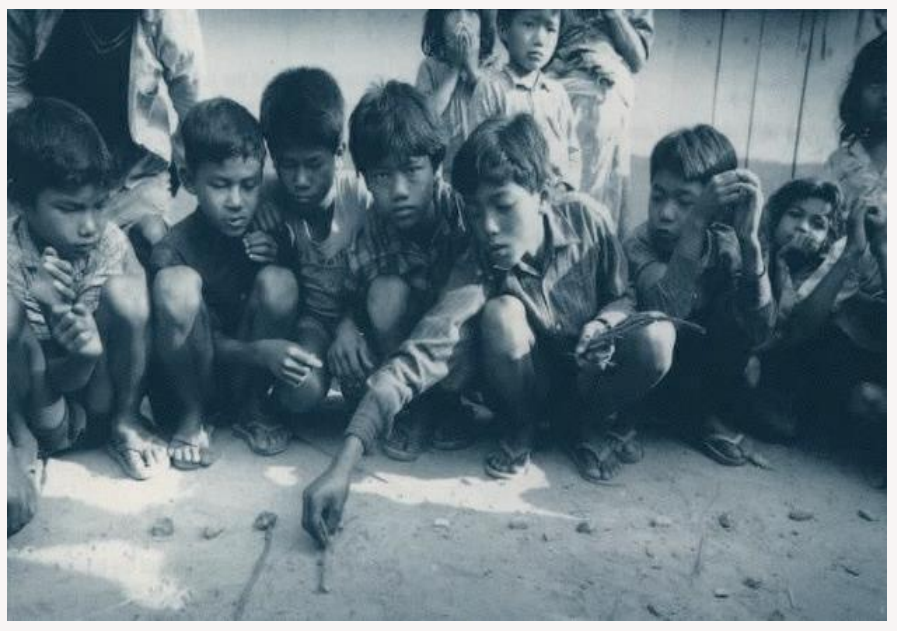

The project Listening to Smaller Voices in Sindhuli District, Bagmati Province, Nepal is one of the earliest examples of using participatory rural appraisal (PRA) with children. It demonstrates not only the utility and success of PRA research methods with children, but also, and perhaps more importantly, the necessity of taking children's views and experiences into account in development planning. Findings showed that social and environmental changes have significant effects on the lives and workloads of children, and since children's work (especially that of girls) is an essential contribution to household livelihood strategies, development agencies need to pay attention to their voices. Children's experiences, while intimately connected to their communities and households, cannot be assumed to be the same (Johnson et al. 1995).

Ansell et al. $(2012,2019)$ show the importance of family and household relationships in how cash transfers and government schemes in Malawi and Lesotho benefit children through intergenerational support and transition.

Beazley et al. (for example, 2018) show the importance of understanding intergenerational relationships in transnational family linkages. Their work focuses on families where parents had migrated, leaving their children, and on how communication and family dynamics change.

Johnson et al. (1995) also pay attention to intergenerational relationships and children's often invisible productive roles in households, community and society. Without creative contributions from children and youth, families and communities could not necessarily survive and prosper (Johnson and West 2018). 


\section{Box 8: Case study - Children's emotional responses to the absence of transnational migrant parents}

Growing rates of transnational migration in Indonesia have left increasing numbers of children 'left behind' as their parents seek better employment opportunities overseas. This trend is amplified in the eastern province of the island of Lombok, where poverty, low education, and falling agricultural yields combined with poor health and food insecurity, have pushed greater numbers of men and women to migrate, leaving behind their children to be cared for by neighbours and families. Beazley et al. (2018) argue that these children's emotional responses are intimately tied to community anxieties about success and failure overseas.

'...children's emotions are rarely considered in scholarship on transnational migration, and are absent in policy formation in Indonesia.' (Beazley et al. 2018: 591)

'The fact that stay-behind children exercise their agency in this way demonstrates that they are not passive victims of their circumstances and some are able to find alternative survival strategies.'

However, scholarship on migration fails

to adequately consider children's emotions. This research demonstrates that children do not exist separately from their communities and families; instead they internalise feelings of cultural shame resulting from their parents' circumstances. Furthermore, despite the national narrative, migration is not a wholly positive experience for children, even when parents are able to send back remittances. Children left behind are extremely vulnerable and although some can exercise agency and seek work outside their villages, this is not a common nor risk-free choice (Beazley et al. 2018).

\section{Evolving capacities}

All children are capable of expressing their own views, taking decisions, and acting in the interest of themselves, their families and their communities. If supported and allowed, they demonstrate (evidenced in the numerous projects profiled in the living archive) their ample capacity to contribute ideas and express their opinions on issues relevant to their lives. Western notions of child development should not be imposed; instead contextualised, local ways of understanding evolving capacities and capabilities should be respected to help assess the form, and extent, of support that children and young people need from adult allies.

The concept of 'social' rather than chronological age is important. In making children's roles in society more visible, we can better understand what children think and do in different contexts and the importance of their involvement (Clark-Kazak 2009). This includes understanding how young people feel about their developing and shifting identities, their evolving capacities and capabilities, the changing expectations of peers and adults and their transitions to adulthood; all of which are embedded in traditional and social norms. 


\section{Box 9: Case study - Tatu Tano}

Tatu Tano was established by the organisation Kwa Wazee in response to a request from the grandchildren of beneficiaries of Kwa Wazee. Kwa Wazee - which means older people in Kiswahili - works in the rural areas of Tanzania most affected by the HIV/AIDS epidemic. It is primarily a cash transfer and social protection programme that supports grandparents who are tasked with caring for orphaned grandchildren whose parents have died due to HIV.

Originally, grandparents requested that Kwa Wazee facilitate conversations between them and their grandchildren. These discussions led to children requesting regular, monthly meetings of their own 'for friendship and so they could do income generation work together' (Clacherty 2018: 1).

\author{
'The children said they wanted \\ the groups for friendship and \\ so they could do income \\ generation work together.'
}

(Clacherty 2018: 1)

Eventually these gatherings developed into Tatu Tano. In Kiswahili, Tatu Tano means three and five. As the name suggests, the children's groups are small and organised by neighbourhoods, rather than villages or towns, which enables frequent collaboration. Kwa Wazee's 2018 annual report states

'Acknowledging the capacity of children is the cornerstone on which Tatu Tano is built. At every point the children lead and decide.'

(ibid:: 3) that since Tatu Tano began in April 2008 with 133 children, nearly 500 groups are now operating (Kwa Wazee 2018). These groups come together with other groups in their area once a month at cluster

meetings to discuss what they have done, deposit their savings, and deliberate on any issues they have or support they need. While Tatu Tano is considered a project of Kwa Wazee and has an adult manager who attends the cluster meetings, 'at every point children lead and decide' (Clacherty 2018: 3) and the manager is only there 'as a source of information and a link to training opportunities' (ibid:: 4). For example, each group receives an initial loan to begin 'But after the training they are confident, they can stand and they say that this is income-generating activities, but it is up to the members of the group to decide when to begin to pay the loan back. normal, this can happen and it is not right. I have got my rights.'

(ibid:: 12)

\section{Why child-led?}

Child-led does not mean that the children are without any type of support. Instead, Tatu Tano recognises children's capacity and agency while actively helping them to build it. Training programmes in agriculture, animal husbandry, financial management, group dynamics, and self-defence are available from past Tatu Tano members and mentors. Importantly, training programmes are not developed in isolation, but rather cooperatively with the children themselves. Members of Tatu Tano are involved in consultation, piloting, and feedback before training programmes are implemented (Clacherty 2018; Kwa Wazee 2018). 


\section{Justice}

We position child rights firmly within a social justice frame that recognises the historical link between human rights and social movements. It therefore reconceptualises child rights as living rights: a translation of rights on paper, to the realities of young lives on the ground. A social justice model strives to shift child rights from an ethic of protection to one of empowerment. It means not only dealing with issues that children and youth raise and with which adults agree, but also the contentious issues where generational perspectives differ, and disagreements need to be negotiated through dialogue. These must include, for example, youth justice, early marriage, and migration. Inclusion of children in qualitative research can also inform institutional change and inform policy and practice, for example, with school improvement plans in Malawi (Blackburn et al. 2005). The problem here is how to ensure that power and traditional hierarchies in communities and institutions are taken into account and that children are heard.

Also relevant here is our overarching framework of living rights, translation and social justice (Hanson and Nieuwenhuys 2013) and learning to listen to children and young people (Johnson and West 2018; Johnson 2015). Taking into account how children and youth are represented in the media but also how they use and interpret it is also relevant here (Buckingham and Bragg 2003). Diversity among children needs to be recognised, which includes understanding their own definitions of marginalisation and exclusion, as well as the impact of structural inequalities on their lives. These understandings go beyond standard government definitions of marginalisation that include gender, ethnicity, and place (see Johnson et al. 2019). Young people also include experiences of abuse, poverty, family and living situations, and experiences of work and education.

\section{Box 10: Case study - Le Mouvement Africain des Enfants et Jeunes Travailleurs (African Movement of Working Children and Youth)}

Started in 1994 in Côte d'Ivoire, Le Mouvement Africain des Enfants et Jeunes Travailleurs (MAEJT) is a child-led organisation aimed at protecting working children and youth. MAEJT currently operates in 27 countries throughout Africa, primarily in West Africa and has an estimated 270,955 active members. Members are organised first into 'grass-roots' groups based on location or vocation, and they work together to address issues that affect them and the children and youth around them. Groups are further organised into regional and national associations. A general assembly meets every three years, bringing together association representatives from each country. These gatherings are an opportunity for members to review their activities and make guidelines for the following years. The majority of MAEJT members are children under the age of 18 and more than half of the members are girls. To ensure that the movement remains child-led, all new members must be under 18 and once a member reaches the age of 24 they must transition out of leadership positions. 


\section{A translation of rights}

The activities of the grass-roots groups are for children and led by children. Activities of different grass-roots groups are specific to each group's needs and capacities. However, all their actions are united in their adherence to the 12 child rights established by the founders of MAEJT. These 12 rights represent a working translation of the UNCRC which is accessible and relevant to MAEJT's members. These rights are: to read and write; to express oneself; to be taught a trade; to play and have leisure; to have health care; to be listened to; to rest when sick; to work in safety; to be respected and have dignity; to stay in the village; to do light and limited work; and to have access to equitable justice.

'The children themselves lead the activities.

The organisation is only there to support

them... so that they can successfully

implement their solutions, ones that

work for them in their working lives.'
'They had some support from adults who understood that they needed to get out of the way.'

(Canavera pers. comm. 2019)

\section{(Child to Child website)}

Resources for members of MAEJT are also in a format accessible to their target audience. Instructional videos are designed with simple messages conveyed by relatable cartoon characters and posters and leaflets are clear whether the viewer is literate or not (African Movement of Working Children and Youth 2011, 2015, 2016b, 2016c; Canavera pers. comm. 2019).

\section{Unusual suspects}

Finding motivators is important and these are not always necessarily the obvious and highly visible international NGOs (INGOs), NGOs, UN agencies or government actors that may have become set in bureaucratic ways. Champions for rejuvenating communities may sit within existing structures and be able to access local power hierarchies; they may be young people who want support to engage with adults, peers and younger children; or they may be creative outsiders who can offer new and imaginative methods to support child and youth integration into decision-making and actions. We know that the old ways of doing things are not working: 'We need to try out different, unlikely networks that pay attention to where children and young people's interests lie and work with role models that they respect, like artists, musicians, rappers, filmmakers, creatives and interactive muralists' (Glencorse pers. comm. 2019). 


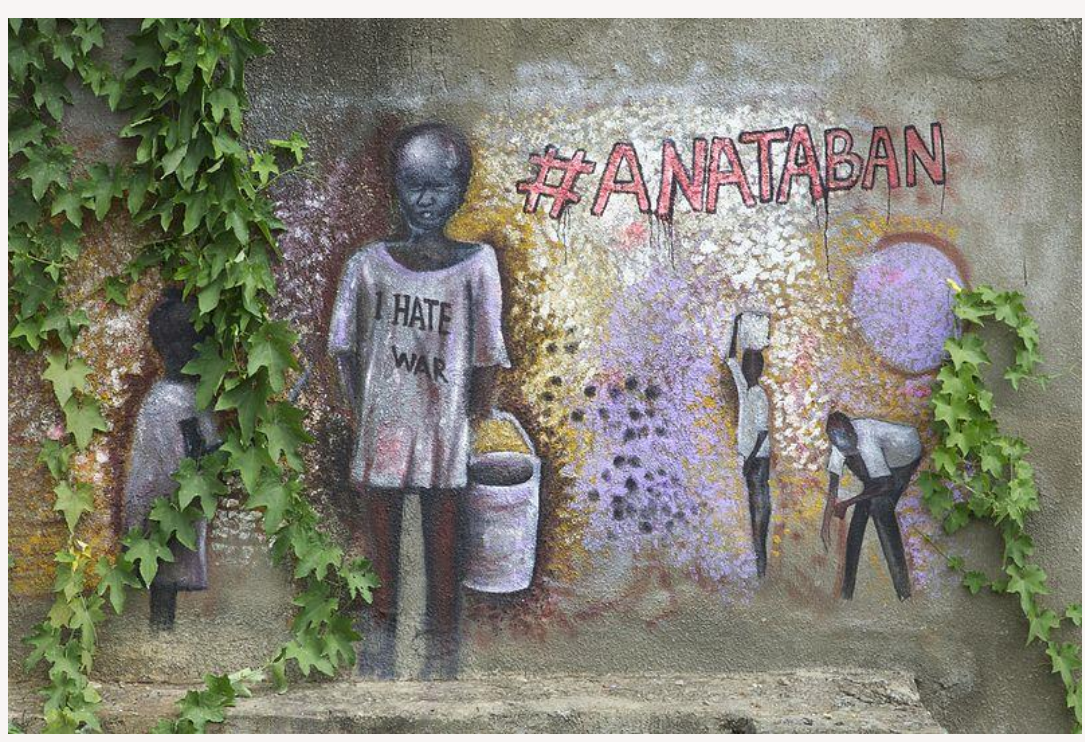

Ana Taban is a South Sudanese artists' collective dedicated to bringing peace to the country. It is formed of young painters, muralists, musicians, designers, poets and performers. First started in 2016 by the artist Jacob Bul Bior, the campaign uses various art forms such as: street theatre, in

the form of forum theatre (Sixdenier 2017); music; graffiti; mural painting; sculpture; poetry. It also produced a comic book, with support from Search for Common Ground, entitled 'Mou and Keji Get Justice at Last', to speak about social injustice, government accountability, and transparency (Kuyu Lokolong and Rana 2018; Dahir 2016).

Murals completed by the artists of Ana Taban can be viewed throughout Juba, the capital city of South Sudan, and depict messages of hope as well as frustration at the ongoing conflict.

Current projects of Ana Taban include the Hagana School Clubs, where they work with secondary schools in Juba to mentor young artists. They also host the Hagana Festival, an annual artists' event designed to encourage young people in South Sudan to actively contribute to the peace process in their country. In 2018 the festival attracted more than 13,000 people (Nyaga 2019).

As stated by the artist Manasseh Mathiang in an interview with Boniface Nyaga:

We have seen the power of art. Young people have been inspired to be agents of change, and it has shifted the political narrative. During the Addis Ababa edition of HLRF [High-level Revitalization Forum] in February 2018, we joined other civil society groups in \#SouthSudan/sWatching campaign. The message reached the representatives of the warring factions and made an impact on the negotiations. Previous talks fell apart because citizens were not involved, so we mobilised citizens online and on the ground so politicians would know that people were watching'.

(Nyaga 2019)
'The young who are tired and left with nothing are the ones who will sew the fabric of our nation back together...'

\section{Tweet from @Anataban 2016.}




\section{Visual and creative praxis}

As well as working with different people, we need to work in different ways. Using visual and creative praxis is an excellent way of ensuring genuine participation. Creative praxis involves using imaginative methods that include arts, games, visual, music, dramatic, moving and more traditional methods within a process that has ethics embedded. This includes respect for all participation of all ages and genders with an attention to difference and intersecting aspects of structural inequality. Methods need to be flexible and developed with and by children and young people, and piloted with them and different stakeholders in communities.

To make child and youth engagement meaningful, methods and voice need to be coupled with agency so that they are not meaningless but feed into transformational processes. This means involving children and youth throughout processes from planning to action and evaluation. Facilitation can be best done through building on capacities within communities and mixing this with external but sensitive input, training and support that does not impose on but appreciates local context. Young people are often the best facilitators.

\section{Box 12: Casestudy - SCREAM: Supporting Child Rights through Education, the Arts, and the Media}

The International Labour Organization's (ILO) Supporting Child Rights through Education, the Arts and the Media (SCREAM) programme aims to educate children and youth on their rights using creative methods - drama, music, visual arts and creative writing - in combination with campaigning and networking methods 'to promote awareness among young people about children's rights, with a focus on child labour, so that they in turn can speak out and mobilise their communities to act' (ILO, n.d.). The programme is fundamentally about children and young people leading processes that address harmful practices and bring about sustainable whole-community change.

'... to promote awareness among young people about children's rights, with a focus on child labour, so that they in turn can speak out and mobilise their communities to act.'

(ILO SCREAM website)

SCREAM was first launched in 2002 and is designed to be implemented by educators in either a year-long programme or in individual workshops. The original 14 modules cover a broad range of topics but focus particularly on child labour. Modules were developed to be adapted to different cultural, economic, and environmental contexts, from formal school classrooms to informal gatherings with limited resources. Some of the specific activities include: creating two collages, one on a common advertisement subject and another on child labour; conducting a survey with community members on child labour; theatre and role play of child labourers; creative writing of stories about the lives of child labourers; writing and performing a play on child labour. Since its launch, SCREAM has grown to include more modules on specific issues, such as HIV/AIDS, armed conflict, and agriculture, and has incorporated new methods, like music. In some countries, SCREAM has even been incorporated into the national curriculum and gained the attention of teachers' trade unions (ibid.). 


\section{Empowerment}

Empowerment is a concept that lies at the root and history of much community-driven and youth-led activism. Power dynamics need to be analysed at all levels and between all actors. Freire's (1996) framing of power is useful because it situates the potential for social change within a process of individual self-realisation that leads to collective action. Although the concept of empowerment is important, the language used to describe it may need to be changed to suit different contexts, recognising what is translatable, transferable, and compelling. Some use 'agency' rather than empowerment, where agency is relational, reliant on others and embedded in peers, families, and communities. When we talk about agency we mean taking children's views seriously as well as supporting the decisions and actions based on these views. It is important to note that one cannot gift agency, or indeed empowerment, to another individual.

The notion of empowerment includes using and developing safe spaces in which children and youth can feel that they can build their confidence, work with their peers and also engage in dialogue with other stakeholders. Important is the inclusion and empowerment of different children and how they feel about the spaces that are created in projects, services and everyday life. This may include, for example, the way in which children with disability are informing service development as was assessed with children in Serbia (Avramović and Žegarac 2016); or the Warren project in the United Kingdom that set up a space for young people who were homeless, unemployed and viewed by many as displaying anti-social behaviour (see Box 13).

\section{Box 13: The Warren Youth Project}

The Warren Youth Project in Hull, UK, is a youth centre run by and for youth with adult support. It offers diverse services, such as counselling, guidance, training, and education to young people who are experiencing a wide variety of difficulties, including but not limited to homelessness, domestic violence, sexual abuse, familyrelationship breakdown, drug abuse, racism, and homophobia. Internal governance of The Warren comes from a parliamentary body called 'The Thing'. The Thing is entirely comprised of young people and it 'debates, decides and votes on the services provision that young people require and in turn ask [the] staff team to deliver those services' (The Warren, n.d.). In this way, young people decide what they need and can seek adult assistance to ensure its delivery. The Warren also serves as a neutral space where young people determine the rules and can police each other to follow guidelines and value the space (The Warren, n.d.).
We didn't call it

participation then.

We called it

empowerment and we were basically the young people with a Centre... at first it was the volunteers in particular and then a whole group of young people who were there started making decisions, making decisions about the budget, making decisions about priorities.

(West pers. comm. 2019) 


\section{Norms}

Institutional and social norms often need to be shifted through a process of negotiation. Ignoring social norms, and treating child rights programmes and processes as separate to them, fail children as agents of change in communities. Social norms of childhood not least need to be surfaced and understood in order to negotiate children's and youth participation.

Many child and youth-led and -centred processes have pointed to adults needing to shift their views and listen to young voices to inform new strategies. Funding, research and intervention to rejuvenate communities therefore needs to engage with all community members, work with existing structures and hierarchies, and enlighten them through a process of creative praxis.

Norms are not always owned by children but are respected by them, alongside traditional and religious beliefs. While often respecting the adults and traditions in their communities, young people may want to edit or shift norms so that harmful practices are changed while preserving a feeling of belonging to a community.

\section{Box 14: Case study - Aware Girls}

Founded by Gulalai Ismail when she was only 16, Aware Girls is an example of an organisation that is not only youth-led but also self-led. Self-led groups are comprised of members from the community that they aim to influence. As such, they are better able to employ culture-specific strategies for messaging and advocacy to challenge social norms and behaviour. Aware Girls works towards women's empowerment, gender equality, and peace. The organisation's membership is comprised of young Pakistani women and girls, aged 12 to 29. Every level of management and decision-making is governed and led by young women. Aware Girls focuses on group formation of young women and girls, capacity building, education and awareness raising, and advocacy and campaigning. One initiative of Aware Girls is their quarterly meetings with political parties which are open to the public. These meetings function to shift perceptions of what is considered normal in Pakistan, as the public attending the meetings can observe young women speaking to

'Because our work is about changing the attitudes of the community and changing the culture with the community, it is very important for us to be seen as insiders: someone who comes from [the community] and who actually believes in empowering and developing the community.'

(Gulalai Ismail, quoted in Holden 2017: 4) policymakers with authority and conviction. Furthermore, these gatherings give young women the opportunity and support to voice their issues and concerns with people in power. This is all made possible through Aware Girls' investment in capacity building and knowledge sharing within their membership (Aware Girls, n.d.; Aware Girls et al. 2014). 


\section{Box 15: Case study - Young Women's Freedom Centre}

Established in 1993, the Young Women's Freedom Centre (YWFC) is a grass-roots organisation in California, US, which is led by and serves women, girls, and transgender gender non-conforming (TGNC) people of colour who have been involved in the criminal justice system and continue to be marginalised through social welfare programmes and poverty. YWFC believes that those most impacted by the criminal justice system are those most knowledgeable about their needs and most capable of creating change in their communities and at a legislative level (YWFC 2019). In March 2020, YWFC launched the campaign Freedom 2030 with the Sister Warriors Freedom Coalition. The campaign aims to end incarceration of women, girls, and TGNC people of colour, and to build alternatives based on transformative justice processes and community work (Sister Warriors Freedom Coalition 2020).

\section{Adultism}

In an interview with Tessa Lewin and Vicky Johnson, Tenaya Jones, YWFC community organiser, and Jessica Nowlan, Executive Director, spoke about their experiences of adultism and how they try to address it in their organisation.

Jones describes adultism as:

\section{not listening to the youth... [thinking] they know what is best for us because they think that when they were young, at our age, and they were going to the same things, so, they know how to fix it but I think that the times are different. \\ (Jones pers. comm. 2019)}

When YWFC was started in 1993 it was entirely youth-led - from grant-writing to building donor relationships. Twenty-six years later, although the organisation is no longer youthled, it remains youth-centred. Nowlan states that one of the major issues the organisation continues to face is adultism, which manifests 'both on the political landscape and also in society'. She reflects that the young people's 'ideas were not looked at as solutions. They were looked at as not powerful'. Particularly, 'as an organisation that centres in the voices, experiences, and ideas of young people, it continues to be a struggle for [YWFC] to really prove that young folks do have the answers' (Nowlan pers. comm. 2019).

Nowlan goes on to explain that YWFC has had to adopt 'the tools that are accepted because we have to challenge adultism in a real way' (ibid.). One of these tools is research, in which Jones is involved, and another is the expectation for the organisation to be represented by an adult, such as Nowlan. As executive director, she sees it as her responsibility 'to facilitate space for the young folks to actually be in power and have a platform to share the solutions' (ibid.). Furthermore, she contends that to overcome adultism, youth need to 'lead the way' and be 'supported with resources, time, development, opportunities' so that we can actually 'imagine a different society' (ibid.). 


\section{Accountability}

Many programmes are accountable to the organisations that deliver them, not to the children they purport to serve. As outlined in the socioecological Ndoro Ndoro model, and the living rights framework, there needs to be a commitment to accountability to children, youth and people in societies. We need to rebuild relationships between people in power and citizens. This is going to be a slow process and to do it we need to engage young people to push for a different way of doing things; for more inclusive, fair and accountable societies. 'We have to engage young people where they are, rather than where we want them to be' (Glencorse pers. comm. 2019). Accountability needs to take into account the frameworks of rights and Sustainable Development Goals; ultimately there need to be ethical protocols and processes that respectfully include children and youth in all stages of analysis, decision-making and action. Evaluation needs to be both sensitive to gender and dis/ability but also to generation/age so that the impact of all interventions can be tracked and so that no child is left behind.

\section{Box 16: Case study - Accountapreneurs}

Accountability Lab's Accountability Incubator programme is meeting young people where they are. In five countries - Liberia, Mali, Pakistan, Nepal, and Nigeria - young civil society leaders are supported to take forward their own ideas and initiatives around creating accountable societies. Support takes the form of mentorship, fundraising, management, and access to networks. Past examples of Accountapreneurs include a Liberian filmmaker in Liberia who set up a film school around accountability and a Nepalese woman who created a crowd-sourced website for young people to access government information more effectively. Accountapreneurs' initiatives are creative and innovative. They use film, information technology, comic books, theatre and radio to make their communities more accountable and engaged (Accountability Lab 2019).

\section{Transformation}

Social and political change requires processes that shift social norms, confront power dynamics and build respectful intergenerational dialogue. Safe spaces can help children and young people to build confidence to engage with adults and can help adults to understand the productive contribution of younger people and to find ways of listening to and acting on their views. Childand youth-centred research and creative research and ethnographies to understand context including power dynamics can lay the ground for more inclusive understanding and intervention. 


\section{Box 17: Case study - Tostan}

Since the start of Tostan's Community Engagement Programme (CEP), 7,200 communities in West Africa in eight different countries have publicly declared their intention to end female genital mutilation (FGM) and child marriage. An evaluation of these communities eight to ten years after the declaration found that 77 per cent of them had permanently ended the practice of FGM; however, the report does not state the extent to which child marriage had also ended. Tostan's CEP is designed to address social norms and behaviours through a process of 'active awareness through community sessions - group meetings in which adolescents and adults of both sexes participate in exercises and games that draw heavily on local cultural knowledge, especially proverbs, songs, and dances' (Vaitla et al. 2017: 14). These sessions are divided into adult and adolescent groups to encourage youth participation. CEP meetings provide an opportunity for women and girls to participate in conversations related to their health and wellbeing while involving men and boys. Furthermore, recommendations from community members that the notion of human rights - such as the right to be free from discrimination - should be included in CEP, has meant that women and girls can also advocate for their right to equal opportunity and therefore freedom from FGM and child marriage. Tostan believes the success of CEP is related to its inductive approach, which allowed communities to express priorities and for programme design to respond accordingly (ibid.).

\section{Energy}

Communities can become tired and adults assume they know what children do, need, and want because they themselves were once children. But they were young in different times and places. With fast-changing contexts, rapidly evolving politics and an existential crisis of climate change, we all need the new insights and energy of children and youth. As Canavera reminds us:

... it is a lovely element of the child rights movement, that it is constantly refreshing itself. There is always a new generation coming up and when it is children who are the leaders of that, that means that the leadership transition is fairly constant.

(Canavera pers. comm. 2019)

Re-energising and rejuvenating processes can be effective through creative praxis using arts, music, visual and moving methods and processes that are flexible and engaging for all ages. Voices and visuals need to be coupled with supporting agency and shifting social norms, children's fresh perspectives can help to navigate new, more hopeful futures in communities. 
Box 18: Case study - United We Dream

United We Dream (UWD) is the largest youth-led immigrant network in the US. UWD tackles issues affecting the lives of immigrant youth, their families, and their communities. Their work focuses on four main areas: winning protection for immigrants; defending against deportations; education access for immigrants; and justice and liberation for LGBTQ immigrants.

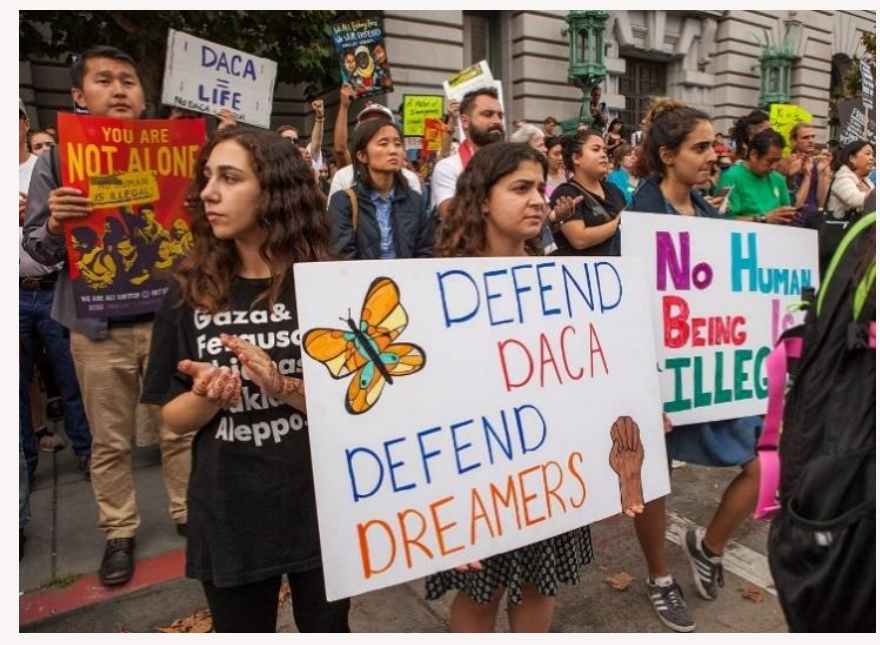

Membership consists of more than 400,000 individuals, many of whom are undocumented, and 100 local groups distributed across 28 different states. Membership is primarily wom $\times n^{7}$ with large representation of people who identify as LGBTQ. Additionally, an estimated 4 million people access UWD resources online.

Youth lead at all levels of UWD. Targeted programmes such as the Build the Dream Leadership Fellowship offer support and training to immigrant youth leaders across the country so that they can better organise their communities around education justice and immigrant rights. The programme provides opportunities for participating fellows to learn about the history of social justice movements; connects fellows with local and experienced grass-roots organisers; gives fellows practical experience in organising events, canvassing, participating in forums, communications and digital organising; and facilitates fellows' growth through diverse activities such as art, music, college prep, and meditation. UWD has been a prominent supporter and advocate of the Deferred Action for Childhood Arrivals (DACA) Act since it came under threat from President Donald Trump who ordered the Department of Homeland Security (DHS) to 'begin an orderly transition and wind-down of DACA'. His action would include the immediate cessation of processing new DACA applications, DACA renewals or applications for advance parole (Trump 2017). ${ }^{8}$

On 18 June 2020, the Supreme Court of the United States of America (SCOTUS) ruled (5-4) that the manner in which the Trump administration ended the DACA programme was 'arbitrary and capricious' (Aguirre 2020) and reinstated the 2012 DACA Memo of the Obama administration. This means that the DHS must begin to accept new DACA applications again; however, they have yet to issue guidance on how to submit first-time applications and advance parole. Although conservative politicians can seek other methods of ending the programme, SCOTUS's ruling opens DACA back up retrospectively for anyone excluded since it was initially rescinded by Trump in 2017. This is considered a major win for 'Dreamers' (Munoz 2020).

\footnotetext{
${ }^{7}$ Womxn is a term widely used since 2015 to include transgender women and women of colour and broadly denotes gender fluidity and intersectionality. This is the spelling used in United We Dream written material and has been used in this report to respect this choice.
} 


\section{Why youth organising?}

Youth organising can achieve both individual transformation and systemic structural change. Unlike traditional youth services, youth organising does not seek to only address individual youth 'problems', but also trains young people in community organising so that they can better challenge power relations and create institutional change in their communities. Youth identify the issues that they want to address and are supported in designing, implementing, and evaluating their own processes for working towards change. Youth services and youth organising represent opposite ends of the youth engagement continuum, a useful tool for identifying best practices in transformational youth work (United We Dream 2018).

\footnotetext{
${ }^{8}$ This is an application that allows immigrants to travel outside the US and to return lawfully. Advance Parole is only available to DACA recipients who demonstrate that their need to travel falls within the categories of: 'humanitarian, education, or employment' purposes (Immigrant Legal Resource Center 2015).
} 


\section{Next steps}

The following section focuses on three potential strands of intervention identified through our analysis of the living archive and the interviews with key experts in the child rights field: youth organising, rejuvenating communities, creative praxis. These strands align with the findings from a network of academics and practitioners in Latin America (Rizzini pers. comm. 2019).

\section{Youth organising}

There is often a crisis or issue through which youth respond and gain respect in communities, such as the Maoist insurgency in Nepal, immigration policy in the US, or global climate change. The experts interviewed and the living archive provided a range of excellent examples, as discussed in this working paper.

In Nepal, young people responded to the need to rehabilitate and reintegrate children who were involved in and affected by armed conflict. A critical analysis of the juvenile justice system led to the formation of the National Coalition for Children as Zones of Peace. Thirty-five grass-roots organisations mobilised to monitor child rights at a local level and highlighted where there was still violence or discrimination towards children who were involved in the conflict. Organisations then lobbied together to feed into the peace process, and managed to get children recognised in the new constitution as having been part of the armed conflict (Shrestha pers. comm. 2019).

In the US, the youth-led immigrant network, United We Dream, works across a range of issues affecting immigrant youth and their families. Their concerted actions have led to major judicial wins for immigrants, including the reinstatement of Deferred Action for Childhood Arrivals (DACA). ${ }^{9}$ Youth involved in United We Dream are supported to design, implement, and evaluate their own processes while addressing power relations between youth and adults.

Fridays For Future has achieved massive global impact and reach. The use of social media and direct action has prompted the proliferation of other youth movements and organisations addressing climate change, as well as the prioritising of environmental issues for some political groups.

Our interviews suggest that the support that young people often need for successful organisation, is the capacity to make their activities both recognised and sustainable. They suggest that more work can be done, in consultation with the young people who are running youth-led organisations and projects, to support:

- help with translation into national languages;

- connections to national and international policy spaces and media;

- creating spaces and platforms for dialogue where children/youth can be heard;

- helping children on committees and to form clubs;

\footnotetext{
${ }^{9}$ DACA is a US immigration policy introduced under President Obama that allows some undocumented immigrants brought to the US as children to apply for two years of deferred action from deportation and to remain legally in the US to study and work (https://www.dhs.gov/deferred-action-childhood-arrivals-daca).
} 
- financial planning and monitoring for donors/stakeholders;

- ongoing logistical support to continue networking and researching (Shrestha pers. comm. 2019; Blagborough pers. comm. 2019).

There is often a gap between populist issues and the most important priorities for the most marginalised children and young people. The most marginalised youth, for example in YOUR World Research in Nepal, wanted young people who were less marginalised to join in a process of creating youth declarations and presenting these to government to make their voices heard about the support and inclusion that young people wanted in local and provincial decisionmaking processes (Shrestha pers. comm. 2019).

Sometimes the typical NGO programmes do not work as they may engage with children who are in schools or already engaged in services locally. If processes only work in schools, some of the most marginalised children and young people are not included as many have dropped out of school for various reasons including pressure to support their families, escaping from harmful norms such as early marriage or failing national exams (Shrestha pers. comm. 2019).

In the Anti-slavery coalition of organisations to engage with domestic workers and young slaves, children and young people had to be involved in different ways depending on the context. As long as it was meaningful in that context and time was taken at the beginning to set this up, it seemed to work in very different ways. Flexibility is needed, depending on the situation, to form coalitions where young people can have more say and leadership (Blagborough pers. comm. 2019).

\section{Child/youth-centred community approaches}

\section{rejuvenating communities}

In their interviews, key experts, drawing on many years of working on child rights, concluded that in order to understand what children need and want, they had to ensure that children and youth were central to community development processes. To do this, they also needed to engage with adults and key stakeholders with power in communities and to gain their support for children's participation, voice and agency. Sustainable development in communities may not immediately be thought of as relevant or needing to be informed by children's perspectives but children's and young people's views, decisions and actions have significantly enriched broader community development outcomes. Considering a broader context of communities can help adults to enter into conversations, where they may immediately be put off by a focus on children's rights. The Sustainable Development Goals, for example, may also allow children to join community conversations more easily. Adding children's and youth perspectives to the topics of mutual interest in communities may be a way for children's interests and agency to become valued, considering the embedded connections, relationships, and dynamics in communities. Children's capacity to release their agency is often limited or denied. Children are rarely passive, so research and lead-in time is needed to show the ways in which children are active in communities and to convince adults to allow them to participate (Ofosu-Kusi pers. comm. 2019). 
Gabriella Trevisan from Porto, Portugal describes the surprise she experienced when first working with children:

It was a big surprise for me listening to children's views on the city. It was a very intergenerational view, so you know it's not like selfish things, saying "I want a new park'. They have very specific concerns about other generations, like older people or people who live on the streets. They have concerns with poverty.

(Trevisan pers. comm. 2019)

These approaches need to start by listening and learning with children and young people alongside others in communities. They may take the form of guided ethnographic case studies, understanding existing structures and hierarchies, contextually informed and applying a socioecological approach where local people are empowered over time to influence their context. The voices of children and young people are central, recognising that they are usually at the margins of community development and decision-making. Local approaches intermixed with new ideas allow a process where people in communities are empowered, rather than ideas imposed. Capturing children's voices is essential but it should not be exploitative: 'Voice is meaningful but only when coupled with true agency' (Wessells pers. comm. 2019). Communities then need help to develop and lead monitoring. It is both about unlocking creative potential in communities, and supporting the children who can navigate and negotiate complex community dynamics (ibid.).

The approach fits with both community-driven and Freirean social pedagogies where people are empowered to break silences and be involved in their own liberation from oppressive norms. Rejuvenating communities and enriching sustainable development with learning from child rights also fits with the child- and youth-centred change-scape approach (for example, Johnson 2011) and the socioecological Ndoro Ndoro model in our approach for REJUVENATE presented in this paper.

Interviewees identified that in order to make community-driven approaches effective in engaging with the children, they would have to work to change adults and social norms, and make children's and young people's roles in society more visible.

It is clear that part of what needs to happen is to develop adults' capacities. As many of our interviewees commented, there is need for a fundamental social and cultural change - most adults don't 'get it'. As Cipriani (pers. comm. 2019) commented:

It's hard to design proper support for youth power if you have not witnessed it first-hand. I think we need a strategy on getting people to grasp youth power and working towards a longer-term commitment to and growth of youth power... not just [a] song-and-dance show at the end of the conference. But actual youth speaking truth to power and gaining that power in changing systems. 
This, of course, is easier said than done. To understand children's transformative potential, it is important to name and identify the social norms in the community, including what children do, and how they feel about their roles in society. Although people think of 'communities' as rural places where children come from, and want to return to, many of the most marginalised children find themselves in informal and migrating informal communities where they form new relationships. We need to understand new and shifting norms in their communities, and what children do in their everyday lives (Mizen pers. comm. 2019).

Approaches to change social norms need to 'fit with culture and context' (Wessells pers. comm. 2019). When there is an imposition of outsider approaches and a lack of critical self-reflection on behalf of the researcher, research and intervention can undermine resilience and empowerment in community development (ibid.). Interventions need to be informed by a strong evidence base that is historically and ethnographically informed, not based on the assumptions of outsiders, or the imposition of Western models of child protection and development. By understanding how traditional practices and new learning is interwoven, the social positioning of the child can also be understood (ibid.).

In developing the capacities of adults to 'get' the value that children and young people bring, adults also need to be supported to recognise their own privilege. Adults have to change and reconceptualise their role to create environments and to start listening in a different way - to turn from being teachers to enablers.

The single most important aspect is 'to be humble', [to] go in as an outsider with the perspective there is more to learn and more to know. They are the experts of their strengths, adversities and challenges. Start with listening.

(Wessells pers. comm. 2019).

Ofosu-Kusi (pers. comm. 2019) commented in an interview that if an initiative was thought to be genuinely child-led, this may be the 'doom of it' within many communities. Children's agency still needs to be negotiated within families and with adults in communities; and children and young people want to belong to their families, so their interdependencies need to be understood in context.

At the moment, the issue of 'child rights is "not alive": politicians are not interested' (Nieuwenhuys pers. comm. 2019). Making children's and youth perspectives and roles in societies visible can help to convince adults of their value and the necessity of including them to achieve social justice and sustainable development. In much of Europe, for example, it seems that there is too much bureaucracy and not the political will to really pay attention to child rights, or indeed to women's rights or refugee rights. There is a gap between how children are struggling for their rights and how politicians, funders and services are currently responding to their realities, and the extent to which they are supporting their decisions and actions (ibid.). 


\section{Creative praxis}

The arts facilitate genuine participation.

Mark Canavera (pers. comm. 2019)

There was consensus among our interviewees that using innovative, ethnographic and artsbased approaches to understand children's lives and perspectives can help to transform communities.

A good starting place for work with children is an ethnographic learning journey about children's lives in which children are central, accompanied by the building of a strong evidence base to inform any intervention. Rather than imposing methods, local communities should pick and choose from toolkits and develop their own way of understanding the issues that they prioritise. Some examples of creative and visual methods include body mapping to show how girls and boys feel and how we can understand issues of child protection and health (Wessells pers. comm. 2019).

Ethnographic and creative methods are ideal for engaging with children and youth in transformational community-driven approaches to research and intervention. Engaging policy and decision makers, however, may require using mixed methods, and creating spaces for dialogue (Johnson 2015).

Creative praxis can form the mechanism to change attitudes and behaviour. Adults in institutions and communities may need to become gradually aware of children's capacities to engage in valuable and imaginative ways (Ofosu-Kusi pers. comm. 2019).

We should not underestimate the power of media, and the power of telling the right story... there is a real power in how the media shapes social norms. We really need [to] think out of the box about how you create things and make them part of the culture; part of the ways that things are... this is [a] potential power tool that it has been grossly under-utilised.

(Bah pers. comm. 2019)

Creativity can help people in institutions and communities to engage with children and young people and their political contexts in a different way. Methods can be developed with local artists, and facilitators can play games and make analysis fun but meaningful. For example, researchers in Rio de Janeiro, Brazil, used conversations, songs and artwork to create contexts accompanied by conversations about skin colour and inequality, for example. Their approach opened up discourses of social justice that led to a broader understanding of decolonialisation, barriers and false distinctions between the global North and South, political participation and children's potential (Rizzini pers. comm. 2019). 


\section{Box 19: Case study - Community support for youth with mental illness}

Arting Health for Impact (AHI) and Lentegeur Hospital in Mitchells Plain, Cape Town, South Africa collaborated on a project to engage young people in their own mental health care services and to reduce community stigma related to mental health illness in young people (Western Cape Government 2018). The process brought together health professionals, visual artists, 25 young people from the Cape Flats and Overberg areas of South Africa who were receiving treatment from the Lentegeur Child and Adolescent Mental Health Services, and people with learning disabilities. In interactive workshops young people practised creative therapies, such as drawing, role playing, story mapping, spray painting, music, and poetry. The workshops aimed to explore youth experiences of receiving care and to improve communication between health professionals and their patients.

Next, the findings from the workshops were used to develop an art piece conveying young people's message to the community. With assistance from professional muralists, this message was painted on a large wall outside the Lentegeur Hospital and was viewable by the community. Additionally, a community outreach event presented the mural to approximately 300 community members of the neighbouring township.

According to the project director, Nabeel Petersen, 'Using a participatory, inclusive process with youth positioned them as active agents for change, and we feel that this played a big influence in assisting them with accepting the project as their own and also in their confident participation in decision-making' (Petersen pers. comm. 2019). 


\section{And finally.}

This paper has outlined the findings of the first phase of our REJUVENATE project. It has presented, through our 'living archive', a history of child rights and participation, and an analysis of what has worked in the field. Grounded in an understanding of child rights as 'living rights' (Hanson and Nieuwenhuys 2013), we propose building on the 3Ps of the UNCRC (protection, provision and participation) towards the 3Ss - space, support and system change. We offer a set of field principles (REJUVENATE) to guide substantively participatory work with children and young people, underpinned by our Ndoro Ndoro model, which refers to intergenerational, community-driven approaches that put children and youth at the centre, while being accountable to them. Finally, we suggest three strands of work that could usefully be supported to move towards a more just, inclusive and sustainable world: youth organising, rejuvenating communities, creative praxis. We invite you to contribute to our project, to critique our work, to improve on it, to help build our living archive, and to test our principles, to rejuvenate. 


\section{Annex: List of interview participants}

\section{In-depth interviews}

Anannia Admassu, University of Brighton, UK/Director, CHADET, Ethiopia

Chernor Bah, Purposeful Productions, Freetown, Sierra Leone

Harriot Beazley, University of the Sunshine Coast, Sippy Downs, Australia

Nina Blackwell, Firelight Foundation, Santa Cruz CA, US

Jonathan Blagbrough, University of Dundee, UK

Eric Braxton, Funders' Collaborative on Youth Organising, New York NY, US

Mark Canavera, Milman School of Public Health, Columbia University, New York NY, US

Don Cipriani, Ignite Philanthropy: Inspiring the End to Violence against Girls and Boys, Rome, Italy

Ben Cislaghi, London School of Hygiene and Tropical Medicine, London, UK

Tom Cockburn, Edgehill University, Osmirk, UK

Swatee Deepak, Stars Foundation/ With and For Girls, London, UK

Pascale Garnier, Université Paris, Sorbonne, Paris, France

Blair Glencorse, Accountability Lab, Washington DC, US

Karl Hanson, University of Geneva, Switzerland

Roger Hart, The Graduate Center of the City University, New York NY, US

Edda Ivan-Smith, The World Bank, Washington DC, US

Tenaya Jones, Young Women's Freedom Centre, San Francisco CA, US

Gerison Lansdown, Independent, London, UK

Fassil Marriam, Child's Rights and Violence Prevention Fund, Kampala, Uganda

Phillip Mizen, Aston University, Coventry, UK

Olga Nieuwenhuys, University of Amsterdam, the Netherlands

Jessica Nowlan, Young Women's Freedom Centre, Oakland CA, US

Yaw Ofosu-Kusi, University of Education, Winneba, Ghana

Claire O'Kane, France/ Wales

Ken Ondoro, Child protection adviser, Kisumu, Kenya

Nabeel Petersen, Wellcome Trust, Cape Town, South Africa

Saji Prelis, Search for Common Ground, Washington DC, US

Irene Rizzini, Catholic University of Rio De Janiero/ Childwatch International, Brazil 
Shubhendra Man Shrestha, Goldsmiths/ YOUR World Research, Kathmandu, Nepal Gabriela de Pina Trevisan, Escola Superior de Educação de Paula Frassinetti, Porto, Portugal Helen Veitch, University of Bedfordshire/ Oak Foundation, UK Michael Wessells, Mailman School of Public Health, Columbia University, New York NY, US Andy West, YOUR World Research, Brighton, UK Veronica Yates, Child Rights International Network (CRIN), London, UK

\section{Short interviews/consultations}

Ingrid Agud, Autonomous University of Barcelona, Spain

Felix Bivens, Empyrean Research, Fayetteville TN, US

Sunday Dogo, ChildHope UK

Sarah Jackson, St Lukes Primary School, Brighton, UK

Tenaya Jones, Young Women's Freedom Centre, San Francisco CA, US

Jessica Nowlan, Young Women's Freedom Centre, Oakland CA, US

Dan Moxon, People, Dialogue and Change, Lancaster, UK

Patrick (previously Nigel) Thomas, previously University of Central Lancashire, UK

Tricia Young, Terre des Hommes/ previously Child-to-child, London, UK 


\section{References}

What follows are three lists of references:

- the living archive of project examples for Phase One of REJUVENATE;

- organisational websites and blogs cited in our interviews and exemplar boxes; and

- wider academic literature referred to in our analysis.

Note that the living archive includes 100 projects that have been analysed using the matrix described in our methodology.

\section{Living archive of project examples (Phase One)}

Abrioux, E. (1998) 'Degrees of participation: a spherical model - the possibilities for girls in Kabul, Afghanistan', in V. Johnson, E. Ivan-Smith, G. Gordon, P. Pridmore, and P. Scott (eds), Stepping Forward: Children and young peoples participation in the development process, Rugby, UK: Practical Action Publishing (accessed 9 November 2020)

Achaleke, C. (2017) Creative Skills for Peace Project: Innovatively promote efforts to prevent/counter violent extremism through developing creative skills/capacity of youth violent offender, blog, OpenIDEO (accessed 9 November 2020)

Adams, E., and Ingham, S. (1998) Changing Places: Children's Participation in Environmental Planning. Children's Society, London: Children's Society

African Movement of Working Children and Youth (2016a) History, Dakar: MAEJT/ Enda-Jeunesse Action (accessed 5 August 2019)

African Movement of Working Children and Youth (2016b) Home, Dakar: MAEJT/ Enda-Jeunesse Action (accessed 9 March 2020)

African Movement of Working Children and Youth (2016c) 'Mobile Children: from "victims" to "actors"', JEUDA 119, Dakar: MAEJT/ Enda-Jeunesse Action (accessed 9 November 2020)

African Movement of Working Children and Youth (2016d) Children and youth on the move, Dakar: MAEJT/ Enda-Jeunesse Action (accessed 9 November 2020)

African Movement of Working Children and Youth (2015) ‘Child Protection Manual by the Associations of Working Children and Youth (AWCY)', JEUDA 126, Dakar: MAEJT/ Enda-Jeunesse Action (accessed 9 November 2020)

African Movement of Working Children and Youth (2013) ' "We say!": We, WCY, are teaching literacy courses!', JEUDA 125, Dakar: MAEJT/ Enda-Jeunesse Action (accessed 9 November 2020)

African Movement of Working Children and Youth (2011) 'Protection of mobile children by organized children and youth', JEUDA 123, Dakar: MAEJT/ Enda-Jeunesse Action (accessed 9 November 2020)

Agud, I., Novella, A., and Llena, A. (2014) 'Conditions for Effective Children's Participation, According to Children's Voices', Revista de Cercetare Si Interventie Sociala 46: 9-21 
Aguirre, S. (2020) 'Immigrant Youth Win at the Supreme Court; We Are Unafraid and Here to Stay', 18 June, Washington DC: United We Dream, (accessed 22 July 2020)

Allen, D. (1998) 'Child participation in programme planning and implementation in the marginalized youth projects, Jamaica', in V. Johnson, E. Ivan-Smith, G. Gordon, P. Pridmore and P. Scott (eds), Stepping Forward: Children and young peoples participation in the development process, Rugby, UK: Practical Action Publishing (accessed 9 November 2020)

Ana Taban (2019a) Our Story, Facebook (accessed 7 August 2019)

Ana Taban (2019b) AnaTaban, Facebook (accessed 7 August 2019)

Ana Taban (2016) Tweet from @Anataban, 5 September 2016, https://twitter.com/anatabanss/status/772827759076896768?lang=en

Ana Taban South Sudan (2016) \#Anataban Official Video - South Sudan Music 2016 (accessed 7 August 2019)

Ansell, N.; Robson, E.; Hajdu, F. and van Blerk, L. (2012) 'Learning from young people about their lives: using participatory methods to research the impacts of AIDS in southern Africa', Children's Geographies 10.2: 169-86, DOI: 10.1080/14733285.2012.667918 (accessed 9 November 2020)

Ansell, N.; van Blerk, L.; Robson, E.; Hajdu, F.; Mwathunga, E.; Hlabana, T. and Hemsteede, R. (2019) Social cash transfers, generational relations and youth poverty trajectories in rural Lesotho and Malawi, London: Brunel University London (accessed 9 November 2020)

Ashby, S.; Anwar, Q.; Zubair, M.; Afifa Wardak, H. and Qadri, G. (2002) Child Protection: The Kotkai Experience, Save the Children UK, Pakistan (accessed 3 December 2020)

Avramović, M. and Žegarac, N. (2016) "'Me at the Centre": perspectives of children with disabilities on community-based services in Serbia', Children's Geographies 14.5: 541-57 (accessed 9 November 2020)

Aware Girls (n.d.) Who We Are, Peshawar: Aware Girls (accessed 9 November 2020)

Aware Girls; Young Feminists Movement and MamaCash (2014) Survey on the perceptions and attitudes of people towards domestic abuse in Pakistan, Peshawar: Aware Girls

Baker, R. and Hinton, R. (2001) 'Approaches to Children's Work and Rights in Nepal', The ANNALS of the American Academy of Political and Social Science 575.1: 176-93 (accessed 9 November 2020)

Barnett, S.; van Dijk, J.; Swaray, A.; Amara, T. and Young, P. (2018) ‘Redesigning an education project for child friendly radio: a multisectoral collaboration to promote children's health, education, and human rights after a humanitarian crisis in Sierra Leone', BMJ363: k4667 (accessed 9 November 2020)

Beazley, H.; Butt, L. and Ball, J. (2018) "'Like it, don't like it, you have to like it": children's emotional responses to the absence of transnational migrant parents in Lombok, Indonesia', Children's Geographies 16.6: 591-603 (accessed 9 November 2020)

Bedford, L.J. (1995) Ondeleni children on their way: 'Street children' in Durban, pasts, presents and futures, Durban: Street Wise 
Bereményi, B.Á.; Larkins, C.; Percy-Smith, B. and Roth, M. (2017) Key Learnings from the PEER Project. A Combined Research Paper, EMIRGRA Working Papers, 136, http://eprints.hud.ac.uk/id/eprint/31335/

Blackburn, J.; Brocklesby, M.A.; Crawford, S. and Holland, J. (2005) 'Operationalising the Rights Agenda: Participatory Rights Assessment in Peru and Malawi', IDS Bulletin 36.1: 91-99, DOI: 10.1111/j.1759-5436.2005.tb00183.x (accessed 9 November 2020)

Blyth-Whitelock, S. (2016) War Child UK Innovation Report: Meeting the Rights of Children Affected by Armed Conflict, War Child UK (accessed 9 November 2020)

Buckingham, D. and Bragg, S. (2003) Young People, Media and Personal Relationships, London: The Independent Television Commission

Cahill, C. (2010) "“Why do they hate us?" Reframing immigration through participatory action research', Area 42.2: 152-61 (accessed 9 November 2020)

Canavera, M.; Lanning, K.; Polin, K. and Stark, L. (2016) "'And then they left": Challenges to child protection systems strengthening in South Sudan', Children and Society 30.5: 356-68 (accessed 9 November 2020)

Casey, S. (2010) Report of The Mapping and Analysis of Ghana's Child Protection System, Ghana Department of Social Welfare and UNICEF, Hong Kong: Child Frontiers Ltd. (accessed 9 November 2020)

Centro de Servicios Educativos en Salud y Medio Ambiente (CESESMA) (2012) Learn to Live Without Violence: Transformative Research by Children and Young People, Matagalpa, Nicaragua: CESESMA

CHADET (2016) Prevention of risky movement of children in the Northern Ethiopia corridor, Addis Ababa: CHADET (accessed 9 November 2020)

Chawla, L. and Driskell, D. (2006) 'The Growing Up in Cities Project: Global Perspectives on Children and Youth as Catalysts for Community Change', Journal of Community Practice 14.1-2: 183-200 (accessed 9 November 2020)

Clacherty, G. (2018) The Tatu Tano child-led organisation: Building child capacity and protective relationships through a child-led organisation, North-western Tanzania, Interagency Learning Initiative (ILI) on community-based child protection mechanisms, the Community Child Protection Exchange, Kwa Wazee

Clacherty, G. (2006) Report on a children's participation process: Towards a South African child labour programme, Pretoria: Save the Children Sweden (accessed 9 November 2020)

Clark, C.R. (2007) 'Understanding Vulnerability: From Categories to Experiences of Young Congolese People in Uganda', Children and Society 21.4: 284-96 (accessed 9 November 2020)

Cox, S. and Robinson-Pant, A. (2003) Empowering Children Through Visual Communication: A research project funded by $C f B T$, Norwich: School of Education and Professional Development, University of East Anglia

Crowley, A. and Skeels, A. (2010) 'Getting the measure of children and young people's participation: An exploration of practice in Wales', in B. Percy-Smith and N. Thomas (eds), $A$ 
handbook of children and young people's participation: perspectives from theory and practice, London and New York NY: Routledge

Cuevas-Parra, P. and Tisdall, E.K.M. (2019) Child-Led Research: From participating in research to leading it: Addressing inequalities in decision making, World Vision International, 10.13140/RG.2.2.12955.52007

Dahir, A.L. (2016) "I am tired": Young South Sudanese are using art to protest the endless cycle of violence and death', 21 September, Quartz Africa (accessed 7 August 2019)

de Vise-Lewis, E.; Schwarz, S. and Mupenda, B. (2018) Tug-of-war: Children in Armed Groups in the DRC: A Study of push and pull factors influencing children to join armed groups 'voluntarily' in North and South Kivu, Democratic Republic of the Congo, London: War Child and Child Frontiers (accessed 9 November 2020)

Duchscherer, D.; Duchscherer, C.; Namgyal, R. and Iqbal, M. (1996) Child Participation in Practice: SCF NWI's experiences in Programming, Save the Children Fund UK (SCF) North West India Programme Office

Dyson, M. and Amara, P.S. (2016) Final Evaluation Report: Increasing Access, Retention and Performance in Primary Education, Brighton: Institute for Development (accessed 9 November 2020)

Frost, D.M.; Fine, M.; Torre, M.E. and Cabana, A. (2019) 'Minority Stress, Activism, and Health in the Context of Economic Precarity: Results from a National Participatory Action Survey of Lesbian, Gay, Bisexual, Transgender, Queer, and Gender Non-Conforming Youth', American Journal of Community Psychology 63.3-4: 511-26 (accessed 9 November 2020)

Garcia, A.P.; Minkler, M.; Cardenas, Z.; Grills, C. and Porter, C. (2014) 'Engaging Homeless Youth in Community-Based Participatory Research: A Case Study From Skid Row', Health Promotion Practice 15.1: 18-27 (accessed 9 November 2020)

Gibbs, L.; Mutch, C.; O'Connor, P. and MacDougall, C. (2013). 'Research with, by, for and about children: lessons from disaster contexts', Global Studies of Childhood 3.2: 129-41 (accessed 9 November 2020)

Gioacchino, G. (2019) 'You defend what you feel: "Presencing" nature as "experiential knowing",' Action Research 17.1: 108-12 (accessed 9 November 2020)

Goodman, D.L. (2005) Water, Sanitation and Hygiene Education: Children and Adolescents Leading the Way in Tajikistan, UNICEF Tajikistan (accessed 9 November 2020)

Grimes, P. (2009) A quality education for all: a history of the Lao PDR Inclusive Education Project 1993-2009, Vientiane, Lao PDR: Save the Children (accessed 9 November 2020)

Guerra, E. (2002) 'Citizenship knows no age: children's participation in the governance and municipal budget of Barra Mansa, Brazil', Environment and Urbanization 14.2: 71-84

Guijt, I.; Fuglesang, A. and Kisadha, T. (1994) It is the Young Trees that Make a Thick Forest: A report on Redd Barna's learning experiences with participatory rural appraisal in Kyakatebe, Uganda, Kampala: Redd Barna Uganda; and London: International Institute for Environment and Development (accessed 9 November 2020) 
Haynes, K. and Tanner, T.M. (2015) 'Empowering young people and strengthening resilience: youth-centred participatory video as a tool for climate change adaptation and disaster risk reduction', Children's Geographies 13.3: 357-71 (accessed 9 November 2020)

Hendriks, T.D.; Reis, R.; Sostakova, M. and Berckmoes, L.H. (2019) 'Violence and Vulnerability: Children's Strategies and the Logic of Violence in Burundi', Children and Society 34.1: 31-45 (accessed 9 November 2020)

Herbst, N.; Glencorse, B. and Gilberds, H. (2017) Innovations to engage youth in Liberia: the role of arts and culture in creating pro-accountability environments, Making All Voices Count Practice Paper, Brighton: Institute of Development Studies (accessed 9 November 2020)

Hoang, L.A. and Yeoh, B.S.A. (2015) 'Children's agency and its contradictions in the context of transnational labour migration from Vietnam', Global Networks 15.2: 180-97 (accessed 9 November 2020)

Holden, L. (2017) Our Voices Are Strong: Lessons from Women's, Girls' and Trans People's Selfled Organisations, Mama Cash

Horelli, L.; Sotkasiira, T. and Haikkola, L. (2009) 'Building towards effective participation: A learning-based network approach to youth participation', in B. Percy-Smith and N. Thomas (eds), A Handbook of Children and Young People's Participation: Perspectives From Theory and Practice, London: Routledge

International Labour Organization (ILO) (n.d.) SCREAM: Supporting Children's Rights through Education, the Arts and the Media (IPEC), International Programme on the Elimination of Child Labour, Geneva: ILO (accessed 5 June 2020)

Johnson, V.; Hart, R. and Colwell, J. (2014) Steps for engaging young children in research: the resource and toolkit, The Hague: The Bernard van Leer Foundation (accessed 27 September 2020)

Johnson, V.; Hill, J. and Ivan-Smith, E. (1995) Listening to smaller voices: children in an environment of change, London: ActionAid (accessed 9 November 2020)

Johnson, V.; Leach, B.; Beardon, H.; Covey, M. and Miskelly, C. (2013) Love, sexual rights and young people: learning from our peer educators how to be a youth centred organisation, London: International Planned Parenthood Federation (IPPF)

Johnson, V. and Nurick, R. (2001) Rights Through Evaluation: Case studies of children's participation in Nepal and South Africa, Brighton: Development Focus (accessed 27 September 2020)

Johnson, V.; Admassu, A.; Church, A.; Healey, J.; and Mathema, S. (2019) 'Layered and Linking Research Partnerships: Learning from YOUR World Research in Ethiopia and Nepal', IDS Bulletin, 50.1: 79-98

Khan, S. (1997) A Street Children's Research, Dhaka: Save the Children and Chinnamul Shishu Kishore Sangstha 
Kimiagar, B. (2016) 'An Analysis of the Organizational Structures of New Types of Children's Associations in Relation to Changing Views of Children's Capacities as Citizens', PhD dissertation, New York NY: The Graduate Center, City University of New York (accessed 9 November 2020) Klocker, N. (2011) 'Negotiating change: working with children and their employers to transform child domestic work in Iringa, Tanzania', Children's Geographies 9.2: 205-20 (accessed 9 November 2020)

Kostelny, K.; Wessells, M. and Ondoro, K. (2014) Community-Based Child Protection Mechanisms in Kilifi, Kenya: A Rapid Ethnographic Study in Two Rural Sites, Interagency Learning Initiative on Community-Based Child Protection Mechanisms and Child Protection Systems (accessed 9 November 2020)

Krueger, A.; Routier, S.; Hiddleston, T. and Crispin, V. (2015) Evaluation of UNICEF-supported child-friendly spaces in the aftermath of Typhoon Haiyan (Yolanda) November 2013-November 2014, UNICEF Philippines

Krueger, A.; Thompstone, G. and Crispin, V. (2014) 'Learning from Child Protection Systems Mapping and Analysis in West Africa: Research and Policy Implications', Global Policy 5.1: 47-55 (accessed 9 November 2020)

Leach, F.; Machakanja, P. and Mandoga, J. (2000) Preliminary Investigation of the Abuse of Girls in Zimbabwean Junior Secondary Schools, Education Research Paper 39, London: Department for International Development (accessed 9 November 2020)

Limboro, C. and Wesonga, D. (2016) Girl Education Challenge (GEC) Wasichana Wote Wasome (Let All Girls Learn) Project: Midline Evaluation Report, Nairobi: Women Educational Researchers of Kenya (WERK) (accessed 9 November 2020)

Lundy, L.; McEvoy, L. and Byrne, B. (2011) 'Working With Young Children as Co-Researchers: An Approach Informed by the United Nations Convention on the Rights of the Child', Early Education and Development 22.5: 714-36 (accessed 9 November 2020)

Matthews, H. (1995) ‘Culture, Environmental Experience and Environmental Awareness: Making Sense of Young Kenyan Children's Views of Place', The Geographical Journal 161.3: 285-95 (accessed 9 November 2020)

McGill, M.; O'Kane, C.; Bista, B.; Meslaoui, N. and Zingg, S. (2015) 'Evaluation of Child and Youth Participation in Peacebuilding: Nepal, Eastern Democratic Republic of Congo, Colombia', Global Partnership for Children and Youth in Peacebuilding (accessed 1 December 2020)

McGill, M.; O'Kane, C. and Giertsen, A. (2017) 'Evaluating Children and Youth Participation in Peacebuilding in Colombia, DRC, and Nepal: Lessons Learned and Emerging Findings', in C. Harker and K. Hörschelmann (eds), Conflict, Violence and Peace (pp. 187-214), Singapore: Springer Singapore, http://doi.org/10.1007/978-981-287-038-4 29

Mclvor, C. (2001) "'Do not look down on us": child researchers investigate informal settlements in Zimbabwe', PLA Notes 7.42: 34-38

Miljeteig, P. (2000) Creating partnerships with working children and youth, Social Protection Discussion Paper Series 21, Social Protection, Unit Human Development Network, Washington DC: The World Bank (accessed 9 November 2020) 
Mizen, P. and Ofosu-Kusi, Y. (2010a) 'Asking, giving, receiving: Friendship as survival strategy among Accra's street children', Childhood 17.4: 441-54 (accessed 9 November 2020)

Mizen, P. and Ofosu-Kusi, Y. (2010b) 'Unofficial truths and everyday insights: understanding voice in visual research with the children of Accra's urban poor', Visual Studies 25.3: 255-67 (accessed 9 November 2020)

Monzani, B.; Sarota, A. and Venturi, B. (2018) Evaluation Report: Inuka! Community-Led Security Approaches to Violent Extremism in Coastal Kenya, Washington DC and Brussels: Search for Common Ground and Agency for Peace (accessed 9 November 2020)

Mwangi, I. (2014) Our Children Matter. The Status of Child Abuse and Child Protection in Kenya and Kilifi County 2014: challenges and recommendations, Kilifi: Kesho Kenya

Narayanasamy, N.; Dwaraki, B.R.; Tamilmani, B. and Ramesh, R. (1996) 'Whither children's hour? An experimental PRA among labouring rural children', PLA NOTES 25: 65-69

Navarro, J.D.L.; Chavez, T.; Irazoqui Ruiz, Y.; Rodriguez, F.; Vences, S. and Aranda, I. (2019) Wall Between Undocumented Families and Health, Washington DC: United We Dream (accessed 9 November 2020)

Nombo, C. (2007) Reflections from the Children's Participating in Governance Project: Budget monitoring within a rights-based framework, Cape Town: Institute for Democracy in South Africa (IDASA)

Nombo, C. and Cassiem, S. (2007) Children Participating in Governance Budget monitoring from a rights-based framework: Training Manual, Pretoria: Idasa-Kutlwanong Democracy Centre Nyaga, B. (2019) 'South Sudanese artist collective Anataban on a mission to bring lasting peace', 11 January, blog, Music In Africa, (accessed 7 August 2019)

Obeng, C. (1998) 'Cultural relativity in Ghana: perspectives and attitudes', in V. Johnson, E. IvanSmith, G. Gordon, P. Pridmore, and P. Scott (eds), Stepping Forward: Children and young peoples participation in the development process, Rugby, UK: Practical Action Publishing

O'Kane, C. (2007) 'Supporting the Development of Children's Groups and Networks in Afghanistan: Reflections on Practice and Possibilities', Children, Youth and Environments 17.1: 222-37

Pagiwa, L. (2018) South Sudan: 'Our current regime is democratic only on paper, not in practice', 29 August, CIVICUS, (accessed 7 August 2019)

Pankhurst, A.; Negussie, N. and Mulugeta, E. (2016) Understanding Children's Experiences of Violence in Ethiopia Evidence from Young Lives, Innocenti Working Paper 2016-25, Florence: Office of Research, UNICEF

Percy-Smith, B. and Burns, D. (2013) 'Exploring the role of children and young people as agents of change in sustainable community development', Local Environment 18.3: 323-39 (accessed 9 November 2020)

Plush, T. (2009) 'Amplifying children's voices on climate change: the role of participatory video', PLA Notes 60: 119-28 
Praxis (2015) Voice for Change: Urban Poor Children Redefining Safe Spaces, Delhi: Praxis Institute for Participatory Practices (accessed 9 November 2020)

Promundo, Instituto PAPAI, Salud y Género, and ECOS (2013) Program H/M/D: A Toolkit for Action Engaging Youth to Achieve Gender Equity, Instituto Promundo (accessed 9 November 2020)

Punch, S. (2000) 'Children's Strategies for Creating Playspaces: Negotiating Independence in Rural Bolivia', in S. Holloway and G. Valentine (eds), Children's Geographies: Living, Playing, Learning and Transforming Everyday Worlds, Oxon: Routledge

Questscope (1995) Urban community development with a focus on the status of children in exceptionally difficult circumstances. Phase one final report: community study results and programme directions, UNICEF Jordan (accessed 9 November 2020)

Radcliffe, S. and Webb, A. (2016) 'Mapuche youth between exclusion and the future: protest, civic society and participation in Chile', Children's Geographies 14.1: 1-19 (accessed 9 November 2020)

Rhodes, C.N.; Halasah, S.D. and Hayashi, J.L. (1995) Urban Community Development with a Focus on the Status of Children in Exceptionally Difficult Circumstances, UNICEF Jordan

Robson, E.; Porter, G.; Hampshire, K. and Bourdillon, M. (2009) "'Doing it right?": working with young researchers in Malawi to investigate children, transport and mobility', Children's Geographies 7.4: 467-80 (accessed 9 November 2020)

Stark, L.; DeCormier Plosky, W.; Horn, R. and Canavera, M. (2015) "He always thinks he is nothing": The psychosocial impact of discrimination on adolescent refugees in urban Uganda', Social Science and Medicine 146: 173-81 (accessed 9 November 2020)

Stark, L.; Macfarlane, M.; King, D.; Lamin, D.; Lilley, S. and Wessells, M. (2014) A CommunityDriven Approach to reducing Teenage Pregnancy in Sierra Leone: Midline Evaluation Brief, London: Save the Children

Stephenson, P. (1998) From play to participation: Including children in the process of development, Middlesex, UK: Tearfund

Swart, J. (1990) Malunde: The Street Children of Hillbrow, Johannesburg: Witerwatersrand University Press

Tammy; Karen; Iffie; Bobbie; Colette; Bessa and Rick (1998) 'The Kit' How Youth Can Evaluate Their Services (p. 40). Ottawa: Youth Services Bureau

Tanner, T. (2010) 'Shifting the Narrative: Child-led Responses to Climate Change and Disasters in El Salvador and the Philippines', Children and Society 24.4: 339-51 (accessed 9 November 2020)

Teshome, E.; Zenebe, M.; Metaferia, H. and Biadgilign, S. (2014) ‘Participation and significance of self-help groups for social development: exploring the community capacity in Ethiopia', SpringerPlus 3: 189 (accessed 9 November 2020)

Theis, J. and Huyen, H.T. (1997) From housework to goldmining: child labour in rural Vietnam, London: Save the Children 
Thorsen, D. (2013) 'Weaving in and out of employment and self-employment: young rural migrants in the informal economy of Ouagadougou', International Development Planning Review 35.2: 208-18 (accessed 9 November 2020)

Törrönen, M.L. and Vornanen, R.H. (2014) 'Young People Leaving Care: Participatory Research to Improve Child Welfare Practices and the Rights of Children and Young People', Australian Social Work 67.1: 135-50 (accessed 9 November 2020)

Trajber, R.; Walker, C.; Marchezini, V.; Kraftl, P.; Olivato, D.; Hadfield-Hill, S.; Zara, C. and Fernandes Monteiro, S. (2019) 'Promoting climate change transformation with young people in Brazil: participatory action research through a looping approach', Action Research 17.1: 87-107 (accessed 9 November 2020)

Vaitla, B.; Taylor, A.; Van Horn, J. and Cislaghi, B. (2017) Social Norms and Girls' Well-BeingLinking Theory and Practice, Washington DC: Data2X

Vakaoti, P. (2017) 'Young people's participation in Fiji: understanding conceptualizations and experiences', Journal of Youth Studies 20.6: 697-712 (accessed 9 November 2020)

van Blerk, L.; Mendel, J.; Rodriguez, A.; Fernandes, F.L. and Rizzini, I. (2019) “'Let's Win this Game Together": Children's Rights Violations, Macro-Securitisation and the Transformative Potential of the 2014 FIFA World Cup in Brazil', Bulletin of Latin American Research 38.3: 284-99 (accessed 9 November 2020)

van Daalen, E.; Hanson, K. and Nieuwenhuys, O. (2016) 'Children's rights as living rights: The case of street children and a new law in Yogyakarta, Indonesia', International Journal of Children's Rights 24.4: 803-25 (accessed 9 November 2020)

Veitch, H.; Dharel, M. and Ojha, R. (2014) Learning from Children Exposed to Sexual Abuse and Sexual Exploitation: The Bamboo Project Study on Child Resilience, London: Children Unite in association with CWISH

Walker, D.; Tristram, B.; Pereznieto, P. and Young, T. (2016) Case Study: Child-Centred Educational Radio Project in Kailahun District, Sierra Leone, United Nations Girls' Education Fund Wellard, S.; Tearse, M. and West, A. (1997) All Together Now: Community Participation for Young People, London: Save the Children

Wessells, M.G. (2010) 'Girls in Armed Forces in and Groups in Angola: Implications for Ethical Research and Reintegration', in S. Gates and S. Reich (eds), Child Soldiers in the Age of Fractured States, Pittsburgh PA: University of Pittsburgh Press

West, A. (1998) Which Way Now? Young people's experiences of leaving care, London: Save the Children; and Hull, UK: The Warren Centre

White, S. (2002) Child Brigade: An Organisation of Street Working Children in Bangladesh, Dhaka: Save the Children Sweden

Wickenden, M. and Kembhavi-Tam, G. (2014) 'Ask us too! Doing participatory research with disabled children in the global south', Childhood 21.3: 400-17 (accessed 9 November 2020) 
Woolfson, R.C.; Heffernan, E.; Paul, M. and Brown, M. (2010) 'Young People's Views of the Child Protection System in Scotland', British Journal of Social Work 40.7: 2069-2085 (accessed 9 November 2020)

Zeng, E.J. and Bordeaux Silverstein, L. (2011) 'China earthquake relief: Participatory action work with children', School Psychology International 32.5: 498-511 (accessed 9 November 2020)

\section{Organisational websites and blogs cited in interviews and exemplar boxes}

Accountability Lab (2019) Accountability Incubator, Washington DC: Accountability Lab (accessed 14 November 2019)

Brighton and Hove City Council (2019) PSHE: Good to be Me Theme, Brighton: Brighton and Hove City Council

Brown, S.J. (2019) '19 Youth Climate Activists of Color Who Are Fighting To Protect The

Earth', Wear Your Voice, blog, 25 September (accessed 3 July 2020)

Burton, N. (2019) 'Meet the young activists of color who are leading the charge against climate disaster', Vox, 11 October (accessed 3 July 2020)

Child to Child (2016) 'Children find their own solutions to change their lives', Our Blog, March (accessed 19 March 2019)

Evelyn, K. (2020) “'Like I wasn't there”: climate activist Vanessa Nakate on being erased from a movement', The Guardian, 29 January (accessed 3 July 2020)

FCYO (2018) Transforming Young People and Communities: New Findings on the Impacts of Youth Organizing, New York NY: Funders' Collaborative on Youth Organizing

Fridays For Future (2020) Who We Are (accessed 3 July 2020)

Immigrant Legal Resource Center (2015) Travel for DACA Applicants (Advance Parole), San Francisco: Immigrant Legal Resource Center (accessed 22 July 2020)

International Labour Organization (ILO) (n.d.) SCREAM: Supporting Children's Rights through Education, the Arts and the Media (IPEC), International Programme on the Elimination of Child Labour, Geneva: ILO (accessed 5 June 2020)

Janfaza, R. (2020) ‘9 Climate Activists of Color You Should Know', Teen Vogue, 3 January (accessed 3 July 2020)

Kuyu Lokolong, D. and Rana, C. (2018) Mou and Keiji get justice at last, The Common Ground Blog, 27 June (accessed 7 August 2019)

Kwa Wazee (2018) Kwa Wazee - The Elderly Organization Report, Muleba District, Tanzania: Kwa Wazee (accessed 26 August 2020)

Local Youth Corner Cameroon (n.d.) Creative Skills for Peace Project, Facebook (accessed 7 August 2019) 
Mestizo Arts and Activism Collective (2014) Dreaming of No /udgement, Mestizo Arts and Activism Collective blog, 15 April, Salt Lake City, US: Mestizo Arts and Activism Collective (accessed 2 October 2020)

Munoz, J. (2020) 'Home is Here Coalition: Trump Must Comply With Supreme Court Ruling on DACA', United We Dream, 13 July (accessed 22 July 2020)

Ocharoenchai, N. (2019) 'Beyond strikes: For these youths, climate activism starts at home', Mongabay, 25 November (accessed 6 July 2020)

Raising Voices (2013) About Us, Kampala: Raising Voices (accessed 6 July 2020)

Search for Common Ground (2019) 1001 Nights: Building Children's Resilience to Violence, Washington DC: Search for Common Ground (accessed 17 July 2020)

Sister Warriors Freedom Coalition (2020) Sister Warriors Freedom Coalition, Oakland CA and Santa Clara County: Sister Warriors Freedom Coalition (accessed 4 August 2020)

Sixdenier, B. (2017) 'An interview with AnaTaban: an artists' collective trying to bring peace to South Sudan', Medium, 15 November (accessed 7 August 2019)

St Luke's School (2019) Pupil Evaluation of Good To Be Me Week, Brighton, UK: St Luke's School The Food Foundation (2019) Children's Future Food Inquiry, London: The Food Foundation (accessed 9 November 2020)

The Warren (n.d.) About Us, Hull, UK: The Warren (accessed 14 November 2019)

Trump, D. (2017) 'Statement from President Donald J. Trump', 5 September, Washington DC: White House (accessed 22 July 2020)

United We Dream (2018) United We Dream / The Largest Immigrant Youth-Led Network in the Country, United We Dream_(accessed 14 November 2019)

Varagur, K. (2019) 'Meet India's teen climate advocate: Ridhima Pandey', The Christian Science Monitor, 30 September (accessed 6 July 2020)

Western Cape Government (2018) Artistic Mural to Change Negative Perception of Mental Health Cape Town: Western Cape Government (accessed 11 August 2020)

Young Women's Freedom Center (YWFC) (2019) About Us, Oakland CA: YWFC (accessed 4 August 2020)

Zero Hour and the National Children's Campaign (n.d.) \#Vote4OurFuture (accessed 3 July 2020)

Broader academicreferences in the text

Ansell, N. (2005) Children, Youth and Development, Oxon and New York NY: Routledge Arnstein, S.R. (1969) 'A Ladder of Citizen Participation', Journal of the American Institute of Planners 35.4: 216-24 (accessed 9 November 2020)

Biesta, Gert J.J. (2010) 'Why "what works" still won't work: From evidence-based education to value-based education', Studies in Philosophy and Education 29.5: 491-503 
Bonvin, J.-M. and Stoecklin, D.P. (2016) ‘Children's Rights as Evolving Capabilities: Towards a Contextualized and Processual Conception of Social Justice', Ethical Perspectives 23.1: 19-39

Bronfenbrenner, U. (ed.) (2005) On making Human Beings Human: Bioecological perspectives on human development, Thousand Oaks CA: Sage

Bronfenbrenner, U. (1979) The Ecology of Human Development: Experiments by Nature and Design, Harvard MA: Harvard University Press

Chambers, R.; Kenton N. and Ashley, H. (eds) (2004) 'Critical reflections, future directions', Participatory Learning and Action, PLA Notes 50, October 2004, London: International Institute for Environment and Development (IIED)

Cipriani, D. (2009) Children's Rights and the Minimum Age of Criminal Responsibility: A Global Perspective, 1st ed., Farnham, UK: Ashgate Publishing

Clark, A. and Moss, P. (2011) Listening to Young Children: The Mosaic approach, London and Philadelphia PA: Jessica Kingsley Publishers

Clark-Kazak, C.R. (2009) 'Towards a Working Definition and Application of Social Age in International Development Studies', The Journal of Development Studies 45.8: 1307-1324 (accessed 9 November 2020)

Cockburn, T. (2007) 'Partners in Power: a Radically Pluralistic Form of Participative Democracy for Children and Young People', Children and Society 21.6: 446-57 (accessed 9 November 2020) de Sousa Santos, B. (2018) The end of the cognitive empire: the coming of age of epistemologies of the South, Durham NC: Duke University Press

Eyben, R.; Guijt, I.; Roche, C. and Shutt, C. (2015) 'The Politics of Evidence and Results in International Development', Playing the game to change the rules? London: Practical Action.

Fattore, T.; Mason, J. and Waton, E. (2017) Children's Understandings of Wellbeing: Towards a children's standpoint, Dordrecht, The Netherlands: Springer

Fraser, N. (2003) 'Social Justice in the Age of Identity Politics: Redistribution, Recognition and Participation' in N. Fraser and A. Honneth (eds), Redistribution or Recognition? A Political Philosophical Exchange, London: Verso

Fraser, N. (1997) Justice Interruptus: Critical Reflections on the 'postsocialist' Condition, New York NY and London: Routledge

Freire, P. (1996) Pedagogy of the oppressed, London: Penguin

Gero, A. and Asker, S. (2012) The Role of Child and Youth Participation in Development Effectiveness: A literature review, Sydney: Child Fund Australia

Ghosh, A. and Chopra, D. (2019) ‘Paid work, unpaid care work and women's empowerment in Nepal', Contemporary South Asia 27.4: 471-85

Goetz, A.M. (2019) 'The politics of preserving gender inequality: de-institutionalisation and reprivatisation', Oxford Development Studies 48.1: 2-17 (accessed 9 November 2020)

Hanson, K. and Nieuwenhuys, O. (eds) (2013) Reconceptualizing Children's Rights in International Development: Living Rights, Social Justice, Translations, Cambridge: Cambridge University Press 
Hart, J. (2008) 'Children's Participation and International Development: Attending to the Political', The International Journal of Children's Rights 16.3: 407-18 (accessed 9 November 2020)

Hart, R. (1992) Children's Participation: From tokenism to citizenship, Innocenti Essay 4, Florence: UNICEF International Child Development Centre (accessed 9 November 2020)

Invernizzi, A. and Williams, J. (2008) Children and citizenship, London: Sage

James, A.; Jenks, C. and Prout, A. (1998) Theorizing Childhood, Cambridge: Polity Press

Johnson, V. (2017) 'Moving beyond voice in children and young people's participation', Action Research 15.1: 104-24 (accessed 9 November 2020)

Johnson, V. (2015) 'Valuing children's knowledge: the politics of listening', in R. Eyben; I. Guijt; C. Roche, and C. Shutt (eds), The Politics of Evidence and Results in International

Development: Playing the Game to Change the Rules?, Rugby, UK: Practical Action Publishing (accessed 9 November 2020)

Johnson, V. (2011) 'Conditions for Change for Children and Young People's Participation in Evaluation: "Change-Scape"', Child Indicators Research 4.4: 577-96 (accessed 9 November 2020)

Johnson, V. and West, A. (2018) Children's Participation in Global Contexts: Going Beyond Voice, London: Routledge

Johnson, V. and West, A. with Church, A. et al. (forthcoming, 2021), Youth and Positive Uncertainty: Negotiating life in post conflict and fragile environments, Rugby, UK: Practical Action Publishing

Kabeer, N. (2008) Paid work, women's empowerment and gender justice: critical pathways of social change, Pathways Working Paper 3, Brighton: Institute of Development Studies

Kellett, M. (2009) 'Children and young people's participation', in H. Montgomery and M. Kellett (eds), Children and young people's worlds: Developing frameworks for integrated practice, Bristol: Policy Press

Khasnabish, D.A. and Haiven, M. (2014) The Radical Imagination: Social Movement Research in the Age of Austerity, 1st ed., London: Zed Books

Kosher H., Ben-Arieh A., Hendelsman Y. (2016) ‘Social Work and Children's Rights: Implications for Practice', in Children's Rights and Social Work, SpringerBriefs in Rights-Based Approaches to Social Work. Cham: Springer, http://doi-org-443.webvpn.fjmu.edu.cn/10.1007/978-3-319-43920$4 \_4$

Lansdown, G. (2010) 'The realisation of children's participation rights: Critical reflections', in B. Percy-Smith and N. Thomas (eds), A Handbook of Children and Young People's Participation, Oxon and New York NY: Routledge

Lansdown, G. (2001) Promoting children's participation in democratic decision-making, Innocenti Insights, Florence: UNICEF International Child Development Centre (accessed 9 November 2020)

Lansdown, G. (1994) 'Children's Rights', in B. Mayall (ed.), Children's Childhoods: Observed and Experienced, London: The Falmer Press 
Larkins, C. (2014) 'Enacting children's citizenship: Developing understandings of how children enact themselves as citizens through actions and Acts of citizenship', Childhood 21.1: 7-21 (accessed 9 November 2020)

Lister, R. (2007) 'Inclusive Citizenship: Realizing the Potential', Citizenship Studies 11.1: 49-61 (accessed 9 November 2020)

Lundy, L. (2007) "Voice" is not enough: conceptualising Article 12 of the United Nations Convention on the Rights of the Child', British Educational Research Journa/33.6: 927-42 (accessed 9 November 2020)

Mannion, G. (2009) 'After participation: The socio-spatial performance of intergenerational becoming', in B. Percy-Smith and N. Thomas (eds), A Handbook of Children and Young People's Participation, Oxon and New York NY: Routledge

Nurick, R. and Johnson, V. (2001) 'Putting child rights and participatory monitoring and evaluation with children into practice: some examples in Indonesia, Nepal, South Africa and the UK', PLA Notes 42: 39-44

OHCHR (1990) Convention on the Rights of the Child, E/CN.4/RES/1990/74, UN Commission on Human Rights

Oswell, D. (2013) The Agency of Children: From Family to Global Human Rights, Cambridge: Cambridge University Press

Pankhurst, A.; Woldehanna, T.; Araya, M.; Tafere, Y.; Rossiter, J.; Tiumelissan, A. and Birhanu, K. (2018) Young Lives Ethiopia: Lessons from longitudinal research with the children of the millennium, Country Report, Oxford: Young Lives, Oxford Department of International Development, University of Oxford

Pattnaik, J. (2004) 'Introduction: Rethinking children and childhood in South Asia', in J. Pattnaik (ed.), Childhood in South Asia: A critical look at issues, policies and programmes, a volume in research in global child advocacy, Greenwich CT: Information Age Publishing Ltd

Percy-Smith, B. and Thomas, N. (2009) A Handbook of Children and Young People's Participation, Oxon and New York NY: Routledge (accessed 9 November 2020)

Roberts, C. (2013) 'Early Puberty, "Sexualization" and Feminism', European Journal of Women's Studies 20.2: 138-54

Shier, H. (2010) 'Children as Public Actors: Navigating the Tensions', Children and Society 24.1: 24-37 (accessed 9 November 2020)

Shier, H. (2001) 'Pathways to participation: openings, opportunities and obligations', Children and Society 15.2: 107-17 (accessed 9 November 2020)

Thomson, P. (2009) Doing Visual Research with Children and Young People, London: Routledge (accessed 9 November 2020)

Tisdall, K. and Davis, J. (2004) 'Making a Difference? Bringing Children's and Young People's Views into Policy-making', Children and Society 18.2: 131-42 
Treseder, P.; Save the Children Fund and Children's Rights Office (1997) Empowering Children and Young People: Training Manual: Promoting Involvement in Decision-making, London: Save the Children

Toope, S.J. (1996) 'The Convention of the Right of the Child: Implications for Canada', in M.

Freeman (ed.), Children's Rights: A Comparative Perspective, Dartmouth, UK: Ashgate Publishing Tudge, J. (2008) The Everyday Lives of Young Children: Culture, Class and Child Rearing in Diverse Societies, Cambridge: Cambridge University Press

UNICEF (2019) The State of the World's Children Report, New York NY: United Nations Children's Fund

Verloo, M. and Paternotte, D. (2018) 'The feminist project under threat in Europe', Politics and Governance 6.3: 1-5 (accessed 9 November 2020)

Wells, K. (2015) Childhood in a Global Perspective, Bristol: Polity Press

Wessells, M. and Monteiro, C. (2006) 'Psychosocial assistance for youth: Toward reconstruction for peace in Angola', Journal of Social Issues 62.1: 121-39 


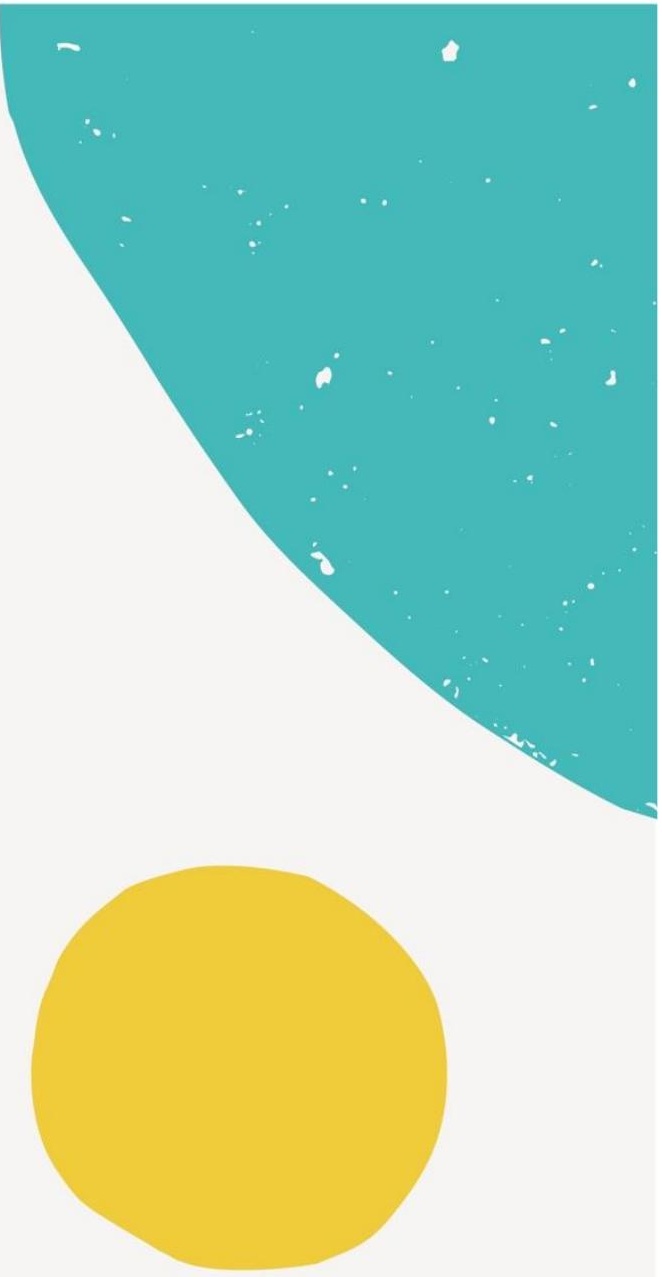

